\title{
Scientific Program Schedule
}

\section{$60^{\text {th }}$ Annual Scientific Meeting}





\section{PRESIDENT'S NEW INVESTIGATOR PLENARY} SESSION

\section{Floridian Ballroom A-F}

Sarah Berga and Kelle Moley

\begin{tabular}{ll}
\hline 9:00 & Complement Activation, Placental Vascular \\
0-001 & Insufficiency and Fetal Growth Restriction in \\
& Placental Malaria. \\
& Andrea L Conroy, Karlee L Silver, Monique \\
& Rennie, Malcolm E Molyneux, John Sled, \\
& Joseph Fletcher, Stephen Rogerson, and Kevin \\
& C Kain.
\end{tabular}

9:15 Endometrioid Ovarian Cancer and

0-002 Endometriosis Originate from the Distal Oviduct. Conditional Activation of Wnt/ $\beta$ Catenin Signaling in Müllerian Duct Derived Organs.

Paul $\mathrm{H}$ van der Horst, Marten van der Zee, Claudia Heijmans-Antonissen, Yundan Jia, Carolien HM van Deurzen, Francesco J DeMayo, John P Lydon, Patricia C Ewing, Curt W Burger, Riccardo Fodde, and Leen J Blok. Rotterdam, Netherlands and Houston, TX, USA.

9:30 Antioxidants Prevent Intrauterine Growth

0-003 Restriction (IUGR) and Cardiac Dysfunction in Chronically-Hypoxic Fetal Sheep.

BJ Allison, KL Brain, Y Niu, CM Cross, N Itani, AD Kane, EA Herrera, and DA Giussani. United Kingdom.

9:45 Conditional Vitamin D Receptor (VDR) Deletion

0-004 Delays Puberty and Permanently Disrupts Female Reproductive Physiology.

Thomas Fisher, Joe Davis, Jun Shu, Cary Dickens, and Genevieve Neal-Perry. Bronx, NY, USA and New York, NY, USA. 
Thursday, March 21, 2013 - Concurrent Session I

4:00 PM-6:00 PM

Concurrent Session

FETUS: GENETICS, GROWTH \& METABOLISM

Floridian Ballroom A-F

Anna David and James Roberts

4:00 Intergenerational Inheritance of Cardiovascular

0-005 Disease Risk Induced by Chronic Fetal

Hypoxia.

Y Niu, BJ Allison, AD Kane, CM Lusby, EJ

Camm, and DA Giussani. United Kingdom.

4:15 Translating the Transcriptome To Develop

0-006 Antenatal Treatments for Fetuses with Down Syndrome.

Faycal Guedj, Dustin Hines, Jeanine C Foley, Philip G Haydon, and Diana W Bianchi. Boston, USA.

4:30 Prenatal Alcohol Exposure Alters Acute

0-007 Phosphorylation of Cellular Signaling

Pathways.

Myriam Ferzli, Robin Roberson, Thea Kuddo, Daniel Abebe, and Catherine Y Spong. DC, USA and Bethesda, MD, USA.

4:45 SOD1 Overexpression Prevents Maternal

0-008 Diabetes-Impaired Wnt Signaling in the

Embryonic Heart.

Fang Wang, Xuezheng Li, and Peixin Yang.

Baltimore, MD, USA.

5:00 Decreased mTOR Activity, and Increased CK2

0-009 Activity and IGFBP-1 Phosphorylation in the

Liver of IUGR Baboon Fetuses.

Majida Abushehab, Tony Shen, Fredrick J

Rosario, Laszlo Gyenis, David Litchfield, Mark

Nijland, Peter W Nathanielsz, Amrita Kamat,

Thomas Jansson, and Madhulika B Gupta.

Canada; London, ON, Canada and TX, USA.

5:15 Chronic Hyperinsulinemia Suppresses

0-010 Glucose-Stimulated Insulin Secretion (GSIS) in the Ovine Fetus.

Sasha Andrews, Laura Brown, Stephanie Thorn, William Hay, Jr., and Paul Rozance. Aurora, CO, USA.

5:30 Placental Metabolic Reprogramming in

0-011 Preeclampsia: Evidence from Measures of Fetal

Oxygen and Glucose Delivery.

Sam Nasseri, NP Illsley, M Alvarez, A Al-Khan, and S Zamudio. Grenada and NJ, USA.

5:45 Neonatal Adiposity Is Predicted by Ultrasound

0-012 Estimates of the Fetal Thigh Volume at 28

Weeks Gestation.

Gaea S Moore, Linda Barbour, Barbra Fisher, Bronwen Kahn, Teri Hernandez, Regina

Reynolds, Melanie Reece, Molly Anderson, Jed

Friedman, Wesley Lee, and Henry Galan.
4:00 PM-6:00 PM

Concurrent Session

INFERTILITY, ART, \& FERTILITY PRESERVATION

\author{
Bonnet Creek Ballroom XI \& XII
}

Vasiliki Moragianni and Emre Seli
4:00
Activated Ovarian Endothelial Cells Promote
0-013
Early Follicular Development and Survival.
Anate Aelion Brauer, Alon Kedem, Peipei Guo, Duancheng Wen, Bi-Sen Ding, Hung-Ching Liu, Shahin Rafii, and Zev Rosenwaks. New York, NY, USA.

4:15 Different Classes of Chemotherapeutic Agents

0-014 Affect Apoptosis, Hormonal Receptors and

WNT Family Members Expression of Human

Granulosa Lutein Cells.

AM Sanchez, V Giorgione, A Paffoni, M

Mugione, L Corti, M Candiani, P Vigano, and P

Panina. Milan, Italy.

4:30 IVF Live Birth Rate Increases with FSH

0-015 Receptor Polymorphism Asn680Ser. Aimee Seungdamrong, Peter G McGovern, Andrea Wojtczuk, and Laura T Goldsmith. Newark, NJ, USA.

4:45 Relationship between Serum Polyunsaturated

0-016 Fatty Acids and Pregnancy in Women

Undergoing In Vitro Fertilization.

Antonina I Frolova, Joan K Riley, Daniel S Ory, Randall R Odem, George A Macones, Kelle H Moley, and Emily S Jungheim. St. Louis, MO, USA.

5:00 The Use of a Luteal Estradiol Protocol in

0-017 Poor Responders: A Systematic Review and

Metaanalysis.

Kasey Reynolds, Kenan Omurtag, Patricia

Jimenez, Methodius Tuuli, and Emily Jungheim.

5:15 Histidine-Rich Glycoprotein Gene

0-018 Polymorphism in Patients with Recurrent

Miscarriages.

Karin E Lindgren, Karin Karehed, Helena

Karypidis, Frida Hosseini, Katarina Bremme,

Britt-Marie Landgren, Lottie Skjoldebrand-

Sparre, Anneli Stavreus-Evers, Inger

Sundstrom-Poromaa, and Helena Akerud.

Uppsala, Sweden and Stockholm, Sweden.

5:30 Assisted Reproductive Technology: Is There

0-019 a Biological Plausibility for Increased Risk in

Autism Spectrum Disorders (ASD)?

Lauren Thomaier, Monica Mainigi, Melissa

Russo, Christos Coutifaris, Conover Talbot, and Irina Burd.

5:45 Subfertility and Meiotic Defects in Chtf18-Null

0-020 Female Mice.

Tanu Singh, Abigail Harris, and Karen

Berkowitz. 
Thursday, March 21, 2013 - Concurrent Session I

4:00 PM-6:00 PM

Concurrent Session

PARTURITION: MYOMETRIUM, MEMBRANES, \& CERVIX

Bonnet Creek Ballroom X

Emmet Hirsch and Donna Slater

\begin{tabular}{ll}
\hline 4:00 & HIF-1a-Mediated Downregulation of MiTF during \\
0-021 & Cervical Ripening: Mechanisms and Effect on \\
& Progesterone Receptors, IL-8, and COX-2 Gene \\
& Expression. \\
& Annavarapu H Kishore, Patrick Keller, and Ruth \\
& A Word. Dallas, TX, USA.
\end{tabular}

4:15 Active MMP-1 Is Markedly Increased in Preterm

0-022 Labor and Causes Uterine Contraction Via

PAR1.

William H Nugent, Anna Solotskaya, Sonya L Washington, John R Grider, Jerome F Strauss III, and Scott W Walsh. Richmond, VA, USA.

4:30 Effect of Simvastatin on Inflammation and 0-023 Oxidative Stress in Human Fetal Membranes. Sanmaan K Basraon, Rheanna UrrabazGarza, Esther Tamayo, Geeta Bhat, Tariq Ali Syed, George Saade, Maged Costantine, and Ramkumar Menon. Galveston, TX, USA.

4:45 Lentiviral miRNA Knockdown and Over 0-024 Expression of Kir7.1 in Murine Myometrium Leads to Profound Effects on Contractility. Conor McCloskey, and Andrew M Blanks. Coventry, United Kingdom.

5:00 Progesterone Regulates Uterine Quiescence O-025 through Endoplasmic Reticulum Stress Mediated Caspase-3 Activation. Arvind Suresh, Pancharatnam Jeyasuria, and Jennifer Condon. Pittsburgh, PA, USA.

5:15 Characterization of Hydrogen Sulfide Signaling 0-026 in Mouse Myometrium.

Brian Wakefield, Kelsey Breen, and K Joseph Hurt. Aurora, CO, USA.

5:30 Adiponectin Leads to Myometrial Relaxation 0-027 and Paradoxically Induces Intracellular Calcium Oscillations in Pregnant Human Myometrial Cells.

Brian W Nielsen, Andrew J McKenzie, Gabriela Goloman, Roger C Young, and Alan K Howe. Burlington, VT, USA.

5:45 The Impact of Advanced Maternal Age on

0-028 Parturition Success in a Pregnant Mouse Model.

Rima Patel, Lucilla Poston, and Rachel M Tribe. London, United Kingdom.
4:00 PM-6:00 PM

Concurrent Session

\section{PLACENTA I}

Floridian Ballroom HI

Denise Hemmings and Thomas Jansson

4:00 microRNA (miR)-17 92 and miR-106a 363

0-029 Clusters Regulate Key Placental Genes To

Repress Human Trophoblast Differentiation:

Mechanisms for Regulation of These miRNAs in Preeclampsia.

Premlata Kumar, Yanmin Luo, and Carole R Mendelson. Dallas, TX, USA.

4:15 Sexual Dimorphism in the Effect of Maternal

0-030 Adiposity on Placental miR-210 Expression. Sribalasubashini Muralimanoharan, Chunming Guo, Leslie Myatt, and Alina Maloyan. TX, USA.

4:30 Emerging Role of the SUMOylation in Placental

0-031 Pathology.

Dora Baczyk, Sascha Drewlo, and John

Kingdom. Toronto, Canada.

4:45 C19MC microRNAs Regulate Cell Migration and

0-032 Invasion in Human Trophoblasts.

L Xie, JF Mouillet, T Chu, XH Shi, Y Ouyang, and $Y$ Sadovsky. Pittsburgh, PA, USA and Beijing, China.

5:00 Glucocorticoid Treatment Enhances

0-033 Hemoglobin Scavenging by Fetal Hofbauer

Cells through a CD163-Dependent Mechanism. Seth Guller, and Zhonghua Tang. New Haven, CT, USA.

5:15 Altered Decorin Expression Leads to Disrupted

0-034 Vascular Endothelial Cell Functions: A Potential Mechanism in the Pathogenesis of Human Fetal Growth Restriction.

Amy KL Chui, Padma Murthi, Shaun P Brennecke, Vera Ignjatovic, Paul T Monagle, and Joanne M Said. Parkville, Victoria, Australia.

5:30 Role of MTA3 in Trophoblast Invasion and 0-035 Fusion.

Ying Chen, Jun Miyazaki, Haruki Nishizawa, Hiroki Kurahashi, Richard Leach, and Kai Wang. Grand Rapids, MI, USA and Nagoya, Japan.

5:45 Activation of Placental Inflammasomes in

0-036 Pregnant Women with High BMI. Irving LMH Aye, Vanessa I Ramirez, Francesca Gaccioli, Susanne Lager, Thomas Jansson, and Theresa L Powell. San Antonio, USA. 
Thursday, March 21, 2013 - Concurrent Session I

4:00 PM-6:00 PM

Concurrent Session

PREECLAMPSIA I

Floridian Ballroom K \& L

Janet Catov and Norman Gant

4:00 Impact of Maternal Obesity on Myogenic

0-037 Tone and Smooth Muscle Calcium Signaling in Myometrial Arteries from Term Pregnant

Women.

Natalia I Gokina, Roger C Young, and Gabriela

Goloman. Burlington, VT, USA.

4:15 Effect of Maternal Obesity in a Mouse Model of

0-038 Preeclampsia.

Joanna L Stanley, Irene J Andersson, Christian

F Rueda-Clausen, Colin P Sibley, Sandra T

Davidge, and Philip N Baker. Edmonton, AB,

Canada; Manchester, United Kingdom and

Auckland, New Zealand.

4:30 Potential Role of Estrogen-Related Receptor $Y$

0-039 (ERRY) in the Pathogenesis of Preeclampsia.

Yanmin Luo, Premlata Kumar, and Carole R

Mendelson. Dallas, TX, USA.

4:45 Decreased Uterine and Mesenteric Artery

0-040 Compliance in Pregnant Relaxin Mutant Mice. Jonathan H Gooi, Meghan Richardson, Maria Jelinic, Jane Girling, Mary E Wlodek, Marianne Tare, and Laura J Parry. Melbourne, Victoria, Australia.

5:00 Sphingosine 1-Phosphate (S1P)-Induced

0-041 Endothelial Permeability Causes Leakage of

Circulating Constrictors Generating Increased Vascular Tone.

D Kerage, $R$ Gombos, and D Hemmings.

5:15 Chronic Binge-Like Alcohol and Shear Stress

0-042 Alter Whole and Subcellular Uterine Artery

Endothelial Nitric Oxide System.

VD Naik, K Subramanian, WX Liao, GE Lopez,

DB Chen, RR Magness, and J Ramadoss.

5:30 Effect of Combination Low Molecular Weight

0-043 Heparin and Vitamin D on Primary Trophoblast

Responses to Antiphospholipid Antibodies.

Stefan M Gysler, Anna K Sfakianaki, Melissa

J Mulla, Meredith Stuhlman, Michael J Paidas,

Jan J Brosens, Larry W Chamley, and Vikki M

Abrahams.

5:45 Systemic Activation of Toll-Like Receptor 9

0-044 Increases Vascular Contractility and Induces

Hypertension in Pregnant but Not in Non-

Pregnant Rats.

Styliani Goulopoulou, Takayuki Matsumoto, Camilla F Wenceslau, Cameron G McCarthy, Kathryn Spitler, and R Clinton Webb. Augusta, GA, USA and Tokyo, Japan.
4:00 PM-6:00 PM

Concurrent Session

REPRODUCTIVE BIOLOGY, OVARIAN

BIOLOGY, \& STEM CELLS

Floridian Ballroom J

KMJ Menon and Kenan Omurtag

4:00 Oogonial Stem Cells Isolated from Ovaries

0-045 of Adult Transgenic Female Mice Generate

Functional Eggs and Offspring Following

Intraovarian Transplantation.

Eun-Sil Park, Dori C Woods, Yvonne AR White, and Jonathan L Tilly. Boston, MA, USA.

4:15 Development of In Vivo Human Endometrial

0-046 Stem Cell Assay.

Kaoru Miyazaki, Tetsuo Maruyama, Hirotaka Masuda, Akiko Yamasaki, Sayaka Uchida, Hideyuki Oda, Hiroshi Uchida, and Yasunori Yoshimura. Tokyo, Japan.

4:30 Bone Marrow-Derived Stem Cells

0-047 Transplantation Improves Fertility in a Murine

Model of Asherman's Syndrome. Hongling Du, Feryal Alawadhi, Hakan Cakmak, and Hugh S Taylor. New Haven, CT, USA.

4:45 Gamma Secretase Inhibition Leads to Reduced

0-048 Stemness and Transcriptional Downregulation of SOX2, LIFR, and PODXL in an Endometriotic Cell Culture Model.

Nurjannah Achmad, Marina Hubert, Kathrin Brueggemann, Anna Starzinski-Powitz, Ludwig Kiesel, Burkhard Greve, and Martin Gotte. Muenster, Germany and Frankfurt, Germany.

5:00 Oocyte mRNA Translation and Protein

0-049 Secretion Is Associated with Maturation and Is under the Control of Cumulus Cells.

H Cakmak, J Chen, AM Zamah, MI Cedars, and M Conti.

5:15 Impaired BRCA1-Related DNA Double Strand

0-050 Break Repair Results in Ovarian Aging. Shiny Titus, Fang Li, Robert Stobezki, Sumanta Goswami, and Kutluk Oktay. Valhalla, NY, USA and New York, NY, USA.

5:30 Evidence That a microRNA (miR122) Regulates

0-051 Luteinizing Hormone Receptor Expression in the Ovary by Controlling LH Receptor mRNA

Binding Protein.

Bindu Menon, Sonia Hovelson, and KMJ

Menon. Ann Arbor, MI, USA.

5:45 Increased Immature Follicle Involution in the

0-052 Fragile X Premutation Mouse.

Joshua Johnson, Gloria E Hoffman, Wei Wei Le, Meltem Kurus, and Karen Usdin. New Haven, CT, USA; Baltimore, MD, USA and Bethesda, MD, USA. 
Friday, March 22, 2013 - Concurrent Session II

\section{CLINICAL GYNECOLOGY}

Floridian Ballroom A-F

Jacqueline Maybin and Hugh Taylor

11:00 Race-Specific Differences in BV Incidence

0-053 Following Vaccination to a GBS Type III-Tetanus Toxoid Vaccine: A Secondary Analysis.

Shareece Davis, Sharon Hillier, and Leslie Meyn.

11:15 Predicting Ectopic Pregnancy: Validation of a 0-054 4-Marker Test.

Suneeta Senapati, Mary D Sammel, Mary E Rausch, Karine Chung, Peter Takacs, and Kurt T Barnhart. Philadelphia, PA, USA; Manhasset, NY, USA; Los Angeles, CA, USA and Miami, FL, USA.

11:30 Long-Acting Contraceptives Containing 0-055 Progestins (LACPs) Induce Endometrial Microvascular Apoptosis Via Paracrine Actions of Stromal Cells.

Ozlem Guzeloglu-Kayisli, Murat Basar, Taryn

Summerfield, John Shapiro, Umit A Kayisli,

Frederick Schatz, and Charles J Lockwood.

Columbus, $\mathrm{OH}$, USA.

11:45 Gene Environment Interactions in Time to

0-056 Menopause: Links between Smoking and Genetic Variation in Sex Steroid Metabolizing Enzymes.

Samantha F Butts, Mary D Sammel, Timothy Rebbeck, David Boorman, Christine Greer, and Ellen W Freeman. Philadelphia, PA, USA and Miami, FL, USA.

12:00 Estrogen Receptor-Specific Agonists

0-057 Differentially Affect Vascular Tone in Arteries of Pre- and Post-Menopausal Women.

Christopher J Nicholson, Michele Sweeney, Stephen C Robson, and Michael J Taggart. Newcastle upon Tyne, Tyne and Wear, United Kingdom.

12:15 Lipid-Induced Reactive Oxygen Species

0-058 Generation Is Related to Ovarian Androgen Hyperresponsiveness to HCG Administration in Normal Weight Women with Polycystic Ovary Syndrome (PCOS).

Frank Gonzalez, Chang Ling Sia, Ola A Abdelhadi, Rose M Melvin, and Tammy J Garrett. Indianapolis, IN, USA.

\section{CLINICAL PARTURITION \& PREMATURITY}

\author{
Bonnet Creek Ballroom XI \& XII
}

Lisa Levine and Gordon Smith

11:00 Human Cytomegalovirus Induces an Innate

0-059 Immune Response Following Infection of Human Decidual Tissues Grown Ex Vivo.

Simcha Yagel, Yiska Weisblum, Amos Panet, Zichria Zakay-Rones, Ronit Haimov-Kochman, Debra Goldman-Wohl, Hagai Amsalem, Caryn Greenfield, Esther Djian, Shay Tayeb, and Dana $G$ Wolf. Jerusalem, Israel.

11:15 The Offspring Gut Human Microbiome Is

0-060 Preferentially Structured by a High Fat Maternal Diet.

Kjersti Aagaard, Jun Ma, Radhika Ganu, David Bader, Antonio Frias, Diana Takahashi, Kevin Grove, and James Versalovic.

11:30 Estradiol and Progesterone Influence on TLR

0-061 Signaling Pathway Gene Expression during Influenza Infection.

Sarah Davis, Leigh Sweet, Karen Oppenheimer, and Mark Phillippe. Burlington, VT, USA.

11:45 Proteomic Derived Biomarker Panel for First

0-062 Trimester Identification of Patients at Risk for

Pre-Term Delivery.

Kevin P Rosenblatt, Kypros H Nicolaides,

Roberto Romero, Peter K Bryant-Greenwood, Argyro Syngelaki, Ramkumar Menon, Robert $S$ Galen, and Mark I Evans. Houston, TX, USA; London, United Kingdom; Detroit, MI, USA; Galveston, TX, USA; Honolulu, HI, USA; Athens, GA, USA and New York, NY, USA.

12:00 Does Maternal Exposure to Flame Retardants 0-063 Increase the Risk of Preterm Birth? Morgan R Peltier, Hschi-Chi Koo, Darios T Getahun, and Ramkumar Menon. Mineola, NY, USA; Pasadena, CA, USA and Galveston, TX, USA.

Statins Prevent Detrimental Effects of Postnatal 0-064 Glucocorticoid Therapy on Arterial Blood

Pressure and the Kidney in Rats. $\mathrm{N}$ Itani, AD Kane, CM Cross, EJ Camm, EA Herrera, and DA Giussani. 


\section{CLINICAL PERINATOLOGY I}

Bonnet Creek Ballroom X

Beth Allison and Timothy Johnson

11:00 Dietary L-Arginine Supplementation Improves

0-065 Birth Outcomes in Experimental Placental

Malaria.

Chloe ER McDonald, Kathleen Zhong, and

Kevin C Kain. Toronto, ON, Canada.

11:15 Maternal Psychosocial Stress Increases the

0-066 Risk of Small for Gestational Age in Male Infants.

AS Khashan, C Everard, LME McCowan, $R$ Moss-Morris, GA Dekker, PN Baker, L Poston, JJ Walker, and LC Kenny. Ireland; New Zealand; United Kingdom; Australia.

11:30 Exposure to Chronic Unpredictable Mild Stress 0-067 (CUMS) during Early Development Causes Autistic like Traits in Genetically Predisposed Shank3 Mutant Male Mice.

A Balasa, G Stinnett, J Bravo, S Mahadevan, R Pautler, and I Van den Veyver. and Houston, TX, USA.

11:45 Sexually Dimorphic Effects of Moderate

0-068 Maternal Nutrient Reduction (MNR) on

Mineralocorticoid Receptor in Fetal Baboon

Liver and Adipose Tissues.

CM Guo, L Myatt, M Njland, PW Nathanielsz, and $\mathrm{K}$ Sun. TX, USA and Shanghai, China.

12:00 Maternal Obesity (MO) Decreases Glucose

0-069 Stimulated Insulin Secretion (GSIS) from Isolated Pancreatic Islet in Male and Female MO Offspring (OFF).

Sumiko Morimoto, Luis Antonio Reyes-Castro, Lizbeth Calzada, Tonantzin C Sosa, Guadalupe L Rodriguez-Gonzalez, Carlos Ibanez, Fernando Larrea, Peter W Nathanielsz, and Elena Zambrano. Mexico, DF, Mexico and San Antonio, TX, USA.

12:15 Intra-Placental Gene Transfer of Human Insulin0-070 Like Growth Factor-1 Restores Altered Liver AKT2 Gene Expression in a Mouse Model of Placental Insufficiency. Khaled Omar, Helen Jones, Swathi Balaji, Sundeeb Keswani, Aimen Shaaban, and Mounira Habli. Cincinnati, OH, USA.
FETUS: PROGRAMMING I

Floridian Ballroom HI

John Newnham and Kathleen Pennington

11:00 Antenatal Betamethasone Increases Transient

0-071 Receptor Potential Cation Channels (TRPC)

Expression in Sheep Arteries.

Jie Zhang, Jeong-Heon Lee, Angela G

Massmann, and Jorge P Figueroa. WinstonSalem, NC, USA.

11:15 Developmental Programming of Adult Onset

0-072 Hypertension in a Mouse Model of IUGR Is

Associated with Promoter Hypermethylation and Reduced Renal Expression of the $\mathrm{H} 19$ Gene.

Jessica Hebert, Xuemei Wu, Arena Morillo, Andres Houseman, and Terry K Morgan.

11:30 Placenta-Specific Loss of Autophagy

0-073 Predisposes the Offspring to Obesity and Hyperglycemia.

Alina Maloyan, Sribalasubashini Muralimanoharan, and Leslie Myatt. San Antonio, TX, USA.

11:45 Adipose Tissue Clock Gene Rhythms:

0-074 Programming by Glucocorticoids and Modulation by Postnatal High Fat and Omega-3 Fatty Acids.

Intan S Zulkafli, Peter J Mark, and Brendan J Waddell. Perth, Western Australia, Australia.

12:00 Maternal Glucocorticoid Treatment Programs

0-075 Methylation-Regulatory Enzymes across Multiple Generations.

A Crudo, A Kostaki, SG Matthews, and M Szyf.

12:15 Transgenic Increase in Maternal n-3/n-6 Fatty

0-076 Acid Ratio Protects Against High-Fat Diet and Obesity-Associated Inflammation, Insulin

Resistance and Fetal Hepatic Lipotoxicity. Margaret J Heerwagen, Kristen E Boyle, Michael S Stewart, and Jed E Friedman. Aurora, CO, USA. 
Friday, March 22, 2013 - Concurrent Session II

\section{GYNECOLOGIC ONCOLOGY}

Floridian Ballroom K \& L

Shannon Hawkins and Shohreh Shahabi

\begin{tabular}{ll}
\hline $11: 00$ & Vaccination with Dendritic Cells Pulsed with \\
0-077 & Novel Autologous Oxidized Whole Tumor \\
& Lysate Induced Anti-Tumor Immunity in \\
& Recurrent Ovarian Cancer Patients. \\
& Janos L Tanyi, Lana Kandalaft, Cheryl L \\
& Chiang, Daniel J Powell, and George Coukos. \\
& Philadelphia, PA, USA.
\end{tabular}

11:15 Expression of Ovarian Cancer Antigens in

0-078 Fetal and Adult Ovarian and Fallopian Tube Epithelium.

Kara K Hoppe, and Elizabeth M Swisher. Seattle, WA, USA.

11:30 Role of Estrogen Receptor Alpha Enhancer 0-079 RNAs in Estrogen-Regulated Transcriptional Responses in Breast Cancer Cells. Shino Murakami, Nasun Hah, Anusha Nagari, and W Lee Kraus. Dallas, TX, USA and La Jolla, CA, USA.

11:45 17- $\beta$-Estradiol Up Regulates Pyruvate Kinase 0-080 M2 Expression in Endometrial Cells to CoActivate Estrogen Receptor- $\alpha$ and To Integrate the Mitogenic Response with the Proliferative Metabolism: A Potential Target for EstrogenInduced Endometrial Proliferation. Salama A Salama, Concepcion R Diaz-Arrastia, Mahmoud A Mohammad, and Gokhan S Kilic. Houston, TX, USA and Galveston, TX, USA.

12:00 HLA Polymorphisms Predict NY-ESO-1 Tumor 0-081 Antigen Serology and Overall Survival in Epithelial Ovarian Cancer.

Sayeema Daudi, Mark Brady, Tony Miliotto, Junko Matsuzaki, Shashikant Lele, and Kunle Odunsi. Buffalo, NY, USA.

12:15 New Gender-Specific Predictive Biomarkers

0-082 of Solid Malignancies Identified through Nanofluidic Genetic Analysis.

Barbara Drew, Marisa Mariani, Steven Seiber, Cristiano Ferlini, and Shohreh Shahabi.

Danbury, CT, USA.

\section{REPRODUCTIVE BIOLOGY, IMPLANTATION \&} ENDOMETRIUM

Floridian Ballroom J

Barbara Anne Croy and Patricia Jimenez

11:00 KLF11 Regulates Endometrial Gene Expression

0-083 Via Epigenetic Histone-Modifiying Mechanisms

Resulting in Dynamic Chromatin-State

Modulation.

Zaid M Tabbaa, Ye Zheng, Ravi P Gada, and Gaurang S Daftary. USA.

11:15 Wnt Signalling in Human Endometrial Epithelial O-084 Progenitor Cells.

James Deane, Fadila Asmaniar, and Caroline E Gargett. Melbourne, Victoria, Australia.

11:30 Aberrant Integrin Expression in the

0-085 Fallopian Tube Due to past Exposure to Chlamydial Infection Predisposes the Tubal Microenvironment to Ectopic Pregnancy. Jeremy K Brown, Nick Wheelhouse, Gary Entrican, Calvin KF Lee, Hilary OD Critchley, and Andrew W Horne. United Kingdom and China.

11:45 Transcriptomic Effects of hsa-miR-30d Over0-086 Expression in Human Endometrial Epithelial Cells (hEEC). Juan M Moreno-Moya, Felipe Vilella, Sebastian Martinez-Escribano, Antonio Pellicer, and Carlos Simon. Valencia, Spain.

12:00 In Vivo Estradiol Stimulates Uterine VEGF

0-087 Receptor 2 Expression in Human Endometrium:

A Randomized, Controlled Trial. William B Davenport, Sarah A Hale, Nicholas Garol, Peter Casson, and Ira Bernstein. Burlington, VT, USA.

12:15 The Impact of Estradiol on uNK-Mediated 0-088 Endometrial Angiogenesis. Douglas A Gibson, Hilary OD Critchley, and Philippa TK Saunders. Edinburgh, United Kingdom. 
Friday, March 22, 2013 - Concurrent Session III

4:30 PM-6:30 PM

Concurrent Session

FETUS: HYPOXIA, CARDIOVASCULAR, BRAIN

Floridian Ballroom A-F

Sandra Davidge and Loren Thompson

4:30 Developmental Programming of In Vivo

0-089 Autonomic Dysfunction by Prenatal Hypoxia Is

Dependent on Xanthine Oxidase (XO). AD Kane, C Lusby, and DA Giussani.

4:45 Prenatal Hypoxia Decreases Mitochondrial

0-090 Protein Expression and Cytochrome C Oxidase

Activity in Guinea Pig Offspring Hearts.

Yazan M Al-Hasan, Gerard A Pinkas, and Loren

P Thompson. Baltimore, MD, USA.

5:00 Biogenic Amine Levels Are Decreased at 0.9

0-091 Gestation (G) in Fetal Hearts of Maternal Obese

(MO) Ewes Accompanying a Decreased Ability

of the Fetal Heart To Maintain Work Against

Increased after Load.

Martin A Javors, Peter W Nathanielsz, Brent

Thompson, Stephen P Ford, and Jun Ren. San

Antonio, TX, USA and Laramie, WY, USA.

5:15 Gestational Hypoxia Results in Elevated

0-092 Plasma Leptin and Altered Central Leptin

Sensitivity in the Hypothalamic Arcuate

Nucleus (ARH) in Neonatal Sprague-Dawley

(SD) Rat.

VE Vargas, S Gurum, K Hyatt, K Hanson, and

DA Myers. Oklahoma City, OK, USA.

5:30 Increased Nitrotyrosine (NT) Expression in

0-093 the Frontal Cortex of IUGR Fetal Baboons in

Late Gestation Indicates That Unlike in Adults,

Fetal Nutrient Restriction Promotes a Pro-

Infammatory State in the Brain.

Cun Li, Mark J Nijland, Dongbin Xie, Peter W

Nathanielsz, and Thomas J McDonald. San

Antonio, TX, USA.

5:45 Antenatal Glucocorticoid Treatment Affects

0-094 Long Term Hippocampal Development in Mice.

CW Noorlander, D Tijsseling, PNE de Graan,

WB de Vries, JB Derks, and GHA Visser. and

Netherlands.

6:00 Transforming Growth Factor Beta1 Is a Potent

0-095 Activator of Drug Transport in the Fetal Blood-

Brain Barrier (BBB).

Stephanie Baello, Majid Iqbal, Enrrico Bloise, William Gibb, and Stephen Matthews.

6:15 Time Course of Inflammatory Fetal Brain

0-096 Injury; Implications for Models of In Utero

Neuroprotection.

Valeria Dell'Ovo, Irina Burd, and Laura M Goetzl. Philadelphia, PA, USA and Baltimore, MD, USA.
4:30 PM-6:30 PM

Concurrent Session

MATERNAL HEALTH, POST-PARTUM HEALTH, \& UROGYNECOLOGY

Bonnet Creek Ballroom XI \& XII

Louise Kenny and Indira Mysorekar

4:30 Preclinical Evaluation of Human Endometrial

0-097 Mesenchymal Stem Cells and Polyamide Mesh as a Tissue Engineering Approach for Pelvic Organ Prolapse (POP) Repair.

Daniela Ulrich, Sharon Edwards, Jacinta White, Ker Sin Tan, John Ramshaw, Anna Rosamilia, Jerome Werkmeister, and Caroline Gargett. Melbourne, Victoria, Australia.

4:45 Estrogen Stimulates HOXA11 Expression in

0-098 Human Uterosacral Ligament Cells Via an Estrogen Response Element in the HOXA11 Promoter.

Yan Ma, Marsha K Guess, Aki Datar, Alex Hennessey, Joshua Johnson, and Kathleen A Connell. Aurora, CO, USA and New Haven, CT, USA.

5:00 Differential Expression of a Novel Protease and

0-099 Protease Inhibitors in the Vagina: Role in Pelvic

Organ Prolapse.

Madhusudhan Budatha, Teodoro I Montoya, Ayako Suzuki, Cecilia K Wieslander, Masashi Yanagisawa, Hiromi Yanagisawa, and Ruth A Word. Dallas, TX, USA.

5:15 Chronic Vestibulitis Is Associated with

0-100 O-100Interleukin-4 Polymorphisms Linked to Interstitial Cystitis and Atopy.

Dawn Pruett, Amy Schilling, Nicky Leeborg, and Terry K Morgan.

5:30 Fatty Acid Ratios and Depressive Symptoms

0-101 in Pregnancy: A Secondary Analysis of the

Mothers, Omega-3 \& Mental Health Study.

Steffen T Brown, Joey Tyner, Ellen L

Mozurkewich, Chelsea M Clinton, Ronald

Schrader, Sheila Marcus, and Zora Djuric.

Albuquerque, NM, USA; New York, NY, USA

and Ann Arbor, MI, USA.

5:45 Anxiety during Early Pregnancy Predicts

0-102 Postpartum Weight Retention in Obese

Mothers.

Annick FL Bogaerts, Bea RH Van den Bergh, Ingrid Witters, and Roland Devlieger. Hasselt, Limburg, Belgium; Netherlands.

6:00 Oxytocin Receptor Polymorphisms and

0-103 Postpartum Weight Retention.

Alison M Stuebe, Alison Wise, Thutrang

Nguyen, Samantha Meltzer-Brody, Karen

Grewen, and Anna-Maria Siega-Riz.

6:15 Small Artery Function in Women at

0-104 Reproductive Age and with a History of Early-

Onset Preeclampsia.

Karolina Kublickiene, Gunilla Ajne, Natalia

Luksha, Annika Dellgren, Ilgar Badalov,

Rebekah Wieland, Marius Kublickas, Henry

Nisell, and Sandra Davidge. Stockholm,

Sweden and Edmonton, AB, Canada. 
PARTURITION: INFLAMMATION \& INFECTION

Bonnet Creek Ballroom X

Ramkumar Menon and Joanna Stanley

4:30 The LPS Preterm Labour Model in Mice: An

0-105 Inverse Relationship between Leukocyte Recruitment to the Myometrium and Delivery Time.

Lydia F Edey, Kieran P O'Dea, Bronwen R Herbert, Masao Takata, and Mark R Johnson. United Kingdom.

4:45 Selective Exposure of the Fetal Ovine Lung to

0-106 E. coli Lipopolysaccharide Induces Systemic Inflammation.

Matthew W Kemp, Paranthaman

Senthamaraikannan, Masatoshi Saito, John

P Newnham, Tom Cox, Alan H Jobe, Boris W

Kramer, and Suhas G Kallapur. Australia; USA; Japan and Netherlands.

5:00 Progesterone Modulates Cervical Antimicrobial 0-111 Immunity.

Catherine $P$ James, Nigel Klein, Mona BajajElliott, and Donald Peebles.

5:15 Assessment of the Efficacy of Intra-Amniotic 0-108 Delivery of CSAIDs on Human Fetal Membrane Inflammation in an Ex-Vivo Two-Compartment Model.

Lisa F Stinson, Demelza J Ireland, and Jeffrey A Keelan. Perth, WA, Australia.

5:30 Surprising Functions of Hyaluronan (HA) in the

0-109 Cervix: A Defensive Mechanism in InfectionInduced Preterm Birth (PTB).

Yucel Akgul, Ann Word, and Mala Mahendroo. Dallas, TX, USA.

5:45 Dietary Phytophenols as Potential Therapeutics

0-110 in Preventing Infection/Inflammation-Induced

Preterm Birth.

Ratana Lim, Courtney Wall, Gillian Barker, and Martha Lappas.

6:00 Mild Intrauterine Inflammation Is Sufficient To

0-107 Disrupt Normal Fetal Neuronal Development. Michal Elovitz, Monique Maubert, Lauren Anton, and Amy Brown. Philadelphia, PA, USA.

6:15 Probiotic Lactobacillus rhamnosus GR-1

0-112 Supernatant Blocks Lipopolysaccharide (LPS)Induced Preterm Birth in Pregnant CD-1 Mice through a Progesterone Independent Pathway. SW Yang, W Li, JRG Challis, G Reid, SO Kim, and AD Bocking. ; Toronto and London, Canada.

\section{PREECLAMPSIA II}

Floridian Ballroom K \& L

Stella Goulopoulou and Robert Powers

4:30 Elevated Testosterone Levels Impairs Uterine

0-113 Vascular Adaptation to Pregnancy by Reducing

Endothelium-Mediated Vasodilation and

Enhancing Vascular Contraction.

Vijay Chinnathambi, Meena Balakrishnan, Chandra Yallampalli, and Kunju Sathishkumar. Galveston, TX, USA.

4:45 The Production of sFlt-1 Splice Variants Is

0-114 Regulated by Jumonji Domain Containing

Protein 6 (Jmjd6) in the Placenta. Kirsten R Palmer, Tu'uhevaha J Kaitu'u-Lino, Louie Ye, Laura Tuohey, and Stephen Tong. Heidelberg, Victoria, Australia.

5:00 Placenta Expression of miR-517a and miR-517c

0-115 Contributes to Trophoblast Dysfunction and Preeclampsia.

Lauren Anton, Anthony O Olarerin-George, Amy Brown, Sindhu Srinivas, John B Hogenesch, and Michal A Elovitz. Philadelphia, PA, USA.

5:15 Effect of 1,25-Dihydroxyvitamin D3 (1,25-D3) on

0-116 Extravillious Trophoblast Invasion In Vitro. David Canovas, Elisavet Vasilopoulou, Laurence S Loubiere, Omi Ohizua, Martin Hewison, Mark D Kilby, and Shiao Y Chan. Birmingham, United Kingdom; Walsall, United Kingdom and Los Angeles, CA, USA.

5:30 Retinol Binding Protein 4 (RBP4) Is

0-117 Significantly Elevated in the First Trimester and across Pregnancy in Obese Women Who Develop Preeclampsia Compared to Similarly Obese Women with Uncomplicated Pregnancies.

Sarah Martin, Nicole Kotchey, and Robert W Powers. Pittsburgh, PA, USA.

5:45 1.25(OH)2D3 Promotes VEGF-A and CuZn-SOD

0-118 Expressions in Endothelial Cells.

Weijie Zhong, Yang Gu, Lynn J Groome, and Yuping Wang. Shreveport, LA, USA.

6:00 The Role of Agonist-Induced Hyperpolarization

0-119 in Enhanced Ca2+ Signaling in P-UAEC.

Roxanne Alvarez, Fu-Xian Yi, Bikash Pattnaik, Ronald R Magness, and lan M Bird. Madison, WI, USA.

6:15 TNF Alpha Induces Gap Junction Dysfunction

0-120 in Sheep Uterine Artery Endothelial Cells; a Model for Preeclampsia.

Amanda C Hankes, Fu X Yi, Mary A Grummer, Ronald R Magness, and lan M Bird. Madison, WI, USA. 
REPRODUCTIVE BIOLOGY

Floridian Ballroom HI

Peter Casson and Gaurang Daftary

4:30 Mirn451 Deficiency Impairs Development of

0-121 Endometriosis in an Experimental Mouse

Model.

Warren B Nothnick, Amanda Graham, and Mitchell J Weiss. Kansas City, KS, USA and Philadelphia, PA, USA.

4:45 In Vivo Characterization of a Novel Disease-

0-122 Protective Role of Transcription Factor KLF11

Arresting Progression of Endometriosis.

Ye Zheng, Zaid M Tabbaa, John K

Schoolmeester, Gary Keeney, Raul Urrutia, and

Gaurang S Daftary. Rochester, MN, USA.

5:00 Vitamin D3 Reduces Tumor-Promoting mTOR

0-123 Signaling Targets by Inducing DDIT4 in Human

Uterine Fibroid Cells.

Sunil K Halder, Archana Laknaur, Kevin G

Osteen, and Ayman Al-Hendy. Nashville, TN, USA.

5:15 Targeting of the Cannabinoid Signalling

0-124 Pathways Affect Endometrial Cell Survival, Proliferation and Inflammation in a Mouse Model of Endometriosis.

AM Sanchez, E Somigliana, A Mugione, G Velasco, E Papaleo, M Candiani, P Vigano, and P Panina. Milan, Italy.

5:30 Vitamin D3 Regulation of the Ovarian Kisspetin

0-125 Receptor: A Novel Excitatory Peptide Pathway Involved in Follicular Maturation and Ovulation in Adult Female Mice.

Zaher Merhi, Joe Davis, Cary Dicken, Jun Shu, Peter Casson, and Genevieve Neal-Perry.

Burlington, VT, USA; Bronx, NY, USA and New York, NY, USA.

5:45 Transthyretin Functions as a Critical Regulator

0-126 of Healthy Embryo Development.

Lori Underhill, Wendy Norris, Brianna Lyttle,

Surendra Sharma, and Jared Robins.

Providence, RI, USA and North Worcester, MA, USA.

6:00 Exencephaly and IUGR in Mouse Embryos

0-127 Lacking the HDL Receptor SR-BI.

Nicolas Santander, Susana Contreras,

Fernanda Awad, Carlos Lizama, Isabella

Passalacqua, Maria Jose Parga, Attilio Rigotti, and Dolores Busso. Santiago, Chile.

6:15 Histone Variant H3.3 Is Required for Activation

0-128 of Paternal Genome in Mouse Embryos.

Duancheng Wen, Alon Kedem, Zev Rosenwaks, and Shahin Rafii. New York, NY, USA.
REPRODUCTIVE ENDOCRINOLOGY \& IMMUNOLOGY

Floridian Ballroom J

Margaret Petroff and Erin Wolff

4:30 Human Endometrial Endothelial Cells Generate

0-129 an Inflammatory and Anti-Viral Response to a TLR3 Agonist.

Graciela Krikun, Julie Potter, Seth Guller, Gil

Mor, and Vikki M Abrahams. New Haven, CT,

USA.

4:45 Expression of the Minor Histocompatibility

0-130 Antigen HA1 in the Syncytiotrophoblast Is Increased by Low Oxygen and Preeclampsia.

Caitlin Linscheid, Paul Singh, Erica Heitmann,

Elizabeth Wickstrom, Herbert Hodes, Traci

Nauser, Lei Qui, and Margaret Petroff. Kansas

City, KS, USA; Kansas City, MO, USA and

Overland Park, KS, USA.

5:00 Natural Cytotoxicity Receptor-1 (NCR1) in

0-131 Uterine Natural Killer (uNK) Cell Function.

Allison M Felker, Alexander P Hofmann, and B

Anne Croy. Kingston, ON, Canada.

5:15 Maternal Age: A Modifiable Risk Factor for

0-132 Congenital Heart Disease.

Claire E Schulkey, Suk D Regmi, and Patrick Y Jay. Saint Louis, MO, USA.

5:30 Maternal Protein Restriction (MPR) in

0-133 Pregnancy Increases Reactive Oxygen Stress

(ROS) in Spermatozoa and Impairs Sperm

Quality in Rat Offspring.

Guadalupe L Rodriguez-Gonzalez, Claudia

Vega, Luis Reyes, Lourdes Boeck, Carlos

Ibanez, Peter W Nathanielsz, Fernando Larrea, and Elena Zambrano. Mexico, Mexico City, Mexico and San Antonio, TX, USA.

5:45 CREB-Regulated Transcription Coactivator 2

0-134 (CRTC2) Is a Coregulator of the Progesterone and Glucocorticoid Receptor.

Micah J Hill, James H Segars, and Tomoshige

Kino. Bethesda, MD, USA.

6:00 TLR10, a TLR2 Co-Receptor, Plays a Role in

0-135 Mediating Bacterial Peptidoglycan-Induced

Trophoblast Apoptosis.

Melissa J Mulla, Kledia Myrtolli, Serkalem

Tadesse, Seth Guller, Errol R Norwitz, and Vikki M Abrahams.

6:15 Role of Arcuate KNDy Neurons in Estrogenic

0-136 Feedback on GnRH Neurons.

Courtney A Marsh, Megan Greenwald-Yarnell, and Martin G Myers, Jr.. Ann Arbor, MI, USA. 
Saturday, March 23, 2013 - Concurrent Session IV

\section{CLINICAL PERINATOLOGY II}

Floridian Ballroom A-F

Rebecca Pollack and Hyagriv Simhan

10:00 Low Serum Adiponectin at Mid Pregnancy

0-137 Is Associated with the Development of Gestational Diabetes in Obese Hispanic Women.

Theresa L Powell, Evelyn Miller, Christiane Meireles, and Vanessa I Ramirez. San Antonio, TX, USA.

10:15 Previous Cesarean Delivery and the Risk of 0-138 Unexplained Stillbirth: Analysis of 128,680 Second Pregnancies in Scotland, 1999-2008. Gordon C Smith. United Kingdom.

10:30 Chronic Maternal Stress during Pregnancy 0-139 Potentiates Stress-Mediated Decrease of Uterine Blood Flow (UBF).

SJ Bischoff, R Schiffner, F Rakers, S Rupprecht, H Schubert, PW Nathanielsz, and M Schwab. Germany and USA.

10:45 Decreasing Birth Weight among Term 0-140 Pregnancies: Are Babies Getting Smaller? Janet M Catov, MinJae Lee, Jia Xu, and Hyagriv N Simhan. Pittsburgh, PA, USA and Houston, TX, USA.

11:00 Cesarean Delivery at Extreme Prematurity: Risk 0-141 of Uterine Rupture Independent of Incision Type.

Sophia R Lannon, Katherine A Guthrie, Jeroen $P$ Vanderhoeven, and Hilary S Gammill. Seattle, WA, USA.

11:15 The Unborn Smoker: Maternal Smoking and 0-142 Implications.

Elad Mei-Dan, Mordechai Hallak, Richard Brown, and Alon Shrim. Hadera, Israel and Montreal, Canada.

EPIDEMIOLOGY, POPULATION HEALTH, \& GLOBAL HEALTH

\author{
Bonnet Creek Ballroom XI \& XII
}

Emily Jungheim and Eric Steegers

10:00 Mortality from Common Malignancies Following

0-143 Hysterectomy with Ovarian Conservation: A Cohort Study from the Rochester Epidemiology Project (REP).

Zaraq Khan, Shannon K Laughlin-Tommaso, Amy L Weaver, Cathy D Schleck, Adil E Bharucha, Elizabeth A Stewart, and Walter A Rocca. Rochester, MN, USA.

10:15 Pregnancy as a Cardiovascular Challenge Test:

0-144 Evaluation of Hypertension and Diabetes in Pregnancy as Predictors for Cardiovascular Disease among 15,175 Women Aged 49-70 Years.

Bas B van Rijn, Karst Y Heida, Jan H Veerbeek, Maria P Koster, Yvonne T van der Schouw, Michiel L Bots, and Arie Franx. Netherlands and United Kingdom.

10:30

0-145

$10: 45$

0-146
Interpregnancy Weight Change and Risk for Adverse Perinatal Outcomes: An Epidemiological Study. Annick FL Bogaerts, Lieveke Ameye, Bea RH Van den Bergh, Ingrid Witters, Evelyne Martens, and Roland Devlieger.

Deprived Neighbourhoods and Adverse Pregnancy Outcomes: A Systematic Review and Meta-Analysis of Observational Studies. Amber A Vos, Anke G Posthumus, Gouke J Bonsel, Eric AP Steegers, and Semiha Denktas. Rotterdam, Netherlands.

Pregnancy Intention and Use of Birth Control among Hispanic Women in the United States: Data from the National Survey of Family Growth.

Lisa M Masinter, Melissa A Simon, and Joe Feinglass. Chicago, IL, USA.

Preconception Genetic Screening and Decision To Test in Patients Preparing for In-Vitro Fertilization Cycles.

Tia Jackson-Bey, Alan M Martinez, Julie M Sroga, Krystene B Dipaola, Michael A Thomas, and Steven R Lindheim. Cincinnati, $\mathrm{OH}$, USA and Tucson, AZ, USA. 
FETUS: PROGRAMMING II

Floridian Ballroom K \& L

Mina Desai and Dean Myers

10:00 Growth Restricted but Enhanced Adipocyte

0-149 Proliferation: Mechanism of Programmed

Adipogenesis.

Mina Desai, Juanita Jellyman, Guang Han, Marie $\mathrm{H}$ Beall, and Michael G Ross.

10:15 Elevated Maternal Androgens Program

0-150 Sex-Specific Vascular Dysfunction and Hypertension in Adult Offspring.

Vijay Chinnathambi, Meena Balakrishnan, Chandra Yallampalli, and Kunju Sathishkumar.

Galveston, TX, USA.

10:30 The Intrauterine Environment: Not a Trivial Risk

0-151 Factor for Cardiovascular Disease.

JA Thompson, R Gros, O Sarr, and TRH

Regnault. Augusta, GA, USA and London, ON, Canada.

10:45 Single Course Antenatal Glucocorticoid Has

0-152 Multigenerational Effects on Growth, Endocrine

Function and Behavior.

Vasilis G Moisiadis, Paul Blakeley, Alisa

Kostaki, and Stephen G Matthews. Toronto, ON, Canada.

11:00 Maternal Melatonin: Effective Intervention

0-153 Against Developmental Programming of

Cardiovascular Dysfunction in Adult Offspring

of Complicated Pregnancy.

JA Hansell, HG Richter, EJ Camm, EA Herrera, and DA Giussani.

11:15 Exposure to Maternal Low Protein Diet In Utero

0-154 Gives Rise to Accelerated Reproductive Ageing in Female Offspring.

CE Aiken, JL Tarry-Adkins, and SE Ozanne.

Cambridge, UK.

\section{FIBROIDS \& ENDOMETRIOSIS}

\author{
Floridian Ballroom HI
}

William Catherino and Kenneth Ward

10:00 Lipoxin A4 (LXA4) Synthesis Pathway Is

0-155 Cycle Regulated in Human Endometrium and

Dysregulated in Women with Endometriosis. Tolga B Mesen, Bruce A Lessey, Geraldine O Canny, Lingwen Yuan, Doug D Taylor, and Steven L Young. Chapel Hill, NC, USA; Greenville, SC, USA and Louisville, KY, USA.

10:15 Meta-Analysis of GWA Studies Identifies New

0-156 Endometriosis Risk Loci.

Dale R Nyholt, Siew-Kee Low, Carl A Anderson, Jodie N Painter, Sakoto Uno, Andrew P Morris,

Stuart MacGregor, Scott D Gordon, Anjali

K Henders, Nicholas G Martin, John Attia, Elizabeth G Holliday, Mark McEvoy, Rodney J

Scott, Stephen H Kennedy, Susan A Treloar,

Stacey A Missmer, Sosuke Adachi, Kenichi

Tanaka, Yusuke Nakamura, Krina T Zondervan, Hitoshi Zembutsu, and Grant W Montgomery. Brisbane, Qld, Australia; Tokyo, Japan; Hinxton, United Kingdom; Oxford, United Kingdom; Newcastle, New South Wales, Australia; Boston, USA and Niigata, Japan.

10:30 Wnt/ $\beta$-Catenin: Paracrine Signaling between

0-157 Stem Cells and Main Population in Uterine Fibroid Cell Growth.

Masanori Ono, Ping Yin, Antonia Navarro, John $S$ Coon, David C Brooks, Saurabh Malpani, Jiajia Ma, Navdha Mittal, Wenan Qiang, Vanida A Serna, Stacy A Druschitz, Takeshi Kurita, Cara J Gottardi, and Serdar E Bulun. Chicago, IL, USA.

Epigenome and Risk of Uterine Fibroids (UF): Altered Phosphorylation of Histone Methyltransferase EZH2 in Stem Cells from UF \& Adjacent Myometrium.

Sangeeta Nair, Chakradhari Sharan, Waseem Khoder, Sarbani Maitra, and Ayman Al-Hendy. Nashville, TN, USA.

11:00 BET1L and TNRC6B Associate with Fibroid

0-159 Risk among European Americans. Digna R Velez Edwards, Kara A Michels, Todd L Edwards, and Katherine E Hartmann.

11:15 Angiotensin Type 1 Receptor Blockade Blunts

0-160 In Vitro Uterine Leiomyoma Proliferation and Endothelin-1 Secretion; Linking Uterine Fibroids with Pre-Hypertension in Premenopausal Patients.

Kedra Wallace, Krystal Frazier, Venessia Johnson, Jeremy Scott, and Babbette LaMarca. Jackson, MS, USA. 


\section{Saturday, March 23, 2013 - Concurrent Session IV}

\section{PARTURITION: HORMONES \& CYTOKINES}

\section{Bonnet Creek Ballroom X}

Jan Heng and Sam Mesiano

10:00 Differential Interaction between Progesterone

0-161 Receptors and AP-1 Members - A Potential Regulatory Switch between Uterine Quiescence and Activation.

Lubna Nadeem, Oksana Synlova, Dong

Xuesen, and Stephen Lye. Toronto, ON, Canada; Canada and BC, Canada.

10:15 A Multi-Center Study Using Proteomics

0-162 Techniques To Identify Maternal Serum Biomarkers of Spontaneous Preterm Delivery. S Parry, H Zhang, J Biggio, R Bukowski, M Varner, I Blair, X Guo, W Andrews, G Saade, S Esplin, J llekis, U Reddy, and Y Sadovsky.

10:30 Two Novel Genetic Variants in the

0-163 Mineralocorticoid Receptor Gene Associate with Spontaneous Preterm Birth. Inge Christiaens, Craig E Pennell, Xin Fang, $\mathrm{Q}$ Wei Ang, and David M Olson. Edmonton, Canada; Wrexham, United Kingdom; Perth, Australia.

10:45 Effects of Leptin on Human Myometrial Cell 0-164 Proliferation. M Barrichon, T Hadi, M Wendremaire, F Goirand, M Bardou, P Mourtialon, P Sagot, and F Lirussi. and Dijon.

11:00 Membrane Progesterone Receptor Alpha:

0-165 Expression in Macrophages and Mouse Models of Preterm Labor.

Jing Lu, Joshua Reese, Yana Filipovich, Varkha Agrawal, and Emmet Hirsch.

11:15 Sterile Intraamniotic Injection of IL1 Alters 0-166 the Microbiome in a Primate Model of Chronic Inflammatory Preterm Birth.

Kjersti Aagaard, Jun Ma, Lisa Miller, Alan Jobe, Suhas Kallapur, and Claire Chougnet. Houston, TX, USA; Davis, CA, USA and Cincinatti, $\mathrm{OH}$, USA.

\section{PLACENTA II: GROWTH, METABOLISM, \&} TRANSPORT

Floridian Ballroom J

Helen Jones and Emily Su

10:00 Metabolic Adaptation of Syncytiotrophoblast

0-167 Mitochondria with Maternal Obesity. J Mele, A Maloyan, and L Myatt. San Antonio, TX, USA.

10:15

0-168

Acetylation of Histone 3 by p300 Increases $11 \beta-H S D 2$ Expression in Human Placental Trophoblasts.

Jianneng Li, Wenjiao Li, Wangsheng Wang, Chao Liu, Weihua Wang, Xunding $\mathrm{Xu}$, and Kang Sun. Shanghai, China.

10:30 Omega 3 Fatty Acid Supplementation

0-169 Attenuates Amino Acid Transport in Placentas of Obese Women and in Primary Trophoblast Cells.

S Lager, VI Ramirez, O Acosta, C Meireles, E Miller, F Gaccioli, F Rosario, ST Weintraub, and TL Powell. San Antonio, TX, USA.

Mechanism of Uptake of Cationic Nanoparticles

0-170 by Human Placental Syncytiotrophoblast Cells. Gautam Kaul, Tristan D Clemons, Killigudi S Iyer, Kamali Pugazhenthi, and Jeffrey A Keelan. Perth, WA, Australia.

11:00 Targeted Disruption of Znf403 Reveals Its Vital 0-171 Role in Regulation of Placental Development. SQ Li, AK Moore, ZJ Lan, J Zhu, X Li, J Lin, $Y$ He, TE Franklin, ST Nakajima, and ZM Lei. Louisville, KY, USA and Salt Lake City, UT, USA.

11:15 PLIN Proteins Play a Key Role in Trophoblast

0-172 Lipid Accumulation.

M Morizane, S-Y Oh, M O'Brien, T Mishima, X-H Shi, and Y Sadovsky. Pittsburgh, PA, USA. 


\section{Thursday, March 21, 2013 - Poster Session I - Bonnett Creek Ballroom}

T-010

\section{ANGIOGENESIS, ENDOTHELIAL DYSFUNCTION}

T-001 Monocytes of Women with Pre-Eclampsia Alter the Inflammatory Response of Human Vascular Endothelial Cells in Co-Culture. Ebtisam Al-ofi, Seth Coffelt, and Dilly Anumba. United Kingdom and Netherlands.

T-002 Fibrinogen Attenuates sFlt-Induced DysAngiogenesis and Increases Vascular Adhesion Molecule Expression in Pre-Eclampsia. Ebtisam Al-ofi, Seth Coffelt, and Dilly Anumba.

T-003 Choline Modulates Soluble-Endoglin in Cultured Human Trophoblasts. Benjamin Y Andrew, Xinyin Jiang, Sara Jones, Marie A Caudill, and Patsy M Brannon. Ithaca, NY, USA.

T-004 The Prostacyclin Analog, Beraprost, Can Paradoxically Increase Vascular Tone. Yurij P Vedernikov, Ancizar Betancourt, Rina Ow, Daren T Tanchico, Hossein Golabbakhsh, and Michael A Belfort. Houston, TX, USA.

T-005 Variation in Endoglin Pathway Genes Is Associated with Preeclampsia. Mandy J Bell, James M Roberts, Sandra A Founds, Arun Jeyabalan, Carl A Hubel, Lauren Terhorst, and Yvette P Conley. and Pittsburgh, PA, USA.

T-006 Plasma Levels of S100B in Women with Preeclampsia.

Lina Bergman, Anna-Karin Wikstrom, Tansim Akhter, Tord Naessen, and Helena Akerud. Uppsala, Sweden.

T-007 Growth Factor-Induced Endothelial Cell Functional Disruption as a Model of Preeclampsia: Translation from Sheep to Human.

Jennifer L Krupp, Derek S Boeldt, Fu-Xian Yi, Dinesh M Shah, and lan M Bird. WI, USA and lowa City, IA, USA.

T-008 Postpartum Vascular Function in an Animal Model of Preeclampsia.

Lesley J Brennan, Jude S Morton, and Sandra T Davidge. Edmonton, AB, Canada.

T-009 AT1-AA Enhances ANGII Induced Hypertension and Renal Vascular Sensitivity. Justin M Brewer, Kedra Wallace, Florian Herse, Janae N Moseley, Ralf Dechend, Gerd Wallukat, James N Martin, Jr., and Babbette B LaMarca. Jackson, MS, USA and Berlin, Germany.
T-011

T-012

T-013

\section{T-014}

\section{T-016}

$\mathrm{T}-017$

\section{$\mathrm{T}-018$}

Lectin-Like Oxidised Low-Density Lipoprotein 1 (LOX-1) Receptor Inhibition Protects Against Pre-Eclampsia Plasma Mediated Vascular Dysfunction.

Fred A English, Fergus P McCarthy, Catherine L McSweeney, Anita L Quon, Jude S Morton, Tatsuya Sawamura, Sandra T Davidge, and Louise C Kenny. Ireland; Canada and Japan.

Preeclampsia Is Associated with Significant Differences in Omental Venous and Arterial Contractility.

Ancizar Betancourt, Yurij P Vedernikov, Jimmy Espinoza, Daren T Tanchico, Hossein Golabbakhsh, and Michael A Belfort. Houston, TX, USA.

Normal Pregnancy Is Associated with a Blunted Vascular Response to Prostacyclin Analogs and Prostacyclin Antagonists, Which Is Exacerbated in Preeclampsia.

Ancizar Betancourt, Yurij Vedernikov, Jimmy Espinoza, Daren T Tanchico, Hossein Golabbakhsh, and Michael A Belfort. Houston, TX, USA.

Differential Expression of the VEGF Receptor in Placentas from Normal and Hypertensive Pregnancies.

Ana M Garcia, Wayne R Cohen, and Alda Tufro. Stamford, CT, USA; Tucson, AZ, USA and New Haven, CT, USA.

Influence of Prepregnancy Physiology on Cardiovascular Adaptation during Pregnancy. Sarah A Hale, Carole McBride, and Ira M Bernstein. Burlington, VT, USA.

Direct Activation of SGC Improves Some but Not All Deleterious Effects of NOS Inhibition during Pregnancy.

Nicole Maille, Richard Adams, Renju Raj, and George Osol. Burlington, VT, USA.

Plasma Volume Expansion and Uterine Blood Flow as Predictors of Birth Weight. Carole A McBride, Gary J Badger, Sarah A Hale, and Ira M Bernstein. Burlington, VT, USA.

Potential Treatment of a Reduced UteroPlacental Perfusion Pressure (RUPP) Model of Preeclampsia Using a Danshen Derivative. Jude S Morton, Lesley J Brennan, and Sandra T Davidge. Edmonton, AB, Canada.

Microcomputed Tomography Suggests Reduced Spiral Artery Number and Coiling Underlies Rapid Uteroplacental Blood Flow in Transgenic Mice with Preeclampsia/IUGR. Monique Y Rennie, Jessica Hebert, Antonio Frias, Xuemei Wu, Kent L Thornburg, and Terry K Morgan. and Portland, OR, USA. 


\section{Thursday, March 21, 2013 - Poster Session I - Bonnett Creek Ballroom}

T-019 4-Methoxyestradiol Induces Proliferation of Uterine Artery Endothelial Cells Occurs Via Activation of p38, p42/44 and JNK MAPKs and Independent of Estrogen and Adrenergic Receptors.

R Villalon Landeros, SO Jobe, J Zheng, and RR Magness.

T-020 microRNA-203 Down-Regulates Suppressor of Cytokine-Singlaing-3 Expression and Increases ICAM Expression and Production in Endothelial Cells.

Yang Gu, Qin Dong, Lynn J Groome, and Yuping Wang. Shreveport, LA, USA.

T-021 Preeclampsia-Upregulated AngiogenesisAssociated microRNA-17 Family miRNAs (17, 20a and 20b) Inhibit Cytotrophoblast Endovascular Transformation. Wen Wang, and Dong-bao Chen. Irvine, CA, USA.

T-022 IL6 and IL8 Differentially Regulate Human Endothelial Functions.

Qing-yun Zou, Ying-jie Zhao, Yan Li, Dong-bao Chen, and Jing Zheng. Madison, WI, USA and Irvine, CA, USA.

\section{BASIC PARTURITION/PREMATURITY}

T-023 Physiologic IgG Changes throughout Pregnancy.

Jena Abel, Jona Conklin, Stephen K Hunter, Ryan Empey, Eric Tyler, Ashley Christensen, Katelyn Talcott, Zuhair K Ballas, Mark K Santillan, and Donna A Santillan. Iowa City, IA, USA.

T-024 Establishing Thromboelastography (TEG) and Platelet Function Analyzer (PFA-100) Reference Ranges in Healthy Pregnant Women. Kathleen M Antony, Roshanak Mansouri, Shiu-Ki Rocky Hui, Purviben Jariwala, Virginia Moreland, Jun Teruya, and Kjersti M Aagaard. Houston, TX, USA.

T-025 Non-Esterified Fatty Acids and Spontaneous Preterm Birth: Factor Analysis To Identify Possible Patterns of Risk. Janet M Catov, Marnie Bertolet, Yi-Fan Chen, and Rhobert Evans. Pittsburgh, PA, USA.

T-026 Lipoprotein Heterogeneity in Black and White Women during Early Pregnancy and Preterm Birth.

Janet M Catov, Rachel H Mackey, Christina M Scifres, and Hyagriv N Simhan. Pittsburgh, PA, USA.

T-027 Inhibition of IL-6 by Curcumin in Uterine Decidual Cells.

Y Sangeeta Devi, Susan Ferguson, Asgerally Fazleabas, and Justin DeKuiper. Grand Rapids, MI, USA.
T-028

The Ability of Progesterone To Regulate the Inflammatory Monocyte Subset during Pregnancy.

Lydia F Edey, Kieran P O'Dea, Bronwen R Herbert, Masao Takata, and Mark R Johnson. London, United Kingdom.

T-029 Haemodynamic Profiling throughout Pregnancy in Normal and Lipopolysaccharide-Treated Mice.

Laura Howe, Zhen Wang, Lydia F Edey, Leiper James, and Mark R Johnson. London, United Kingdom.

T-030 Longitudinal Expression of Apolipoprotein Subtypes in Complicated Pregnancies: A Targeted Proteomics Approach to Differential Diagnosis.

Danielle L Ippolito, Shannon K Flood-Nichols, and Peter G Napolitano. Tacoma, WA, USA.

T-031 Activation of NF- $\kappa B$ in Human Amnion Is Mediated through $\mathrm{G}_{\alpha \mathrm{i}}$ and Is Mimicked by the Oxytocin Receptor Antagonist - Atosiban. SH Kim, A Blanks, S Thornton, M Johnson, PR Bennett, and $\mathrm{V}$ Terzidou. United Kingdom.

T-032 Cervical-Length Indicated Cervical Cerclage Versus Routine Antenatal Care after Treatment for Cervical Precancer.

Maria Kyrgiou, SE Taher, Andrew Shennan, Patrick Soutter, and Phillip Bennett. London, United Kingdom.

T-033 Nucleotide Oligomerization Domain 1 (NOD1) and NOD2 Regulate Mediators of Fetal Membrane Rupture: Implications for Preterm Birth.

Ratana Lim, and Martha Lappas.

T-034 Changes in Progesterone Receptor Membrane Component 1 (PGRMC1) Expression in Fetal Membrane Cells with Progesterone, TNF- $\alpha$ and Oxidative Stress Stimulus. Yan Meng, David Schomberg, Amy Murtha, and Liping Feng. Durham, NC, USA.

T-035 DNA Methylation Differences in Umbilical Cord Blood from a Preterm Birth Population. Sasha E Parets, Karen N Conneely, Varun Kilaru, Tariq A Syed, George Saade, Alicia K Smith, and Ramkumar Menon. Atlanta, GA, USA and Galveston, TX, USA.

T-036 Quantification of Fetal Fibronectin Improves the Accuracy of Prediction of Spontaneous Preterm Birth in High Risk Asymptomatic Women. Danielle Abbott, Manju Chandiramani, Paul Seed, Rachel Tribe, and Andrew Shennan. United Kingdom. 
CLINICAL PARTURITION/PREMATURITY I

T-037 Cerclage and PPROM: Is There a Role for Amniocentesis?

Eduardo Aguin, Cosmas Van De Ven, Marcos Cordoba, Samet Albayrak, and Ray BahadoSingh. Ann Arbor, MI, USA; New York, NY, USA and Detroit, MI, USA.

T-038 Second Stage of Labor and Estimated Blood Loss.

Eduardo Aguin, Sarah Wallett, Michelle Housey, Marjorie Treadwell, and Cosmas Van De Ven.

T-039 Intrauterine Contraction Patterns at Baseline and during the Pre-Epidural Intravascular Fluid Bolus in Term Labor.

Rebecca Benfield, Dawn Daniels, Sarah Buck, Joy Shepard, Jan Salstrom, Denise Brigham, Melydia Edge, Melvin Swanson, and Edward Newton. Greenville, NC, USA.

T-040 A Silk-Based Biomaterial for Cervical Injection: A Pilot Study of Biocompatibility in a Pregnant Rat Model.

Agatha S Critchfield, Jeannie C Kelley, Reid McCabe, Lauren Richey, Simona Socrate, Errol R Norwitz, David L Kaplan, and Michael House. Boston, MA, USA; Medford, MA, USA and Cambridge, MA, USA.

T-041 Intrapartum Fever, Epidural and Histologic Chorioamnionitis.

William M Curtin, Philip J Katzman, Heather Florescue, and Leon A Metlay. Hershey, PA, USA and Rochester, NY, USA.

T-042 Success of Cervical Cerclage in Singleton Pregnancy.

Meg Hill, and Judith Burgis. Columbia, SC, USA.

T-043 Combined Foley Catheter and Prepidil Gel for Cervical Ripening: A Randomized Trial. Meg Hill, Anthony Gregg, Stanette Brown, Judith Burgis, and Paul Browne. Columbia, SC, USA.

T-044 Are Clean Gloves on Labor and Delivery Truly Clean?

Laura Houston, Scott Sullivan, David Soper, Laura Goetzl, and Lisa Steed. Charleston, SC, USA.

T-045 The Effect of Inflatable Obstetric Belts in Nulliparous Pregnant Women Receiving Patient-Controlled Epidural Analgesia during the Second Stage of Labor.

Yoon Ha Kim, Jong-Woon Kim, Hye Yon Cho, Hee-Young Shin, JongChul Shin, Sea Kyung Choi, Keun-Young Lee, Ji-Eun Song, and PilRyang Lee. Gwangju, Korea and Seoul, Korea.

T-046 Term Induction Increases Risk for Cesarean Delivery, Regardless of Parity.

Lisa D Levine, Adi Hirshberg, Michal A Elovitz, and Sindhu K Srinivas. Philadelphia, PA, USA.
T-047

The Risk of Preterm Birth in a Subsequent Pregnancy Is Decreased Following a Term Induction Compared to Term Spontaneous Labor.

Lisa D Levine, Adi Hirshberg, Michal A Elovitz, and Sindhu K Srinivas. Philadelphia, PA, USA.

T-048 Failed Induction of Labor: Can It Be Defined? Lisa D Levine, Adi Hirshberg, Michal A Elovitz, and Sindhu K Srinivas. Philadelphia, PA, USA.

T-049 The Effect of Smoking and Sexual Activity on Amniotic Fluid Cytokine Levels in the Early Second Trimester of Pregnancy. Shaofu Li, Matthew Payne, Dorota A Doherty, Jan E Dickinson, Jeffrey A Keelan, and John P Newnham. Crawley, WA, Australia.

T-050 Manual Rotation To Reduce Cesarean Delivery in Persistent Occiput Posterior or Transverse Position: A Cost-Effectiveness Analysis. Jamie Lo, Allison Allen, Brian Shaffer, Yvonne Cheng, Jeff Broberg, and Aaron Caughey. Portland, OR, USA; San Francisco, CA, USA and Provo, UT, USA.

T-051 The Impact of Height on Cesarean Delivery among Different Racial Ethnic Groups. Jamie Lo, Yvonne Cheng, Judith Chung, Jonathan Snowden, Sanae Nakagawa, Kathryn Melsop, Elliott Main, William Gilbert, and Aaron Caughey. Portland, OR, USA; San Francisco, CA, USA; Orange, CA, USA and Stanford, CA, USA.

T-052 Ultrasonographic Cervical Length Assessment after Cervical Cerclage.

TA Manuck, MJ Kamyar, JLB Byrne, RM Silver, MS Esplin, TF Porter, and MW Varner. UT, USA.

T-053 Proteomic Biomarkers for Spontaneous Preterm Birth: A Systematic Review of Literature.

Marian Kacerovsky, Maria Regina Torloni, Ivana Musilova, Vojtech Tambor, Juraj Lenco, and Ramkumar Menon. Hradec Kralove, Czech Republic; Sao Paulo, Brazil; Pardubice, Czech Republic and Galvestone, USA.

T-054 Angiotensinogen Thr235 Genetic Variant Is Associated with Preterm Labor in Japanese Women.

Rebecca Sauerwein, Daphne Ang, Jorge Tolosa, Gillian Bryant-Greenwood, Tim Dye, Lynnae Sauvage, and Terry K Morgan. and $\mathrm{HI}$, USA.

T-055 Manual Rotations; Are They Really the Safer Alternative for Rotational Vaginal Delivery? Nicola Tempest, Anna Hart, Stephen Walkinshaw, and Dharani K Hapangama. United Kingdom. 


\section{Thursday, March 21, 2013 - Poster Session I - Bonnett Creek Ballroom}

T-056 The Relationship between Histological Chorioamnionitis, Maternal and Fetal Inflammatory Response and Perinatal Outcome in PPROM Pregnancies.

Panagiotis Tsiartas, Marian Kacerovsky, Teresa Cobo, Ivana Musilova, Helena Hornychova, and Bo Jacobsson. Gothenburg, Sweden; Hradec Kralove, Czech Republic; Barcelona, Spain and Oslo, Norway.

\section{CLINICAL PERINATOLOGY}

T-057 Chronic Maternal Psychological Stress Impairs Cerebral Development in Fetal Sheep with Specific Effects on Myelination.

I Antonow-Schlorke, D Hollstein, J Quendt, F Rakers, V Frauendorf, O Witte, and M Schwab. Jena, Germany.

T-058 Measuring the Effect of Maternal Position Changes on Cardiac Output Using Electric Cardiometry in Women with Epidural

Anesthesia during the Active Phase of Labor. Jerasimos Ballas, Kristin Mantell, and Thomas Archer. San Diego, CA, USA.

T-059 Correlation between Pregnancy-Specific Anxiety and Other Markers of Stress in Women with Multiple Gestations.

Carolyn Weiss, Yair Blumenfeld, Deirdre Lyell, Henry Lee, Athena Panzar, Elizabeth Kogut, and Cheryl Koopman.

T-060 Perinatal Outcome of Twin Pregnancies Following Early Transvaginal Multiple Pregnancy Reduction. Jigal Haas, Jehoshua Dor, Ariel Hourvitz, Yoav Yinon, and Adrian Shulman. Ramat Gan, Israel and Kfar Saba, Israel.

T-061 Maternal Obesity (MO) Increases Maternal and Offspring Corticosterone (Cort) Production: Effects of Maternal (M) Exercise (MEx). Carlos Ibanez, Roberto Chavira, Luis ReyesCastro, Claudia J Bautista, Claudia VegaGarcia, Peter W Nathanielsz, and Elena Zambrano. Mexico City, DF, Mexico and San Antonio, TX, USA.

T-062 Pregnancy Outcome in Ovine Model of Elevated Maternal Cortisol. Maureen Keller-Wood, Xiaodi Feng, and Charles E Wood. Gainesville, FL, USA.

T-063 Intrapartum Fetal Heart Rate Patterns in Term Infants with Clinical Chorioamnionitis. Yuki Kodama, Hiroshi Sameshima, Tsuyomu Ikenoue, Masatoki Kaneko, and Seishi Furukawa. Kiyotake, Miyazaki, Japan.
T-064

Cerebrovascular Events (CVE) in an Obstetric Population Requiring Intensive Care Unit (ICU) Admission.

Caroline C Marrs, Brendan D Connealy, Oscar A Viteri, Maria S Hutchinson, Alfredo F Gei, and Baha M Sibai. Houston, TX, USA.

T-065 Fetal Anomaly Screening in Obese Women: Is MRI Cost Effective When Ultrasound Is Limited?

Nicole E Marshall, Allison Allen, Jenna Emerson, Jorge Tolosa, Leonardo Pereira, Brian Shaffer, and Aaron B Caughey. Portland, OR, USA.

T-066 Amniocentesis in Preterm Labor between 24-29 Weeks' Gestation and Neonatal/Infant Outcomes.

Laura Meints, Rachel Harrison, Samet Albayrak, Anushka Chelliah, Michael Kruger, and Ray Bahado-Singh. Detroit, MI, USA.

T-067 A Scoring System for Severity of Placenta Accreta.

Sam Nasseri, Adam Bogomol, Manuel Alvarez, Themba Nyirenda, Stacy Zamudio, and Abdulla Al-Khan. Grenada and NJ, USA.

T-068 Neonatal Antioxidant Treatment Prevents Impaired Cardiovascular Function at Adulthood Following Neonatal Glucocorticoid Therapy. Y Niu, EA Herrera, RD Evans, and DA Giussani.

T-069 Maternal Resveratrol (Rvt) before and in Pregnancy Improves Anxiety Type Behavior in Rat Offspring (OFF) of Obese Mothers (MO) Fed a High Energy Diet (HED). Luis Reyes, Claudia Vega, Margarita Lucas, Guadalupe L Rodriguez-Gonzalez, Thalia Romero, Emma Vazquez, Fernando Larrea, Peter W Nathanielsz, and Elena Zambrano. Mexico, Mexico City, Mexico and San Antonio, TX, USA.

T-070 Uterine Artery Doppler Velocimetry Facilitates Risk Assessment of Patients with Abnormal Analytes.

Hilary A Roeder, Kristen M Klisser, Gina M James, Louise C Laurent, and Douglas A Woelkers. San Diego, CA, USA.

T-071 Doppler Assessment of Fetal Circulation Does Not Improve the Prediction of Adverse Outcomes above That of Uterine Artery Screening Alone. Hilary A Roeder, Kristen M Klisser, Gina M James, Louise C Laurent, and Douglas A Woelkers. San Diego, CA, USA.

T-072 Hepatic Insulin Resistance: Effects of Postnatal Glucocorticoid and Antioxidant Therapy. KL Skeffington, MS Martin-Gronert, AD Kane, EA Herrera, DS Fernandez-Twinn, SE Ozanne, and DA Giussani. and United Kingdom. 


\section{DEVELOPMENTAL BIOLOGY}

T-073 Investigating the Role of Tbx4 in the Germline. Nataki C Douglas, Ripla Arora, Mark V Sauer, and Virginia E Papaioannou.

T-074 The Impact of Maternal Sucrose and High Fructose Corn Syrup Consumption during Pregnancy on the Rat Offspring. Sheridan Gentili, and Carla R Toop. Adelaide, South Australia, Australia.

T-075 H19 IncRNA-Mediated Regulation of Gene Expression in Granulosa Cells.

Amanda N Kallen, Jing Ma, and Yingqun Huang. New Haven, CT, USA.

T-076 Expression of CRH and CRH Regulating Proteins in Placentas of Non-Human Primates. Bingbing Wang, Tianmeng Luo, Serkalem Tadesse, Suzette Tardif, Corinna Ross, Jay Schulkin, Michael Power, Todd Rosen, and Errol Norwitz. Boston, MA, USA; New Brunswick, NJ, USA; Seattle, WA, USA; San Antonio, TX, USA and Washington, DC, USA.

T-077 Characterization of the Secretome of 2-Cell Mouse Embryos Cultured In Vitro to the Blastocyst Stage with and without Protein Supplementation.

Liang Yu, Tanya Burch, Silvina Bocca, Julius Nyalwidhe, Estella Jones, Jose Horcajadas, and Sergio Oehninger.

\section{DEVELOPMENTAL ORIGINS OF HEALTH I}

T-078 The Role of Xanthine Oxidase Pathway in Programmed Cardiac and Endothelial Dysfunction in Young Adult and Aged Rats. BJ Allison, JJ Kaandorp, C Lusby, AD Kane, CM Cross, JB Derks, and DA Giussani. Cambridge, United Kingdom and Utrecht, Netherlands.

T-079 Developmental Programming of Cardiac Mitochondrial Dysfunction by Prenatal Hypoxia. T Ashmore, AD Kane, C Lusby, AJ Murray, and DA Giussani. United Kingdom.

T-080 Prenatal Dexamethasone (DEX) Exposure but Not Postnatal Stress in Mice Worsens Stroke Outcome in Later Life.

C Bergmeier, F Kronert, I Antonow-Schlorke, S Rupprecht, OW Witte, and M Schwab. Germany.

T-081 Maternal Environment Alters Pancreatic Endocrine Cell Development in Fetal Baboons. Amy Quinn, Sanjeet Panda, Peter Nathanielsz, and Cynthia Blanco. San Antonio, TX, USA and Corpus Christi, TX, USA.

T-082 Maternal Controlled Exercise Improves Glucose Disposal in Mouse Offspring. Lindsay G Carter, Brice Kinney, and Kevin J Pearson. Lexington, KY, USA.
T-083

Altered Endothelial Function Associated with Diabetes Begins In Utero.

Silvija Cvitic, Livinia Gordon, Ursula Hiden, Luciana Lassance, Richard Saffery, and Gernot Desoye. Graz, Austria and Melbourne, Australia.

T-084 Programming Effects of Maternal Leptin and Food Restriction on Developing Fetuses and Offspring.

Jennifer L Harper, Kathleen A Pennington, Gerialisa Caesar, Lindsey M Beffa, and Laura C Schulz. Columbia, MO, USA.

T-085 Undernourishment In Utero and Subsequently Rapid Infantile Growth Induce Transformation from a "Metabolically Healthy Obese" into a "Metabolically Morbidly Obese" by Adipose Tissue Remodeling of Mice: A Possible Involvement in Developmental Origins of Metabolic Syndrome.

Hiroaki Itoh, Kohmura K Yukiko, Kiko Muramatsu, Kaori Yamazaki, Kotomi Nagahashi, Naoaki Tamura, Toshiyuki Uchida, Kazunao Suzuki, and Naohiro Kanayama. Hamamatsu, Japan.

T-086 MiR-18a Is Involved in Fetal Cardiac Response to Maternal Obesity.

Alina Maloyan, Tamisa Koythong, Sribalasubashini Muralimanohara, and Leslie Myatt. San Antonio, TX, USA.

T-087 Monthly Variations in Birthweight, Placental Shape and Histopathology: Potential Role for Seasonal Affects in Developmental Programming. Abigail M Pape, and Terry K Morgan.

T-088 Alteration of Cardiac Glucose Metabolism in Low Birth Weight Lambs with Cardiac Hypertrophy. Kimberley CW Wang, Chin H Lim, I Caroline McMillen, Jaime A Duffield, Doug A Brooks, and Janna L Morrison. Adelaide, South Australia.

T-089 Rapid Infantile Growth as a Risk of Fatty Liver in Later Life - A Study of Mouse Animal Model with Undernourishment In Utero.

Keiko Muramatsu, Yukiko Kohmura, Kaori Yamazaki, Kotomi Nagahashi, Toshiyuki Uchida, Kazunao Suzuki, Kazuhiro Sugihara, Hiroaki Itoh, and Naohiro Kanayama. Hamamatsu City, Shizuoka-ken, Japan.

T-090 In Vitro Culture and Embryo Transfer Increases Heart Weight but Not Basal Blood Pressure in Fetal or Early Postnatal Life. Monalisa Padhee, I Caroline McMillen, Severence M MacLaughlin, Song Zhang, David O Kleemann, Simon K Walker, and Janna L Morrison. Adelaide, South Australia. 


\section{Thursday, March 21, 2013 - Poster Session I - Bonnett Creek Ballroom}

T-091 Offspring Effects of Butter and Lard Based High Fat Diet Consumption during Mouse Pregnancy.

Kristen M Platt, and Kevin J Pearson. Lexington, KY, USA.

T-092 A Novel Mouse Model of Diet-Induced Maternal Obesity with Fetal Overgrowth. Fredrick J Rosario, Theresa L Powell, and Thomas Jansson. San Antonio, TX, USA.

T-093 Low Dose Dexamethasone (DM) at 0.68 Gestation (G) Programs Arterial Hypertension and Vascular Dysfunction in Adult Female Sheep Offspring.

S Rupprecht, S Ford, J Mueller, M Schwab, $O$ Witte, R Codery-Cotter, M Nijland, and P Nathanielsz. Jena, Germany; Laramie, USA and San Antonio, USA.

T-094 Gender Differences in the Effect of Antenatal Betamethasone (Beta) Exposure on NHE3 and $\mathrm{Na} / \mathrm{K}-\mathrm{ATPase}$ Expression in Adult Sheep Kidney.

Yixin Su, Jianli Bi, Jorge P Figueroa, and James C Rose. Winston-Salem, NC, USA.

T-095 Influence of Maternal Stress during Pregnancy in Females Born Small on F2 Male Metabolic and Cardiovascular Outcomes.

Mary E Wlodek, Jean Cheong, Alanna Hanvey, Melanie Tran, Andrew J Jefferies, and Karen M Moritz. Melbourne, Victoria, Australia and St Lucia, Queensland, Australia.

T-096 Low Maternal Birth Weight Is Associated with Transmission of Cardio-Renal and Metabolic Deficits and Dysfunction.

Mary E Wlodek, Melanie Tran, Linda A Gallo, Alanna Hanvey, Luise A Cullen-McEwen, Kerryn T Westcott, Andrew J Jefferies, and Karen M Moritz. Melbourne, Victoria, Australia; Clayton, Victoria, Australia and St Lucia, Queensland, Australia.

T-097 Intrauterine Growth Restriction and Maternal High Fat, High Cholesterol Diet Increase Hepatic Cholesterol and Decrease Hepatic SREBP2 in Rat Offspring at Birth.

Erin Zinkhan, Jeanette Chin, Jen Zalla, Xing Yu, Chris Callaway, Lisa Joss-Moore, and Robert Lane. Salt Lake City, UT, USA.

\section{ENDOMETRIOSIS/ADENOMYOSIS}

T-098 Stress Management in the Pathophysiology of an Endometriosis Model.

Caroline B Appleyard, Myrella L Cruz, Siomara Hernandez, Antonio E Ramirez, Anixa Hernandez, Kenira J Thompson, and Idhaliz Flores. Ponce, Puerto Rico.
T-099 Expression of Progesterone Receptor-A and -B in Eutopic Endometrium, Peritoneal Endometriosis and Endometrioma. Mohamed A Bedaiwy, Lijuan Yi, William Hurd, James Liu, Tommaso Falcone, and Sam Mesiano. Cleveland, Oh, USA.

T-100 B Cell Lymphoma Protein 6 (BCL-6), Suppressor of Cytokine Signaling 2 (SOCS2) and Their Potential Role in Endometriosis. Emily Evans-Hoeker, Lingwen Yuan, Bruce A Lessey, and Steven L Young. Chapel Hill, NC, USA and Greenville, SC, USA.

T-101 The Expression of EMT Markers in Epithelial Cells of Normal Endometrium and Endometriotic Lesions. Masataka Furuya, Kayuko Ito, Hirokazu Arima, Hirotaka Masuda, Hideyuki Saya, and Yasunori Yoshimura. Shinjuku, Tokyo, Japan.

T-102 Estrogen Receptor Signalling Contributes to Neuroangiogenesis during Peritoneal Endometriosis.

Erin Greaves, Frances Collins, Andrew W Horne, and Philippa TK Saunders. Edinburgh, United Kingdom.

T-103 Endometriosis and Low Oestrogen May Reduce Human Non-Pregnant Myometrial Contractility without a Parallel Reduction in Expression of L-Type Calcium Channels.

Hayley Robinson, Pramudi Wijaysiri, Jo Drury, Susan Wray, and Dharani Hapangama. and United Kingdom.

T-104 Stress Enhances Uterine and Colonic Contractility in Endometriosis. Siomara Hernandez, Myrella L Cruz, Antonio E Ramirez, Anixa Hernandez, and Caroline B Appleyard. Ponce, Puerto Rico.

T-105 Endometrial and Endometriotic Lesion Immune Cell Populations in a Baboon Model of Endometriosis.

Alison J Hey-Cunningham, Asgerally $\mathrm{T}$ Fazleabas, Andrea G Braundmeier, Robert Markham, Ian S Fraser, and Marina Berbic. Sydney, NSW, Australia; Grand Rapids, MI, USA and Urbana, IL, USA.

T-106 The Relationship between Serum Eicosapentaenoic Acid Levels and Endometriosis: Insight from Women Undergoing In Vitro Fertilization. Margaret M Hopeman, Daniel S Ory, Kelle H Moley, and Emily S Jungheim. Saint Louis, MO, USA.

T-107 DNA Methylation Is Involved in Gene Expression Regulation in Cycling Human Endometrium with Deficiencies in Endometriosis. Sahar Houshdaran, Zara Zelenko, Juan C Irwin, and Linda C Giudice. San Francisco, CA, USA. 


\section{Thursday, March 21, 2013 - Poster Session I - Bonnett Creek Ballroom}

T-108 Expression of FKBP52 in Human Adenomyosis. Chih-Feng Yen, Frederick Schatz, Umit Kayisli, Chyi-Long Lee, Charles J Lockwood, and S Joseph Huang. Tao-Yuan, Taiwan and Columbus, $\mathrm{OH}$, USA.

T-109 Activation Status of Macrophages in Lesions from a MacGreen/SCID Mouse Model of Endometriosis.

M Zahied Johan, WV Ingman, SA Robertson, and ML Hull. Adelaide, South Australia, Australia.

T-110 Aberrant Expression and Activity of DNA Methyltransferase 3B in Endometriotic Stromal Cells.

Toshiyuki Kakinuma, Matthew T Dyson, Diana Monsivais, Mary Ellen Pavone, Saurabh S Malpani, Masanori Ono, Makio Shozu, and Serdar E Bulun. Chicago, IL, USA and Chiba, Japan.

T-111 Endometrial Stromal Stem Cells from Women with Endometriosis Abnormally Express COX-2, StAR, CYP19A1 and Apoptotic Markers. Graciela Krikun, Balamuthu Kadalmani, Karthikeyan Palanivel, and Hugh S Taylor. New Haven, CT, USA and Tamilnadu, Tiruchirappalli -620024 , India.

T-112 mRNA Expression of Transcription Factors and Cytokines in Immune Cells of Ovarian Endometrioma.

Antonio S Lagana, Pizzo Alfonsa, Angela D’Ascola, Francesca M Salmeri, Vincenza Sofo, Giovanni Retto, Emanuele Sturlese, Rosanna De Dominici, Irene Borrielli, and Salvatore Campo. Italy.

T-113 Suppressor of Cytokine Signaling (SOCS) Expression in Normal and Abnormal Endometrium.

Bruce A Lessey, Jung-Yoon Yoo, Jae-Wook Jeong, Sarah Gill, Lingwen Yuan, Steven L Young, and Asgerally T Fazleabas. Greenvile, SC, USA; Grand Rapids, MI, USA and Chapel Hill, NC, USA.

T-114 Stromal Localisation of the miR-99 and -125 microRNA Families in Endometriotic Tissues. Jonathan T McGuane, Mohammad Z Johan, Zhao Wang, Emily L Paterson, Greg J Goodall, and Mary L Hull. University of Adelaide, SA, Australia and Adelaide, SA, Australia.

T-115 Sustained Improvement in EndometriosisRelated Pelvic Pain with Leuprolide or Norethindrone Treatment.

Ozgul Muneyyirci-Delale, Cassandra Charles, Ninet Sinaii, Jenny Anopa, Mudar Dalloul, and Pamela Stratton. Brooklyn, NY, USA and Bethesda, MD, USA.
T-116

Treatment with Bazedoxifene and Conjugated Estrogens Results in Regression of Murine Experimental Endometriosis.

Hanyia Naqvi, Sharif Sakr, Thomas Presti, Graciela Krikun, Ben Auerbach, and Hugh S Taylor. New Haven, CT, USA.

T-117 How Sensory Innervation Impacts the Intensity of Endometriosis-Associated Pain.

Kathleen M Peters, Paul Wrigley, and Ian S Fraser. Sydney, Australia.

T-118 Evaluating the Psychological Contributors to the Amplification of Endometriosis-Associated Pain.

Kathleen M Peters, Michael K Nicholas, Ian S Fraser, and Paul Wrigley. Sydney, NSW, Australia.

T-119 Interrelationship among Levator Spasm, Sensitization, Myofascial Dysfunction, Anxiety and Depression in Patients with Endometriosis and Chronic Pelvic Pain.

Pamela Stratton, Ninet Sinaii, Izabella

Khachikyan, Robin Ortiz, Julie Gemmill, and Jay Shah. ; Bethesda, MD, USA; IL, USA and NY, USA.

T-120 Estradiol and Inflammatory Cytokines Induce Neuroangiogenic Responses in Endometriosis Stromal Cells.

Antonio MC Francisco, Jie Yu, Tamer Yalcinkaya, Erika B Johnston-MacAnanny, Neil Sidell, Sarah L Berga, and Robert N Taylor. Winston-Salem, NC, USA and Atlanta, GA, USA.

T-121 GWAS Identify Novel Loci Associated with Endometriosis.

Hans Albertsen, Rakesh Chettier, Pamela Farrington, and Kenneth Ward. Salt Lake City, UT, USA.

T-122 Exploration of Urinary Biomarkers as a Possible Screening Tool in Endometriosis. Fred TK Wong, Robert Markham, Ben Crossett, Ian Fraser, and Cecilia Ng. Sydney, NSW, Australia.

\section{FIBROIDS}

T-123 Is Pre-ART Myomectomy Cost-Effective in Women with Intramural (IM) Fibroids?

Kate Devine, Mary Egbuniwe, Sunni Mumford, and Alicia Y Armstrong.

T-124 Prolactin as a Biomarker for Tumor Burden and Response to UPA Therapy in African American Women with Symptomatic Leiomyoma.

Karenne N Fru, Gary Levy, Robert Wesley, Lynnette Neiman, Aradhana Venkatesan, and Alicia Armstrong. Bethesda, MD, USA. 
T-125 Vitamin D3 Reverse Developmental Reprogramming by Modulating EZH2 Histone Methyltransferase Activities in Human Fibroid Stem Cells.

Sunil K Halder, Sangeeta Nair, Chakradhari Sharan, and Ayman Al-Hendy. Nashville, TN, USA.

T-126 The Effect of Menses on the Assessment of Sexual Function. Shannon K Laughlin-Tommaso, Bijan J Borah, and Elizabeth A Stewart. Rochester, MN, USA.

T-127 Ulipristal Acetate Decreases TGF- $\beta 3$

Expression and Dissolves Extracellular Matrix in Leiomyoma Cells.

Gary Levy, Minnie Malik, Joy Britten, James H Segars, and William $\mathrm{H}$ Catherino. Bethesda, MD, USA.

T-128 TGF- $\beta 3$ Downregulation Using PPAR Agonists:

A Potential Treatment Strategy for Leiomyomas. Natu N Mmbaga, Leo Doherty, and Hugh S Taylor. New Haven, CT, USA.

T-129 Differential Expression of Steroid Receptors (ER, PR, VDR) in Stem Cells from Myometrium in Women with (MyoF) Versus without (MyoN) Uterine Fibroids; MyoF as a Pre-Tumor State. Sangeeta Nair, Chakradhari Sharan, Jyotsna Thota, Ahsen Chaudhury, Sarbani Maitra, and Ayman Al-Hendy. Nashville, TN, USA.

T-130 Uterine Fibroids Are Associated with Low Serum Levels of 25-OH Vitamin D. Alessio Paffoni, Paola Vigano', Lucia Cardellicchio, Andrea Busnelli, and Edgardo Somigliana. Milan, Italy.

T-131 Health Literacy and Knowledge of Uterine Fibroids amongst Urban Women: A Pilot Study. Hannah S Recht, Geraldine E Ekpo, Tanaka J Dune, Maureen E Brocks, Eden R Cardozo, Krista J Childress, and Erica E Marsh. Chicago, IL, USA.

T-132 Leiomyoma Smooth Muscle Cells and Fibroblasts Are Clonal: Evidence for Cell Differentiation after Tumor Initiation. Marina Zaitseva, Sarah J Holdsworth-Carson, Beverley J Vollenhoven, and Peter AW Rogers. Parkville, Victoria, Australia and Clayton, Victoria, Australia.

T-133 Paricalcitol, None-Hypercalcemic Vitamin D Receptor Activator, Inhibits Proliferation of Human Uterine Leiomyoma Cells.

Chakradhari Sharan, Sunil K Halder, Sangeeta Nair, and Ayman Al-Hendy. Nashville, TN, USA.

\section{GENETICS/EPIGENETICS}

T-134 Epigenetic Regulation by DNA Methylation in Fetal Membranes: Geographical Expressions of the Actors and Potential Links on Tissue Weakening.

Corinne Belville, Gael Clairefond, Sabine Chauveau, Denis Gallot, Vincent Sapin, and Loic Blanchon. Clermont-fd, France.

T-135

Differential Expression of Lin28 and Let-7 in Term Gestational Tissue.

Hsiu-Wen Chan, Martha Lappas, Sarah WY Yee, Kanchan Vaswani, Murray D Mitchell, and Gregory E Rice. Herston, Queensland, Australia and Melbourne, Victoria, Australia.

T-136 DNA Methylation Patterns in Hamster In VivoProduced Embryos. Carla Collado, Hehai Wang, Tianbing Ding, Jeff Reese, Judy Aschner, and BC Paria.

T-137 Novel Reference Genes for Normalizing Human Placenta Gene Expression Studies.

Amy L Creekmore, Kerry L Sanders, Men-Jean Lee, and Jill L Reiter. Indianapolis, IN, USA.

T-138 KLF11 Arrests Progressive Endometriosis Via a Novel, Epigenetic Sin3/Histone Deacetylase (HDAC) Mediated Mechanism.

Ravi P Gada, Ye Zheng, Zaid M Tabbaa, Raul Urrutia, and Gaurang S Daftary. Rochester, MN, USA.

T-139 Evolutionary Genetics of Dizygotic Twinning and Small Body Size in Callitrichine Primates. R Alan Harris, Suzette D Tardif, Tomas Vinar, Derek E Wildman, Julienne Rutherford, Jeffrey Rogers, Kim C Worley, and Kjersti M Aagaard.

T-140 The Identification of Candidate Genes in Mullerian Aplasia.

Ellison G Taylor, Hyung-Goo Kim, Lynn P Chorich, and Lawrence C Layman. Augusta, GA, USA.

T-141 Temporal and Spatial HP1 Epigenetic Signals in Oocytes and Early Embryo Development. Phoebe H Leonard, Adrienne Grzenda, Dean E Morbeck, Jolene R Fredrickson, Charles C Coddington, Raul Urrutia, and Gwen A Lomberk. Rochester, MN, USA.

T-142 Cord Blood Leptin Gene Promoter DNA

Methylation Is Associated with Infant

Birthweight.

Corina Lesseur, David A Armstrong, Alison G Paquette, Allison A Appleton, Devin C Koestler, James F Padbury, Margaret R Karagas, and Carmen J Marsit. Hanover, NH, USA; Lebanon, $\mathrm{NH}$, USA and Providence, RI, USA.

T-143 Epigenetic Aspects of Ectopic Pregnancy: DNA Methylation Patterns in the Fallopian Tube. Laura C Londra, Douglas Ruden, Michael Diamond, and Ray Bahado-Singh. Baltimore, MD, USA and Detroit, MI, USA. 
T-144 Effects of a Maternal Obese Environment on DNA Methylation in the Placenta.

Kohzoh Mitsuya, and Leslie Myatt. TX, USA.

T-145 Genome-Wide Methylation Profile Identifies Genes Involved in the Pathogenesis of Endometriosis.

Hanyia Naqvi, and Hugh S Taylor. New Haven, CT, USA.

T-146 Epigenetic Modulation of the Placental Serotonin Response Pathway and Its Role in Development.

Alison G Paquette, Corina Lesseur-Perez, David Armstrong, Devin Koestler, Barry M Lester, and Carmen J Marsit. Hanover, NH, USA and Providence, RI, USA.

T-147 Mutation Analysis of the PIN1 Gene in 68 Caucasian Patients with Premature Ovarian Failure.

Elliott G Richards, Qing Liu, William Gibbons, Ignatia B Van den Veyver, and Ertug Kovanci. Houston, TX, USA.

T-148 Replication of Gestational Age Dependent DNA Methylation Differences in a Preterm Birth Cohort.

Alicia K Smith, Sasha E Parets, Karen N Conneely, Varun Kilaru, Tariq A Syed, George Saade, and Ramkumar Menon. Atlanta, GA, USA and Galveston, TX, USA.

T-149 Estriol Developmentally Programs Uterine Gene Methylation and Subsequent Adult Expression:

A Functional Role for Estriol in Pregnancy. Yuping Zhou, Geraldine Brichant, Huan Yang, Sirisha Gudavalli, and Hugh S Taylor. New Haven, CT, USA.

T-150 Digging Deeper To Find Predictive Markers for Endometriosis.

Rakesh Chettier, Hans Albertsen, and Kenneth Ward. Salt Lake City, UT, USA.

T-151 Methylation Analysis of Inhibin/Activin Genes in Maternal Leukocyte DNA in Early Normal Pregnancy and Preeclampsia at Delivery. Wendy M White, Angelica Garrett, Jonathan O'Brien, Elizabeth Baldwin, Arij Faksh, Brian Brost, Carl Rose, Norman Davies, Kristi Borowski, Zhifu Sun, Stephen T Turner, and Vesna D Garovic. Rochester, MN, USA.

T-152 Detecting Confounding Due to Cellular Heterogeneity in Buffy Coat DNA Methylation Analysis by Comparison with Reference Epigenomes.

Wendy M White, Sriram Raghuraman, Angelica Garrett, R Allan Harris, Cristian Coarfa, Andrew R Jackson, Matthew Roth, Zhifu Sun, Aleksandar Milosavljevic, and Vesna D Garovic.

\section{GLOBAL HEALTH}

T-153 Iron Supplementation during Pregnancy: Friend or Foe.

Chander P Arora, Marian Kacerovsky, Balazs Zinner, luliana Ceausu, Kinga Lancz, Serghiy Shurpyak, Sukhveer S Sandhu, Calvin J Hobel, and Sandor G Vari. ; Czech Republic; Hungary; Romania; Slovakia (Slovak Republic) and Ukraine.

\section{GYNECOLOGIC ONCOLOGY}

T-154 Invasive Vulvar Cancer in Women with Human Immunodeficiency Virus; a Clinical and Pathologic Review of Cases at an Urban Medical Center in the United States. Joseph A De La Garza, Fausto Andrade, Joseph A Lucci III, John P Diaz, and Erica Barrios. Miami, FL, USA.

T-155 Conservative Management of Vulvar Intraepithelial Neoplasia among Women with Human Immunodeficiency Virus. Joseph A De La Garza, Fausto Andrade, Joseph A Lucci III, John P Diaz, and Erica Barrios. Miami, FL, USA.

T-156 Feasibility of Interpretation of Postoperative

Peritoneal Washing Cytology. Melissa Dawson, Shaheen Kaka, Robert Samuelson, Mary Chacho, Thomas Rutherford, and Shohreh Shahabi. Danbury, CT, USA.

T-157 Androgen Levels and Sexual Function in Female Cancer Survivors. Lauren NC Johnson, Mary D Sammel, Maureen Prewitt, Lara Lechtenberg, Brenda L Efymow, and Clarisa R Gracia.

T-158 Cancer Incidence and Survival in US

Population: Evidence for a Gender Effect. Michael Kopf, Cristiano Ferlini, Joann Petrini, Robert Samuelson, and Shohreh Shahabi. Danbury, CT, USA.

T-159 Novel Autologous Whole-Tumor Antigen Combinatorial Immunotherapy for Recurrent Ovarian Cancer. Janos L Tanyi, Lana Kandalaft, Cheryl L Chiang, Daniel J Powell, and George Coukos. Philadelphia, PA, USA.

T-160 Rare Finding of Serous Borderline Tumors in Paratubal Cysts. Charis A Venditti, Robert Samuelson, Shohreh Shahabi, Mary Chacho, and Jessica Dodge. Danbury, CT, USA.

T-161 Aggressive Angiomyxoma of the Vagina and Pelvis: A Case Series. Amanda Wilmot, Robert Samuelson, Pei Hui, Peter Schwartz, and Shohreh Shahabi. Danbury, CT, USA. 


\section{Thursday, March 21, 2013 - Poster Session I - Bonnett Creek Ballroom}

\section{HORMONES, CYTOKINES}

T-162 Enigmatic Role of Interleukin (IL)-1 $\beta$ in the Timing of Delivery in the Long-Evans Rat. T Ishiguro, J Takeda, X Fang, JC Robbins, GA Metz, and DM Olson. Edmonton, Canada; Tokyo, Japan and Lethbridge, Canada.

T-163 Adipokinins in Pregnancies at Risk for Preterm Delivery. Michelle A Kominiarek, Cecilia T Gambala, Weihua Gao, and Krista Varady.

T-164 Enhancement of Inflammation-Associated Genes by Progesterone in IL-1 $\beta$-Stimulated Human Myometrial Cells.

Kaiyu Lei, Suren Sooranna, Phillip Bennett, and Mark R Johnson. United Kingdom.

T-165 Prostaglandin (PG)F2 $\alpha$ Induces mRNA Expression of VEGF Isoforms and Modulates Expression of VEGF Receptors R1 and R2 in Human Myometrial Smooth Muscle Cells (HMSMC).

C Xu, KB Leimert, K Popowycz, DM Slater, $S$ Woods, X Fang, $X \mathrm{Ni}$, and DM Olson. Edmonton, Canada; Shanghai, China and Calgary, Canada.

T-166 A Longitudinal Assessment of Omentin during Pregnancy.

Samantha H Mast, John M O'Brien, Rebecca I Epstein, and Kristin H Ashford. Lexington, KY, USA.

T-167 The Correlation of Serum Leptin and Recurrent Pregnancy Loss.

Stephanie T Romero, Margarita Sharshiner, David W Branch, and Robert M Silver. Salt Lake City, UT, USA.

T-168 Interpregnancy Interval and Anti-Inflammatory Cervical Cytokine Milieu among Women with Prior Preterm Birth.

Raj Shree, and Hyagriv Simhan. Pittsburgh, PA, USA.

T-169 Myocardial Expression Level of Hypertrophy Marker Genes in a Guinea Pig Model of Left Ventricular Pressure Overload. Julia Zollner, Suren R Sooranna, and Mark R Johnson. London, United Kingdom.

\section{HORMONES, GROWTH FACTORS, CYTOKINES}

T-170 Is Placental Drug Transport Compromised Following Acute and Chronic Prenatal Endotoxemia?

Enrrico Bloise, Melaine C Audette, Sophie

Petropoulos, Mohsen Javam, Manzerul Bhuiyan, William Gibb, and Stephen $\mathrm{G}$ Matthews. Toronto, ON, Canada and Ottawa, ON, Canada.
T-171

Thyroid Stimulating Hormone (TSH) Receptor Expression and Function in Human Placenta and Decidua.

Neil K Vanes, Laurence S Loubiere, Elisavet Vasilopoulou, Phillip Cox, Christopher J McCabe, Mark D Kilby, and Shiao Y Chan. Birmingham, United Kingdom.

T-172 CD11b+ Myeloid-Derived Suppressor Cell Subset Induced from Peripheral Blood Mononuclear Cells Co-Cultured with Human Placental Cell Lines.

Aaron J Epstein, Saman S Karimi, Melissa G Lechner, Menache Kfir, Deborah A Wing, and Alan L Epstein. Orange, CA, USA and Los Angeles, CA, USA.

T-173 Distinct Inflammatory Profile in Placenta from Women Experiencing Reduced Fetal Movements: A Cause of Placental Dysfunction? Sylvie Girard, Alexander EP Heazell, Colin P Sibley, Stuart M Allan, and Rebecca L Jones. Manchester, United Kingdom.

T-174 Role of Inflammatory Chemokines in Gestational Diabetes Pathogenesis. D Giuffrida, A Rolfo, AM Nuzzo, E Piccoli, S Cardaropoli, A Piazzese, N Di Simone, and T Todros. Turin, Italy and Rome, Italy.

T-175 Leptin Receptor Expression in Placentas of Macrosomic Fetuses.

Erin I Lewis, Margarida YY Lei, Peggy S Sullivan, and Janzen Carla. Los Angeles, CA, USA.

T-176 Effects of Combination Antiretroviral Therapy on Progesterone Levels and Birth Outcome in a Mouse Model. Eszter Papp, and Lena Serghides. Toronto, ON, Canada.

T-177 Placental Myostatin Is Localised in Trophoblast of First and Third Trimester Placentae: An Immunohistochemistry Study. Hassendrini N Peiris, Diane Payton, Anthony Chan, and Murray D Mitchell. Herston, Queensland, Australia.

T-178 Ovarian Hormone Signaling Defects Are Associated with Asynchronous PeriImplantation Events in a Mouse Model of Preeclampsia, BPH/5. Jenny L Sones, Yi Zhou, Ashley K Woods, Catherine E Isroff, Margarete G Knudsen, and Robin L Davisson. Ithaca, NY, USA and New York, NY, USA.

T-179 Differential VEGF mRNA Splicing in Preeclampsia and Normotensive Human Placentas.

Tevy Tith, Wen Wang, Deborah A Wing, John Kingdom, and Dong-bao Chen. 


\section{Thursday, March 21, 2013 - Poster Session I - Bonnett Creek Ballroom}

T-180 Down-Regulation of TIMP3 Leads to Increased TNF $\alpha$ Production Mediated by ADAM17 in Placental Trophoblasts. Yang Gu, Rong Ma, Lynn J Groome, and Yuping Wang. Shreveport, LA, USA.

T-181 Placental CRH Inhibition by Progesterone Relies on Progesterone Receptor Isoform A. Bingbing Wang, Nataliya Parobchak, Max Rosen, Anh Nguyen, and Todd Rosen. New Brunswick, NJ, USA.

T-182 Comparison of Phospholipid Molecular Species of Human Placenta between Preeclampsia and Normal Case by Imaging Mass Spectrometry. Kaori Yamazaki, Takahiro Hayasaka, Keiko Muramatsu, Kotomi Nagahashi, Chizuko Yaguchi, Hiroaki Itoh, Naohiro Kanayama, and Mitsutoshi Setou. Hamamatsu, Shizuoka, Japan.

T-183 Why Is Chronic Low Oxygen Critical for Human Endothelial Function? Jing Zheng, Yi-zhou Jiang, Yan Li, Christina Kendziorski, and Dong-bao Chen. Madison, WI, USA and Irvine, CA, USA.

\section{BREAST}

T-184 Syndecan-1 (CD138) Modulates Breast Cancer Stem Cell Properties Via Regulation of IL-6Mediated STAT3 Signaling. Sherif A Ibrahim, Hebatallah Hassan, Ludwig Kiesel, Burkhard Greve, and Martin Gotte. Muenster, Germany.

T-185 Myoferlin Depletion Increases Adhesion of Breast Cancer Cells and Alters Adhesion Complex Protein Architecture.

R Li, M Bechel, B Blackstone, J Willard, W Ackerman, H Powell, and D Kniss. and Columbus, $\mathrm{OH}$, USA.

T-186 Characterization of AKAP13, Progesterone Receptor and Estrogen Receptor Gene Expression in Breast Cancer Cells. Shvetha M Zarek, Paul H Driggers, Minnie Malik, and James H Segars. Bethesda, MD, USA.

\section{LACTATION}

T-187 Low Protein Diet in Pregnancy and Lactation Alters Rat Mammary Gland (MG) Long Chain Polyunsaturated Fatty Acid Synthesis (LCPUFAs): Consequences for Milk Composition. Claudia J Bautista, Victoria Ramirez, Regina J Bautista, Peter W Nathanielsz, and Elena Zambrano. México City, Mexico and San Antonio, TX, USA.

\section{MATERNAL HEALTH}

T-188 Vitamin D Metabolism in Pregnancy: Effects of UVB Exposure and Obesity in Non-Human Primate Model.

Natalia Schlabritz-Lutsevich, Brian Brocato, Danielle Tate, Giancarlo Mari, Andrzej

Slominski, and Arnold Postlethwaite. Memphis, TN, USA.

\section{MENOPAUSE}

T-189 The Relationship between Osteoprotegerin, RANKL and Bone Turnover Markers among Postmenopausal Women with and without Osteoporosis: A Cross-Sectional Study. Mohammad Ardawi, Quri Mohammad, Rouzi Abdulrahim, Sharifa Alsibiani, and Nawal Alsinani.

T-190 Bringing Estrogens Back to Cardiovascular Health: Focus on GPR30 in Women and Men. Samsul Arefin, Ilgar Badalov, Rebekah Wieland, and Karolina Kublickiene. Stockholm, Sweden.

T-191 Bazedoxifene Treatment Decreases Expression of BRCA2 in Mouse Mammary Gland.

Catha Fischer, Jamie Kulak, Levent Mutlu, Barry Komm, and Hugh Taylor. New Haven, CT, USA and Collegeville, NJ, USA.

T-192 Tapering and Low Dose Maintenance GnRH Agonist Therapy for Symptomatic Uterine Leiomyoma in Perimenopausal Women: "DrawBack Therapy."

Toshihiro Yoshimura. Kumamoto, Japan.

\section{REPRODUCTIVE AGING}

T-193 Myometrial Artery Calcifications Increase with Aging.

Sarah C Hessler, Gerson Weiss, Debra S Heller, Peter G McGovern, Sara S Morelli, and Laura T Goldsmith. Newark, NJ, USA.

T-194 Novel Variants in the H1FOO Gene Are Associated with Premature Ovarian Failure. Katie Bolt, Qing Liu, Alfred Balasa, William E Gibbons, Joe Leigh Simpson, and Ertug Kovanci. Houston, TX, USA and Miami, FL, USA.

T-195 Kisspeptin: Switching Gears from the Brain to the Ovary.

Zaher Merhi, Sangita Jindal, Athena Zapantis, Dara Berger, Erkan Buyuk, and Peter Casson. Burlington, VT, USA and Bronx, NY, USA. 


\section{Thursday, March 21, 2013 - Poster Session I - Bonnett Creek Ballroom}

\section{MYOMETRIAL BIOLOGY, CONTRACTION}

Evidence of Hypoxic Preconditioning in LatePregnant Rat and Laboring Human Uterus. Mohammed Alotaibi, Sarah Arrowsmith, and Susan Wray. Liverpool, United Kingdom.

T-197 Hormonal Regulation of Hydrogen SulfideProducing Enzymes in the Mouse Uterus. Kelsey E Breen, Robert Valdez, Brian Wakefield, and K Joseph Hurt. Aurora, CO, USA.

T-198 Relaxant Effect of Selective Estrogen Receptor Modulators (SERMs) on Human Pregnant Myometrial Contraction. Noppamart Whangteeranon, Apilada Ojaroen, Areepan Sophonsritsuk, Patama Promsonthi, and Boonsri Chanrachakul. Bangkok, Thailand.

T-199 A High Fat, High Cholesterol Diet Alters mRNA Levels of PPARy and FABP-3 in Pregnant Rat Myometrium.

Jeanette Chin, Erin Zinkhan, Jennifer Zalla, Ben Numpang, Robert Lane, and Lisa Joss-Moore. Salt Lake City, UT, USA.

T-200 Contractile Mechanisms in the Cervix and Uterus.

Emma S Darios, and Stephanie W Watts. East Lansing, MI, USA.

T-201 Roles of Tyrosine Residues in Multiple Functions of p54nrb. Liangliang Liu, Wayne Hung, Ning Xie, and Xuesen Dong. Vancouver, BC, Canada.

T-202 Progesterone Regulation of Estrogen Receptor $\alpha$ Isoforms: A Possible Mechanism for CAP Protein Modulation through Alternative Splicing. Karen Florio, Evan Easton, Rebecca Moreci, and Pancharatnam Jeyasuria. Pittsburgh, PA, USA.

T-203 Lactate Significantly Decreases Myometrial Contractility. Jacqui-Ann Hanley, Annabelle Kendrick, Andrew Weeks, and Susan Wray. and Liverpool, United Kingdom.

T-204 Uterine Myometrial Stretch Augments Production of Angiogenic and Proinflammatory Factors.

Shannon Kostin, Darren Clas, Benjamin Suratt, Matthew Poynter, and George Osol. Burlington, VT, USA.

T-205 A Disproportionate Uterine Endoplasmic Reticulum Stress Response Triggers the Onset of Preterm Birth.

Chandrashekara N Kyathanahalli, Jeyasuria Pancharatnam, and Jennifer C Condon. Pittsburgh, PA, USA.
T-206

Prolonged Elevation of cAMP Enhances Spontaneous Contractility in Human Myometrium from Pregnant Women at Term. Pei F Lai, Rachel M Tribe, and Mark R Johnson. United Kingdom.

T-207 Term Nullipara in Spontaneous Labor with an Active Phase Arrest Are Associated with SUMOPathway Activation in the Cell Free Plasma (cfP) Transcriptome. Gene Lee, Yafeng Dong, Helen Zhou, Minghui Tai, and Carl P Weiner. Kansas City, KS, USA.

T-208 Optimal Electrical Stimulation Parameters To Contract the Postpartum Uterus. Steven Miller, Gregory Carr, and Robert Garfield. Phoenix, AZ, USA.

T-209 Epigenetics of Human Myometrium:

Relationship to the Length of Gestation and the Onset of Labor. Kohzoh Mitsuya, Natasha Singh, Suren R Sooranna, Mark R Johnson, and Leslie Myatt. TX, USA and London, United Kingdom.

T-210 Pregnancy Specific Uterine E2 Action Is Regulated by Alternate Estrogen Receptor $\alpha$ Isoforms as a Consequence of Differential Promoter Usage.

Rebecca S Moreci, Christina Kachulis, Lee R Sang, Robert C Moore, Steve N Caritis, and Pancharatnam Jeyasuria. Pittsburgh, PA, USA.

T-211 Neutrophil Elastase in Term and Preterm Labor: A Novel and Potent Uterotonic Enzyme That Acts Via PAR 1.

William H Nugent, Sonya L Washington, John R Grider, Jerome F Strauss III, and Scott W Walsh. Richmond, VA, USA.

T-212 Investigation of the Myometrial Leak Current: Is NALCN the Source?

Erin L Reinl, Rafael Cabeza, Ramon A Lorca, Cara C Rada, and Sarah K England. St. Louis, MO, USA and lowa City, IA, USA

T-213 Effects of Vaginal and Topical Progesterone (P4) on Delivery, Plasma P4 Levels and Myometrial Electromyographic Activity (EMG) in Pregnant Rats. Shao-Qing Shi, Leili Shi, and Robert Garfield. Phoenix, AZ, USA.

T-214 Myomesin2 Gene and Protein Expression in Human and Mouse Myometrium Is Associated with Labour Onset.

Oksana Shynlova, Khetsopon Srikhajon, Nicole Warrington, Craig Pennell, and Stephen Lye. Toronto, ON, Canada; Canada and Bangkok, Thailand.

T-215 Myometrial-Specific Spatiotemporal Splicing Patterns in Pregnancy. David MW Cork, Stephen C Robson, Julian Venables, and Alison J Tyson-Capper. Newcastle upon Tyne, United Kingdom. 
T-216 Transglutaminase Presence and Activity in the Rat Uterus and Cervix.

Lindsey W Young, Janice Thompson, Kiyotaka

Hitomi, and Stephanie W Watts. and Japan.

T-217 A New Mechanism for Cooperative Effects in Myometrium; Oscillations of Interstitial Potassium.

Roger C Young, and Gabriela Goloman.

Burlington, VT, USA.

T-218 Outward K Currents Are Expressed throughout the Entire Action Potential in Pregnant Rat Myometrium.

Roger C Young, and Gabriela Goloman. Burlington, VT, USA.

\section{POLYCYSTIC OVARY SYNDROME}

T-219 Testing for Insulin Resistance in Polycystic Ovary Syndrome (PCOS) - Fasting Plasma Levels of Glucose and Insulin Is All That Is Needed.

Albert Asante, Phoebe H Leonard, Zaraq Khan, Jani R Jensen, Stewart A Elizabeth, and Coddington C Charles. Rochester, MN, USA.

T-220 Hyperandrogenic Polycystic Ovary Syndrome (PCOS) Patients Have Reduced Pregnancy Rates Compared to Non-Hyperandrogenic PCOS Patients Following In Vitro Fertilization (IVF).

April E Batcheller, Kelci A Rodriguez-Peterson, Alan M Martinez, Michael A Thomas, Krystene B DiPaola, and Julie E Sroga. Cincinnati, $\mathrm{OH}$, USA.

T-221 Effects of Lipophilic and Hydrophilic Statins on Growth and Steroidogenesis of Rat Ovarian Theca-Interstitial Cells.

Antoni J Duleba, Israel Ortega, Scott Stanley, Jesus Villanueva, and Anna Sokalska.

T-222 Metformin Treatment Improves Vascular Reactivity in a Rat Model of Polycystic Ovary Syndrome (PCOS).

Amanda Hurliman, George Osol, Peter Casson, and Nicole Maille. Burlington, VT, USA.

T-223 Comparison of Continuous Glucose Monitoring (CGM) Parameters and Standard Diagnostic Testing for Diabetes in Women with Polycystic Ovary Syndrome (PCOS).

Mary E McAsey, Miriam S Krause, Alison Huff, Arturo Garza-Cavazos, Steven Radke, Kathleen Groesch, and J Ricardo Loret de Mola. Springfield, IL, USA and Louisville, KY, USA.

T-224 Skeletal Muscle Gene Expression of TNFa in Women with PCOS.

Mamie R McLean, Gordon W Bates, Katherine Sweatt, Michael Stec, Barbara Gower, and Anna Thalacker-Mercer. Birmingham, AL, USA and Ithaca, NY, USA.
T-225

Validation of a New Index of Insulin Resistance in Non-Obese Women with Polycystic Ovary Syndrome.

Andrea Morciano, Francesca Sagnella, Anna Tropea, Francesca Moro, Carola Palla, Elisa Scarinci, Alex Federico, Antonio Lanzone, and Rosanna Apa. Rome, Italy and Troina, Italy.

T-226 Low Plasma Levels of Atrial Natriuretic Peptide and Adiponectin in Women with Polycystic Ovary Syndrome.

Patricia B Marques, Helen L Del Puerto, Adelina M Reis, Ana L Candido, and Fernando M Reis. and Belo Horizonte, Brazil.

T-227 Metabolic and Behavioral Effects of Bariatric Surgery on a Rat Model of Polycystic Ovary Syndrome.

llana B Ressler, Bernadette E Grayson, and Randy J Seeley. Cincinnati, OH, USA.

T-228 Serum Anti-Mullerian Hormone Levels Decrease after Metformin Administration in Women with Polycystic Ovary Syndrome More in Patients with Lean PCOS Despite Their Normal Levels of Insulin Resistance.

May-Tal Sauerbrun, Martin Keltz, Matthew Lederman, Mario Vega, and Daniel Stein. New York, NY, USA.

T-229 Abnormal Endometrial Receptivity in PCOS Patients May Be Responsible for Subfertility. Maureen B Schulte, Ray Tsai, and Moley H Kelle. St. Louis, MO, USA.

T-230 Increased Insulin-Resistance and $\beta$-Cell Function in Polycystic Ovary Syndrome Women - Does Ethnicity Play a Role? Ido Sirota, Daniel E Stein, Mario Vega, and Martin D Keltz. New York, NY, USA.

T-231 Body Mass Index as a Predictor for InsulinResistance and Pancreatic $\beta$-Cell Function in Polycystic Ovary Syndrome Patients Versus Controls.

Ido Sirota, Daniel E Stein, Mario Vega, and Martin D Keltz. New York, NY, USA.

T-232 Placental Growth Factor Is Increased While Its Soluble FLT-1 Receptor Is Decreased in Follicular Fluid of Women with Polycystic Ovarian Syndrome.

Reshef Tal, David B Seifer, Aya Shohat-Tal, Richard V Grazi, and Henry E Malter. Brooklyn, NY, USA.

T-233 Predictive Value of LH/FSH Ratio for Ovulation Induction in Patients with Polycystic Ovary Syndrome.

Irene Woo, Kyle Tobler, Ayatallah M Khafagy, Mindy S Christianson, Melissa Yates, and Jairo Garcia. Baltimore, MD, USA and Cairo, Egypt. 


\section{Thursday, March 21, 2013 - Poster Session I - Bonnett Creek Ballroom}

POPULATION HEALTH

T-234 Michigan Birthing Hospital Approach to Tdap Vaccination in an Obstetrical Population. Fariha Hussain, Cristi A Carlton, Courtnay $R$ Londo, Patricia A Vranesich, and Bernard Gonik. Detroit, MI, USA and Lansing, MI, USA.

T-235 Organizational Applicability of a Shared Care Approach in the Obstetric Collaborations in the Netherlands.

Anke G Posthumus, Vera LN Scholmerich, Adja JM Waelput, Amber A Vos, Lieke C De Jong-Potjer, Rachel Bakker, Gouke J Bonsel, Peter Groenewegen, Eric AP Steegers, and Semiha Denktas. Rotterdam, Netherlands and Amsterdam, Netherlands.

T-236 An Evidence Based Infrastructure with Methods and Tools To Implement Preconception Care.

Sevilay Temel, Toon AJJ Voorham, Eric AP

Steegers, and Semiha Denktas. Rotterdam, Netherlands.

\section{POST PREGNANCY HEALTH}

T-237 Why Normal Pregnancy Is Protective Against Hypertension in Mothers Later Life?

Egle Bytautiene, Michael Wen, Talar Kechichian, Phyllis Gamble, Esther Tamayo, and George R Saade. Galveston, TX, USA.

T-238 Differences in Individual Cardiovascular Risk between Hypertensive Pregnancy Disorders at Term and Severe Very Early Onset Preeclampsia. Wietske Hermes, Ingrid P Gaugler-Senden, Arie Franx, Ben Willem J Mol, and Christianne JM de Groot. Netherlands.

T-239 Adherence to Post Partum Diabetes Screening in a Regional High Risk Perinatal Center. Faro Revital, Schwebel Marlene, and Distefano Valeria. New Brunswick, NJ, USA.

T-240 The Efficacy and Prognosis of B-Lynch Compression Sutures for Postpartum Hemorrhage.

Mari Tadakawa, Masatoshi Saitoh, Hidekazu Nishigori, Takashi Sugiyama, Junichi Sugawara, and Nobuo Yaegashi. Sendai, Miyagi, Japan.

T-241 Extraperitoneal Cesarean Section: Introduction of a "New" Surgical Technique.

Carmen Tappauf, Mike F Janicek, and Wolfgang Schoell. Graz, Austria and Scottsdale, AZ, USA.

T-242 Extraperitoneal Versus Transperitoneal Cesarean Section and Surgical Morbidity: A Randomized Controlled Trial. Carmen Tappauf, Eva Schest, Philipp Reif, Uwe Lang, Mike F Janicek, and Wolfgang Schoell. Graz, Austria and Scottsdale, AZ, USA.
T-243

Higher Homocysteine Levels after Pregnancy Complicated by Hypertensive Disorders; an Potential Early Marker of Endothelial Dysfunction in Women with High Risk of Cardiovascular Disease.

Sanne Visser, Henk Blom, Wietske Hermes, Annemieke Heijboer, Arie Franx, Marielle van Pampus, Ben Willem Mol, and Christianne de Groot. Netherlands.

\section{STEM CELLS}

T-244

\section{Can We Model Human EVT Differentiation} Using Stem Cells?

Katsuyuki Adachi, Danny J Schust, Laura C Schultz, Mitsuyoshi Amita, Toshihiko Ezashi, and R Michael Roberts. Columbia, MO, USA.

T-245 Comparison of Gene Expression Profile of SSEA-1 Expressing Endometrial Epithelial Progenitor Cell Sub-Population in Women with and without Endometriosis.

Hannan K Al-lamee, Anthony J Valentijn,

Patricia A Murray, and Dharani K Hapangama.

T-246 Platelets Released from Megakaryocytes Generated from Human Endometrial Stromal Stem Cells Share Similar Ultrastructural Characteristics with Peripheral Platelets. Jinju Wang, Shuzhen Chen, Wenfeng Zhang, Sara Foley, Teresa Pfaff-Amesse, Barbara Hull, Yanfang Chen, and Lawrence S Amesse. Dayton, $\mathrm{OH}$, USA.

T-247 More Effective Way To Generate Trophoblast Cells from Human Embryonic Stem Cells by Using BMP4 with Inhibitors of Activin A Signaling and FGF Receptor. Mitsuyoshi Amita, Toshihiko Ezashi, Andrei Alexenko, Katsuyuki Adachi, and R Michael Roberts. Columbia, MO, USA.

T-248 Endometrial Mesenchymal Stem Cells Differentiate to a CD146-/PGFRB+

Progesterone-Responsive Endometrial Stromal Fibroblast Phenotype. Fatima Barragan, Joseph C Chen, Ashley George, Nargis Kohgadai, Terhi T Piltonen, David Erikson, Juan C Irwin, and Linda C Giudice. San Francisco, CA, USA.

T-249 Is Endometriosis an Inevitable Consequence of the Unique Differentiation Potential of SSEA-1 Expressing Human Endometrial Epithelial Cell Subpopulation? Louise da Silva, Anthony Valentijn, Jo Drury, Patricia Murray, and Dharani Hapangama. United Kingdom.

T-250 Assessment of Proangiogenic Stem Cell Concentrations in Women Undergoing In Vitro Fertilization.

Rebecca Flyckt, Kewal Asosingh, Benjamin Nutter, Nina Desai, and Jeffrey Goldberg. Cleveland, OH, USA. 


\section{Thursday, March 21, 2013 - Poster Session I - Bonnett Creek Ballroom}

T-251 The Effect of Estrogen Compounds on Human Embryoid Bodies.

Seung-Yup Ku, Hoon Kim, Yoon Young Kim, Seok Hyun Kim, Young Min Choi, and Shin Yong Moon. Seoul, Korea.

T-252 Alterations of Human Pluripotent Stem CellDerived Cardiomyocytes during Prolonged In Vitro Culture. Seung-Yup Ku, Seok Hyun Kim, Young Min Choi, and Shin Yong Moon. Seoul, Korea.

T-253 Effects of Ginsenosides on Differentiation Potential of Human Embryonic Stem Cells. Jun Beom Ku, Yoon Young Kim, Seung-Yup Ku, Seok Hyun Kim, Young Min Choi, and Shin Yong Moon. Conneticut, USA and Seoul, Republic of Korea.

T-254 Embryoid Bodies as a Stem Cell Model for Steroidogenic Cell Commitment and Ovarian Development. Shane T Lipskind, Jennifer S Lindsey, Adam Kiezun, Joshua WK Ho, Behzad Gerami-Naini, and Raymond M Anchan.

T-255 Murine Endometrial Parenchymal Stromal and Epithelial Cells Are Derived from Bone Marrow. Sara S Morelli, Pranela Rameshwar, and Laura T Goldsmith. Newark, NJ, USA.

T-256 The Initial Lung Inflammation Resulting from Ventilation-Induced Lung Injury in Preterm Lambs Is Not Altered by Human Amnion Epithelial Cells.

Timothy JM Moss, Jacqueline M Melville, Valerie A Zahra, Melissa L Siew, Megan J Wallace, Graham Jenkin, and Graeme R Polglase. Clayton, Victoria, Australia.

T-257 Amnion Epithelial Cells Prevent Brain Inflammation Resulting from Aggressive Neonatal Resuscitation of Preterm Lambs. Timothy JM Moss, Aminath Azhan, Jacqueline M Melville, Kelly J Crossley, Samantha K Barton, Courtney McDonald, Graham Jenkin, Graeme R Polglase, and Mary Tolcos. Clayton, Victoria, Australia.

T-258 Regulated Progressive Conversion of Bone Marrow Derived Stem Cells into Endometrial Epithelial Cells In Vivo.

Levent Mutlu, Paula G Figueira, Efi E Massasa, Graciela Krikun, and Hugh S Taylor. New Haven, CT, USA.

T-259 Bone Morphogenetic Protein 4 Signaling Promotes Differentiation of Adult Mouse OvaryDerived Oogonial Stem Cells into Oocytes In Vitro. Eun-Sil Park, and Jonathan L Tilly. Boston, MA, USA.
$\mathrm{T}-260$

Second and Third Trimester Human Amniotic Fluid Stem Cells Engraft after In Utero Transplantation in Immunocompetent Mice. Panicos Shangaris, SW Steven Shaw, Michela Pozzobon, Martina Piccoli, Caterina Pipino, Kuang-Han Lee, Andrea Schiavo, Panagiotis Maghsoudlou, Jane Lin, Paolo De Coppi, and Anna David. London, United Kingdom and Padua, Italy.

T-261 Differential Nuclear $\beta$-Catenin and Wnt Target Protein Expression in the Functional and Basal Glands of Benign Human Full Thickness Endometrium in Endometrial Regeneration and after Hormonal Therapy.

Nicola Tempest, Anthony Valentijin, Josephine Drury, Shahram A Ibrahim, John R Jenkins, and Dharani K Hapangama. United Kingdom.

T-262 Oogonial Stem Cells: A Source for Autologous Germline Mitochondria. Dori C Woods, and Jonathan L Tilly. Boston, MA, USA.

T-263 An Energetic - Not Pelvic - Explanation for the Evolution of Human Gestation and Fetal Growth. Holly M Dunsworth. Kingston, RI, USA.

T-264 Variation of Outcomes in PPROM Based on Ethnicity: A Pilot Study. David Banh, Harold W Kolni, Ndaya Muleba, and Manuel E Rivera-Alsina. Dallas, TX, USA. 


\section{CLINICAL GYNECOLOGY}

F-001 Relationship between Abnormal Uterine Bleeding (AUB) Knowledge and Health Literacy in Urban African-American Women (AAW). Maureen E Brocks, Hannah S Recht, Marissa S Ghant, and Erica E Marsh. Chicago, IL, USA.

F-002 Myosonographic Diagonistics for Pelvic Pain. Frank F Tu, and Kevin M Hellman. Evanston, IL, USA and Chicago, IL, USA.

F-003 Cost-Benefit Analysis of Laparoscopic vs.

Abdominal Hysterectomy. Preethi Kamtam, Vivek Gupta, Abdulla Al-Khan, Manuel Alvarez, Stacy Zamudio, and Michael Sbarra. NJ, USA.

F-004 Optimizing the Modified Laparoscopic Vecchietti Procedure. Abdulrahim Rouzi, Nora Sahly, Abdullah Kaki, and Hassan Abduljabbar.

F-005 Characteristics of Women with Bacterial Vaginosis Undetected by Amsel Criteria. Katherine J Sapra, Tara M Randis, Susan Whittier, Shari E Gelber, and Adam J Ratner. New York, NY, USA.

F-006 Combination Gefitinib \& Methotrexate To Treat Ectopic Pregnancy.

Monika Skubisz, Andrew Horne, Colin Duncan, Hilary Critchley, Euan Wallace, Peter Neil, and Stephen Tong. Clayton, Victoria, Australia; Edinburgh, Scotland, United Kingdom and Melbourne, Victoria, Australia.

\section{CONTRACEPTION}

F-007 Enhanced Endometrial Cell Expressed FKBP51 Accompanies Long-Acting Contraceptives Containing Progestins (LACPs) Use.

Murat Basar, Umit A Kayisli, Lynn Buchwalder, Graciela Krikun, Ozlem Guzeloglu Kayisli, Frederick Schatz, and Charles J Lockwood. Columbus, OH, USA and New Haven, CT, USA.

F-008 The PK/PD Relationship of Ethinyl Estradiol and Unscheduled Bleeding or Spotting for an Ascending-Dose, Estrogen/Progestin Combination Oral Contraceptive (OC). Mona Darwish, Mary Bond, Nancy Ricciotti, Jennifer Hsieh, Cynthia A Walawander, and Ted Grasela.

F-009 Pharmacokinetic Profile of an AscendingDose, Estrogen/Progestin Combination Oral Contraceptive.

Mona Darwish, Mary Bond, Nancy Ricciotti, Jennifer Hsieh, Jill Fiedler-Kelly, and Ted Grasela.
CLINICAL PARTURITION/PREMATURITY II

F-010 Short and Long Term Infant Outcomes after Emergency Cervical Cerclage in Spontaneous Preterm Birth: A Case-Control Study. Sara Consonni, Federica Accordino, Patrizia Vergani, Tiziana Fedeli, Francesca Pelizzoni, Agnese Pizzardi, Marta Schiliro, and Anna Locatelli. Monza, Italy.

F-011 Vaginal Microbiome Remains Stable during Normal Pregnancy.

Marina Resendes de Sousa Antonio, Nicholas

Chia, Patricio Jeraldo, Carl Yoeman, Karen

Nelson, Brenda Wilson, Bryan White, and

Douglas Creedon. Rochester, MN, USA;

Urbana, IL, USA and Rockville, MD, USA.

F-012 Perioperative Complications of Cervical

Cerclage at Periviability.

Daphnie Drassinower, Cande Ananth, Helain J Landy, Sarah H Poggi, and Annette PerezDelboy. New York, NY, USA; Washington, DC, USA and Alexandria, VA, USA.

F-013 To Decrease Cesarean Section Rate We Need To Focus in Avoiding the First One, Review of Oxytocin Use at a County Hospital. Kristina Roloff, Sheppard Peng, and Valenzuela J Guillermo. Colton, CA, USA.

F-014 Differential Expression of Leukocyte Lysate Proteins in Threatened Preterm Labour Using iTRAQ.

Yujing J Heng, Mary WF Lee, Brett G Larsen, Lorne Taylor, Monika Tucholska, Craig E Pennell, Tony Pawson, and Stephen J Lye. Toronto, ON, Canada and Perth, WA, Australia.

F-015 Hair Cortisol and Fetal Adrenal Ultrasound, Potential Non-Invasive Markers of Preterm Birth.

M Camille Hoffman, Randal G Ross, Mark Laudenslager, and John Hobbins. USA.

F-016 Predictors of Mortality in Pregnancies Complicated by PPROM.

Roohi Jeelani, Ichchha Madan, Anushka Chelliah, Mike Kruger, and Ray Bahado-Singh. Detroit, MI, USA.

F-017 Vitamin D Deficiency Increases the Risk of Spontaneous Preterm Birth. Louise C Kenny, Mairead Kiely, Joy Y Zhang, Michael Kinsella, and Ali S Khashan. Ireland.

F-018 Analysis of Fecal Microflora Composition in Preterm Infants Using 16S rRNA. Masako Kitsunezaki, Manabu Kemmochi, Mari Ooka, Takashi Ito, Masahiko Nowatari, Yuki Bando, and Masahiro Ishii. Sagamihara, Kanagawa, Japan. 
F-019 Outcomes of Expectant Management with Serial Antenatal Monitoring in Postterm Pregnancy.

llaria Pozzi, Agnese Pizzardi, Serena Mussi, Maddalena Incerti, Anna Locatelli, Marta Schiliro, and Patrizia Vergani. Monza, Italy.

F-020 Risk Factors for Severe Perineal Laceration in Spontaneous Vaginal Deliveries.

Meghan E Pratts, Ayatallah M Khafagy, Anne E Burke, Jamie D Murphy, Cynthia H Argani, and Erika F Werner. Baltimore, MD, USA.

F-021 Premature Delivery in HIV+ Mothers on HAART Is Associated with an Expanded Peripheral Blood CD56+ Subset.

Nishel Shah, Samantha Westrop, Naomi LowBeer, David Hawkins, Nesrina Imami, and Mark Johnson. London, United Kingdom.

F-022 Pathogenesis of Influenza in Pregnancy: Role of Inflammatory Markers and Viremia.

Alan Tita, Joseph Biggio, Jeffrey Szychowski, Elena Lobashevsky, Mark Pritchard, Richard Whitley, and William Andrews. Birmingham, AL, USA.

F-023 Epidural Analgesia Is Associated with Intrapartum Fever and Increased Second Stage Maternal Temperature without Adverse Neonatal Outcome.

Evelien Kempen, and Olivier WH van der Heijden. Nijmegen, Netherlands.

F-024 Neonatal Outcomes after Fetal Acidemia. Emilie L Vander Haar, Jaclyn M Coletta, Mary E D'Alton, and Cynthia Gyamfi-Bannerman.

F-025 Outcomes of Expectantly Managed Pregnancies with Multiple Gestations and Mid-Trimester Preterm Premature Rupture of Membranes (PPROM). Luchin F Wong, Tracy A Manuck, Calla M Holmgren, Robert M Silver, and Michael W Varner. Salt Lake City, UT, USA.

F-026 Oral Administration of Live Lactobacillus rhamnosus GR-1 Bacteria Alters the Vaginal Microbiome Profile in Pregnant CD-1 Mice. SW Yang, W Li, JRG Challis, G Reid, GB Gloor, and AD Bocking. ; Toronto, Canada and London, Canada.

F-027 Outcomes of Expectantly Managed Parturients after Betamethasone for Preterm Premature Rupture of Membranes.

Christopher M Young, Latasha Nelson, and Svena Julien. Orange, CA, USA; Chicago, IL, USA and Baltimore, MD, USA.

F-028 Use of a Second Application of Vaginal Dinoprostone for Cervical Ripening in Nulliparous Patients.

Noelia Zork, Richard Burwick, and Marie Beall. Torrance, CA, USA.
F-029

A Negative Fetal Fibronectin Is Still Reassuring in Asymptomatic Women with a Transvaginal Cervical Length $<10 \mathrm{~mm}$.

Noelia Zork, Anne Holland, Caroline Pessel, Sara Brubaker, Cynthia Gyamfi-Bannerman, Joy Vink, Karin Fuchs, and Cande Ananth. New York, NY, USA.

\section{DEVELOPMENTAL ORIGINS OF HEALTH II}

F-030 Mouse Model of Intrauterine Inflammation: Long-Term Neurologic Sequelae in Offspring. Irina Burd, Tahani Dada, Wance Firdaus, Eman Alqahtani, Shorouq AlRebh, Jiangyang Zhang, Susumu Mori, Mikhail Pletnikov, and Michael Johnston.

F-031 Increased Testosterone Levels in In Utero Programmed Adult Female Offspring Mediates Vascular Dysfunction and Hypertension. Vijay Chinnathambi, Meena Balakrishnan, Chandra Yallampalli, and K Sathishkumar. Galveston, TX, USA.

F-032 Endocrine Disruptor (Bisphenol A) Increases Proliferation and Lipid Storage of Adipocyte Progenitor Cells. Mina Desai, Juanita Jellyman, Guang Han, Marie $\mathrm{H}$ Beall, and Michael G Ross.

F-033 Reduced Insulin Response in Human Umbilical Vein Endothelial Cells from Pregnancies with Maternal Obesity Is Associated with Activation of PERK Branch of Endoplasmic Reticulum Stress Pathway. Marcelo E Farias, Francisco Westermeier, Juan P Kusanovic, Jose A Poblete, Francisco Mardones, and Luis Sobrevia. Santiago, Chile.

F-034 Seasonal Impact in the Frequency of Isolated Fetal Defects.

Valentina Giardini, Maria Verderio, Francesca Pelizzoni, Lyudmyla Todyrenchuk, and Patrizia Vergani. Monza, Monza e Brianza (MB), Italy.

F-035 Programmed Adipose Angiotensinogen Contributes to Hypertension in Offspring of Obese Dams. Cristiane Guberman, Guang Han, Michael G Ross, and Mina Desai.

F-036 In Utero Magnesium (Mg) Deficiency Programs Brain Development, Growth, Immune Function, and Behavior in the Offspring. Madhu Gupta, Malvika H Solanki, Amanda Roman, Burton Rochelson, Toby Klein, Pato Huerta, Xiangying Xue, Prodyot Chatterjee, and Christine N Metz. Manhasset, NY, USA.

F-037 Identifying Loci of Interest Linking Adverse Intrauterine Environment and an Aging Phenotype.

Hye Heo, Jessica Tozour, Fabien Delahaye, Andrew $\mathrm{H}$ Chung, Yongmei Zhao, Nir Barziali, and Francine $\mathrm{H}$ Einstein. 


\section{Friday, March 22, 2013 - Poster Session II - Bonnett Creek Ballroom}

F-038 Maternal Calorie Restriction Induces Renal Phenotypic and Epigenetic Dysregulation in Male Offspring.

Hye J Heo, Howard Slomoko, Fabien Delahaye, Jessica Tozour, Yongmei Zhao, Zhongfang Du, Kimberly J Reidy, and Francine H Einstein. Bronx, NY, USA.

F-039 Antenatal Betamethasone (Beta) Effects on Ryanodine (RyR) Mediated Vascular Reactivity in Adult Sheep.

Jeong-Heon Lee, Jie Zhang, Angela G Massmann, Lourdes Flores, and Jorge $P$ Figueroa. Winston-Salem, NC, USA and Jeonju, Jeonbuk, Korea.

F-040 Antenatal Glucocorticoids Increase In Vitro Vascular Reactivity in the Adult Offspring Via the ADPR Cyclase Pathway. Jeong-Heon Lee, Jie Zhang, Angela G Massmann, and Jorge P Figueroa. WinstonSalem, NC, USA.

F-041 Effects of Antenatal Glucocorticoids and DietInduced Obesity on Plasma and Adipose Tissue Adiponectin.

Angela G Massmann, Lourdes Flores, JeongHeon Lee, Jie Zhang, and Jorge P Figueroa. Winston-Salem, NC, USA.

F-042 Methylation at Imprinted Insulin-Like Growth Factor-2 (IGF2) Is Vulnerable to Lead Exposure in Human Embryonic Kidney Cells. Susan K Murphy, Monica D Nye, and Cathrine Hoyo. Durham, NC, USA and Chapel Hill, NC, USA.

F-043 Unpredictable Variable Prenatal Stress (UVPS) Leads to Adult Overweight and Elevates Anxiety in Male but Not Female Rat Offspring. April E Ronca, Kristina M Strickland, Patricia L Scott, Christina D Tulbert, Jonathan J Morgan, Leah C Allen, and Lisa A Baer. Winston-Salem, NC, USA and Houston, TX, USA.

F-044 Bisphenol A Increases Neural Progenitor Cell Proliferation and Alters Neurogenesis. Mina Desai, Guang Han, Marie H Beall, and Michael G Ross.

F-045 Placental Angiogenesis and ASD: Measurable Differences in Placental Vascular Structure. C Salafia, T Girardi, C Newschaffer, R Miller, C Walker, D Misra, P Katzman, J Moye, M Fallin, I Herz-Picciotto, and L Croen. Staten Island, NY, USA; Larchmont, NY, USA; Philadelphia, PA, USA; Rochester, NY, USA; Sacramento, CA, USA; Detroit, MI, USA; Rockville, MD, USA; Baltimore, MD, USA and Oakland, CA, USA.
F-046

Independent Effects of Impaired Fetal Growth and a High-Fat/High-Fructose Postnatal Diet on Adipose and Liver Development in Young Adult Guinea Pigs.

Ousseynou Sarr, Jennifer A Thompson, Lin Zhao, and Timothy TRH Regnault. London, ON, Canada.

F-047 Increased Desaturated Fatty Acids in Offspring of Obese Dams: Mechanism of Programmed Obesity and Adiposity.

Emily L Seet, Jennifer K Yee, Michael G Ross, and Mina Desai.

F-048 Effect of Lactation on Programmed Offspring Obesity and Fatty Acid Desaturation. Emily L Seet, Jennifer K Yee, Michael G Ross, and Mina Desai.

F-049 Epigenetics of Preterm Labor: Distinct Patterns of Chromatin Modifying Enzymes and Altered Expression of Cytokines in Myometrial Tissue of Rats Exposed In Utero to Benzo(a)Pyrene. Chandrasekhar Thota, Archana Laknaur, Bobb Lesley, Darryl Hood, and Ayman Al-Hendy. Nashville, TN, USA.

\section{EPIDEMIOLOGY}

F-050 Novel Web Portal To View Integrated Biorepository and EMR Data.

Donna A Santillan, Monika Ahuja, Yi Wang, Boyd Knosp, Kimberly K Leslie, Stephen K Hunter, and Mark K Santillan. Iowa City, IA, USA.

F-051 Maternal 25-Hydroxvitamin D, Duration of Labor, Instrumental Delivery, and Cesarean Section in a Multi-Center US Cohort. Alison D Gernand, Hyagriv N Simhan, Mark A Klebanoff, and Lisa M Bodnar. Pittsburgh, PA, USA and Columbus, $\mathrm{OH}$, USA.

F-052 Evolution of Maternal Body Mass Index and Gestational Weight Gain in the Region of Flanders (Belgium) 2009-2011: An Epidemiological Study. Annick FL Bogaerts, Bea RH Van den Bergh, Ingrid Witters, Evelyne Martens, and Roland Devlieger.

F-053 Recent Trends in Preterm Birth Subtypes and Its Impact on Perinatal Outcome: Race/ Ethnicity.

Darios Getahun, Michael J Fassett, T Gemzu, and Steven J Jacobsen. Pasadena, CA, USA; Los Angeles, CA, USA and Piscataway, NJ, USA. 
F-054 An Innovative Approach to Recruitment and Biospecimen Collection: A Study of Spina Bifida Genetics.

Katherine Lazaruk, Kelly Sitts, Courtney Beyer, Edward Lammer, Gary Shaw, and Dennis Gilbert. Foster City, CA, USA; Oakland, CA, USA and Stanford, CA, USA.

F-055 The Impact of Maternal Alcohol Consumption on Pregnancy Outcomes.

Fergus P McCarthy, Linda M O'Keeffe, Ali S Khashan, Robyn A North, James J Walker, Philip N Baker, Gus Dekker, Lucilla Poston, Lesley ME McCowan, Louise C Kenny, and On Behalf of SCOPE Consortium. Ireland; United Kingdom; New Zealand and Australia.

F-056 Barriers Preventing Early First Prenatal Visit. Rathna Nuti, Vera von-Bergen, Ena Sharma, Bennet Boyd, Lauren Hermann, Urvi Shah, and V Daniel Castracane. Odessa, TX, USA.

F-057 Cesarean Delivery and Subsequent Birth Interval, Ectopic Pregnancy, Miscarriage or Stillbirth - A Danish Register-Based Study. Sinead M O Neill, Esben Agerbo, Louise C Kenny, Tine B Henriksen, Patricia M Kearney, Richard A Greene, Preben B Mortensen, Jennifer E Lutomski, and Ali S Khashan. Ireland and Denmark.

F-058 Cesarean Section and Subsequent Pregnancy Interval - A Systematic Review.

Sinead M O Neill, Patricia M Kearney, Louise C Kenny, Tine B Henriksen, Jennifer E Lutomski, Richard A Greene, and Ali S Khashan. Ireland and Denmark.

F-059 Systematic Review of the Effects of Low to Moderate Alcohol Consumption during Pregnancy and Speech and Language

Development in Infants. Linda M O'Keeffe, Richard A Greene, and Patricia M Kearney. Cork, Ireland.

F-060 Moderate Alcohol Consumption in Early, Middle and Late Pregnancy and Small for Gestational Age, Preterm Birth and Birth Weight: A Retrospective Cohort Study. Linda M O'Keeffe, Gemma Daly, Patricia M Kearney, and Richard A Greene. Cork, Ireland.

F-061 Whom Should We Believe? Patient Based vs Professional Based Screening for Antenatal Psychopathology and Psychosocial Problems. Chantal Quispel, Mijke P Lambregtse-van den Berg, Erwin Birnie, Witte J Hoogendijk, Eric AP Steegers, and Gouke J Bonsel. Rotterdam, Netherlands.
F-062 Psychopathology, Psychosocial Problems, Substance Use and Adverse Pregnancy Outcomes among Pregnant Women in an Urban Versus a Rural Area. Chantal Quispel, Gouke J Bonsel, Eric AP Steegers, Witte J Hoogendijk, and Mijke P Lambregtse-van den Berg. Rotterdam, Netherlands.

F-063 Genotypic Variations in the VDR Fok1SNP Modify Association of Smoking on BV Prevalence in Non-Pregnant Women. Katherine J Sapra, Tara M Randis, Chase W Shutak, Susan Whittier, Shari E Gelber, and Adam J Ratner. NY, NY, USA.

F-064 Birth Weight and Attention Problems: Same Genetic Mechanism?

Nina H Van Mil, Regine PM SteegersTheunissen, Ehsan Motazedi, Vincent WV Jaddoe, Andre G Uitterlinden, Albert Hofman, Eric AP Steegers, Frank C Verhulst, and Henning Tiemeier.

F-065 Antepartum Obstetric Admission to an Intensive Care Unit (ICU): Experience from a Large Tertiary Center.

Oscar A Viteri, Brendan D Connealy, Caroline C Marrs, Maria S Hutchinson, Alfredo F Gei, and Baha M Sibai. Houston, TX, USA.

F-066 Vitamin D Receptor Gene Polymorphisms and Spontaneous Preterm Birth.

Shu-Qin Wei, Anne-Monique Nuyt, ZhongCheng Luo, Francois Audibert, Pierre Julien, and William Fraser. Montreal, QC, Canada.

\section{GROWTH AND METABOLISM}

F-067 Early Maternal Dexamethasone Treatment and the Choice of Reference Genes for Normalization of RT-PCR in Fetal Sheep Liver. Thorsten Braun, Huaisheng Xu, Loreen Ehrlich, Sahofu Li, Joachim Dudenhausen, John Newnham, Andreas Plagemann, John Challis, and Deborah Sloboda. and China.

F-068 DNA Methylation of Somatotropic Axis Genes in Relation to Postnatal Growth and Metabolism Following Ad.VEGF Treatment of GrowthRestricted Sheep Fetuses.

David J Carr, Raymond P Aitken, John S Milne, Donald M Peebles, John F Martin, Ian C Zachary, Jacqueline M Wallace, and Anna L David. London, United Kingdom and Aberdeen, United Kingdom.

F-069 Oxygen Dependent Increase in Fetal-Placental Plasma PAl-1 in Placental Insufficiency

Mediates Angiogenesis. Maxim D Seferovic, and Madhulika B Gupta. London, ON, Canada. 


\section{Friday, March 22, 2013 - Poster Session II - Bonnett Creek Ballroom}

F-070 Sex Differences in Fetal Growth in Response to Exercise in Pregnancy.

Sarah A Hopkins, James C Baldi, Wayne S Cutfield, Lesley McCowan, and Paul L Hofman. St. Louis, MO, USA; Dunedin, New Zealand and Auckland, New Zealand.

F-071 Cardiac Myocyte Growth Dynamics Change at Birth.

Sonnet S Jonker, Samantha Louey, Kent L Thornburg, J Job Faber, and George D Giraud. and USA.

F-072 Comparison of Oxidative Stress Markers in Umbilical Cord Blood of Vaginal and Cesarean Delivery.

Yoon Ha Kim, Jong Woon Kim, Eun Ji Noh, Jong Ho Moon, and Tae-Bok Song. Gwangju, Korea.

F-073 Growth Restriction: Identifying Fetuses at Risk. Heidi K Leftwich, Bethany Schmidt, Bethany Dicks, Yvette Cordova, and Isabelle Wilkins. Chicago, IL, USA.

F-074 IUGR in Fetal Baboons at 0.9 Gestation (G) Increases Fetal Pancreatic 11-Betahydroxysteroid Dehydrogenase (11 $\beta$ HSD) 1 and Decreases $11 \beta H S D 2$. Implications for Later Life Failure of Insulin Secretion. Cun Li, Dongbin Xie, Mark J Nijland, Thomas J McDonald, and Peter W Nathanielsz. San Antonio, TX, USA.

F-075 Elevated Fetal Plasma Norepinephrine Suppresses Insulin and Alters Fetal Metabolism Prior to Growth Restriction in an Ovine Model of Placental Insufficiency. Antoni R Macko, Xiaochuan Chen, Miranda J Anderson, Amy C Kelly, and Sean W Limesand. Tucson, AZ, USA.

F-076 Effects of Fetal Adrenal Demedullation at $\mathbf{0 . 7}$ Gestation on Fetal Growth and Metabolism at 0.9 Gestation in an Ovine Model of Placental Insufficiency and Intrauterine Growth Restriction. Antoni R Macko, Dustin T Yates, Amy C Kelly, Miranda J Anderson, and Sean W Limesand. Tucson, AZ, USA.

F-077 The Effect of Maternal Supplementation and Ethnicity on Umbilical Cord Serum Folates. Devika Maulik, Leon van Haandel, and J Steven Leeder. Kansas City, KS, USA and Kansas City, $\mathrm{MO}$, USA.
F-078

Fat Cell Size Distribution and Lipid Dysfunction in Offspring Following Maternal and Offspring (OFF) Exercise Interventions To Prevent Developmental Programming Resulting from Maternal Obesity (MO) in the Rat.

Benjamin Ehler, Carlos Ibanz, Magaly Vazquez, Luis Reyes-Castro, Claudia Vegas-Garcia, Claudia J Bautista, Joel Michalek, Peter W Nathanielsz, and Elena Zambrano. San Antonio, TX, USA and DF, Mexico.

F-079 Genetic Influences on Fetal Growth Are Specific to Head Circumference, Abdominal Circumference and Femur Length. CE Pennell, QW Ang, JA Marsh, SW White, L Briolais, MK White, JP Newnham, and SJ Lye. Perth, Australia; Toronto, Canada and Canada.

F-080 Maternal Magnesium Supplementation Modulates IL-1 $\beta$ Levels in a Rat Model of Intrauterine Growth Restriction.

Amanda Roman, Madhu Gupta, Malvika Solanki, Xiangying Xue, Prodyot Chatterjee, Burton Rochelson, and Christine Metz. Manhasset, NY, USA.

F-081 B Lymphocyte Stimulator (BLyS) Levels at the Time of Delivery.

Hindi E Stohl, William Stohl, and Richard H Lee.

F-082 Sexual Dimorphic Adipogenic Adaptation of Preadipocytes to Moderate Maternal Nutrient Restriction (MNR) and IUGR in the Fetal Baboon at 0.9 Gestation (G). Yourka D Tchoukalova, Rashmi Krishnapuram, Ursula A White, Xiaobing Fang, Mark J Nijland, and Peter W Nathanielsz. Baton Rouge, LA, USA and San Antonio, TX, USA.

F-083 Depot-Dependent Transcriptional Effects of Maternal Nutrient Restriction (MNR) on Adipocyte Precursor Cells from Female Baboon Fetuses at $\mathbf{0 . 9}$ Gestation (G). Yourka D Tchoukalova, Ursula A White, Rashmi Krishnapuram, Xiaobing Fang, Mark J Nijland and Peter W Nathanielsz. Baton Rouge, LA, USA and San Antonio, TX, USA.

F-084 Comparison of the Impact IUGR Has on Development of the Serotonergic Nervous System in Non-Human Primates at 120- \& 165Day Gestation (dg). Brent J Thompson, Wenrui Ye, Ashley D Denny, Cun Li, Thomas J McDonald, and Peter W Nathanielsz. San Antonio, TX, USA.

F-085 Characterisation of Abnormal Fetal Growth Results of the National Multicenter Prospective PORTO Trial.

Julia Unterscheider, Sean Daly, Michael P Geary, Mairead M Kennelly, Fionnuala M McAuliffe, Keelin O'Donoghue, Alyson Hunter, John J Morrison, Gerard Burke, Patrick Dicker, Elizabeth Tully, and Fergal D Malone. Ireland. 
F-086 Does Pre-Pregnancy BMI, Gestational Weight Gain and Dietary Intake in Pregnant Teens Influence Fetal Fat Accretion? Corrie M Whisner, Eva K Pressman, Bridget E Young, Elizabeth M Cooper, Ruth A Queenan, and Kimberly O O'Brien. Ithaca, NY, USA and Rochester, NY, USA.

F-087 Customized Assessment of Fetal Growth Improves Detection of Young Adults with Metabolic Abnormalites as a Consequence of Fetal Growth Restriction.

SW White, JP Newnham, LJ Beilin, QW Ang, SJ Lye, and CE Pennell. Australia and Canada.

F-088 Measuring Circulating RNA Transcripts Coding Growth Factors To Detect Fetal Growth Restriction.

Clare L Whitehead, Susan P Walker, Sonali Mendis, and Stephen Tong. Heidelberg, Vic, Australia.

\section{HYPOXIA, CARDIOVASCULAR FUNCTION}

F-089 Ketamine Decreases Apoptotic and Inflammatory Gene Expression in Fetal Hippocampus Exposed to Global Acute Hypoxic Hypoxia.

Eileen I Chang, and Charles E Wood.

Gainesville, FL, USA.

F-090 Programming of Aortic Stiffness by Fetal Chronic Hypoxia and Oxidative Stress. C Daruwalla, Y Niu, CM Cross, EJ Camm, ML Oyen, and DA Giussani. and United Kingdom.

F-091 Fetal Cardiac Time Intervals and Its Correlation with Behavioral States in Low and High-Risk Pregnancies.

Kenneth B Keplinger, Bhargavi Sriram, Rathinaswamy B Govindan, Pam Murphy, Curtis L Lowery, and Hari Eswaran. Little Rock, AR, USA and Washington, DC, USA.

F-092 Fetal Heart Rate Variability (fHRV) Analysis in Early Labor May Identify Neonatal Severe Acidemia: Come-Back of Fetal TransAbdominal ECG.

DL Durosier, T Stampalija, C Herry, S Wang, D Casati, A Seely, Z Alfirevic, E Ferrazzi, and MG Frasch. QC, Canada and ON, Canada.

F-093 Continuous Fetal Heart Rate Variability (fHRV) Analysis Detects Early Acidemia Regardless of Pre-Existent Hypoxia or Inflammation. D Durosier, G Green, I Batkin, AJE Seely, MG Ross, BS Richardson, and MG Frasch. Montréal, Canada; Ottawa, Canada; USA and London, Canada.

F-094 Galantamine, Known as Acetylcholinesterase Inhibitor Reduces Brain Damage Induced by Hypoxia-Ischemia in Newborn Rats.

Seishi Furukawa, Li Yang, Hiroshi Sameshima, and Tsuyomu Ikenoue. Miyazaki, Japan.
F-095

Influence of Chronic Hypoxia on Optical Density of $\mu$-Opioid Receptors in Fetal Rat Brain.

Janusz Jacek Kraczkowski, Katarzyna Maria Karwasik-Kajszczarek, Jacek Marcin Robak, and Anna Kwa\&\#347;niewska. Lublin, Poland.

F-096 Intracranial Mesenchymal Stem Cell Attenuates Perinatal Brain Injury in Animal Model. Martin M Mueller, Andreina Schoeberlein, Ursula Reinhart, Marianne Messerli, Ruth Sager, and Daniel Surbek. Bern, Switzerland.

F-097 Long Term Hypoxia in the Ovine Fetus Alters Hepatic Expression of Key Genes Governing Fatty Acid Synthesis.

Dean A Myers, Kanchan M Kaushal, and Charles A Ducsay. Oklahoma City, OK, USA and Loma Linda, CA, USA.

F-098 Effect of Long Term Hypoxia on eNOS Phosphorylation and Cortisol Biosynthesis in the Ovine Fetal Adrenal.

E Newby, K Kaushal, D Myers, and C Ducsay. Loma Linda, CA, USA and Oklahoma City, OK, USA.

F-099 Neuronal Nitric Oxide Synthase (nNOS) Is Increased in Serum of Encephalopathic Neonates.

Elisabeth Nigrini, Ernest Graham, Sarahn Wheeler, Talaibek Borbiev, Michael Johnston, and Irina Burd. Baltimore, MD, USA.

F-100 Thalamic Locus Mediates Hypoxic Respiratory Depression in Lambs.

Arezoo Rajaee, Basil Ibe, Catalina Guerra, Sumair Husain, Lawrence Kruger, and Brian J Koos. Los Angeles, CA, USA and Torrance, CA, USA.

F-101 Collagen Deposition in the Embryonic Chicken Outflow Tract Is Regulated by Hemodynamic Forces.

Monique Y Rennie, Michael Danilchik, Sandra Rugonyi, and Kent L Thornburg. and Portland, OR, USA.

F-102 Development of an Artificial Placenta Using a

Premature Lamb Model. Masatoshi Saito, Yuichiro Miura, Akio Funakubo, Tadashi Mastuda, Junichi Sugawara, and Nobuo Yaegashi. Sendai, Miyagi, Japan and Hatoyama, Saitama, Japan.

F-103 Brain Inflammation and Injury in Response to Repetitive Umbilical Cord Occlusions with Severe Acidemia in the Ovine Fetus. Alex Xu, Karolina Piorkowska, Brad Matushewski, Rob Hammond, and Bryan S Richardson. and London, ON, Canada.

F-104 Quantitative Proteomics Analysis of HypoxiaResponsive Proteomes in Trophoblast Cells. Hong-hai Zhang, Ying-ying Yang, Lan Huang, and Dong-bao Chen. and Irvine, CA, USA. 


\section{Friday, March 22, 2013 - Poster Session II - Bonnett Creek Ballroom}

\section{IMPLANTATION/ENDOMETRIUM}

F-105 Intermedin: A Novel Regulator of MUC1 at the Maternal Fetal Interface.

Rexanna Chan, Meena Balakrishnan, Chandra Yallampalli, and Madhu Chauhan. Galveston, TX, USA.

F-106 SLC35C2 Regulates Crosstalk between Maternal-Fetus during Implantation. Ying Chen, Kai Wang, and Richard E Leach. Grand Rapids, MI, USA.

F-107 A Role for Androgens during Endometrial Breakdown and Early Regeneration in a Mouse Model of Menstruation.

Fiona L Cousins, Alison A Murray, Hilary OD Critchley, and Philippa TK Saunders. Edinburgh, United Kingdom.

F-108 Interleukin-8 Expression Is Not Regulated by Increased Intracellular cAMP in Human Endometrial Epithelial Cells.

Amy Shah Dhesi, Sara S Morelli, Andrea Wojtczuk, Gerson Weiss, and Laura T Goldsmith. Newark, NJ, USA.

F-109 Fibroid-Exposed Endometrial Stromal Cells (ESC) Demonstrate Altered Bone Morphogenetic Protein 2 (BMP-2) Signaling. Leo F Doherty, and Hugh S Taylor. New Haven, CT, USA.

F-110 Proteomic Analysis of Receptive Versus Non-Receptive Endometria Diagnosed by the Endometrial Receptivity Array Revealed Differential Protein Profiles, Highlighting the Down-Regulation of Progesterone Receptor Membrane Component 1 (PGRMC1).

Francisco Dominguez, Tamara Garrido-Gomez, Alicia Quinonero, Oreto Antunez, Manuel Sanchez del Pino, and Carlos Simon. Valencia, Spain.

F-111 Bisphenol A Influence on Human

Decidualization In Vitro.

Romani Federica, Tropea Anna, Scarinci Elisa, Catino Stafania, Palla Carola, Federico Alex, Lanzone Antonio, and Apa Rosanna. Roma, Italy and Troina, Enna, Italy.

F-112 High Levels of Insulin Promote AKT and mTOR Specific Insulin Resistance in Primary Stromal Endometrial Cells.

Clare A Flannery, Emily C Turner, Elizabeth Oliver, and Hugh S Taylor.

F-113 Direct Comparison of Decidualization Protocols: Estradiol and Progestin Are Insufficient for Decidualization.

Clare A Flannery, Elizabeth Oliver, Emily C Turner, and Hugh S Taylor.
$\mathrm{F}-114$

ANXA2 Inhibition Disrupts Endometrial Stromal Cells (ESCs) Decidualization.

Tamara Garrido-Gomez, Francisco Dominguez, Alicia Quinonero, and Carlos Simon. Valencia, Spain.

F-115 Endometrial Thickness on the Day of hCG Trigger Positively Correlates with ART Outcomes and Differs by Racial Group. Micah J Hill, Heba Eltoukhi, Kevin S Richter, Eric Widra, and Erin F Wolff. Bethesda, MD, USA and Rockville, MD, USA.

F-116 Combined Use of Serum Cotinine, ADAM12 and Fibronectin Levels May Be Useful as a Theoretical Multiplex Test To Diagnose Ectopic Pregnancy in Women Presenting with Pregnancy of Unknown Location. Jeremy K Brown, Colin Duncan, Tom Bourne, Adam Jowicz, Martina Messow, and Andrew W Horne. United Kingdom.

F-117 Use of Steroids and Antibiotics by US Fertility Centers.

Vasiliki A Moragianni, Sinem Fethiye Karipcin, Anna Merport Modest, and Alan S Penzias. Boston, MA, USA; New York, NY, USA and Waltham, MA, USA.

F-118 Oral Contraceptive Pills (OCP) Interfere with Nucleolar Channel System (NCS) Formation during the Window of Implantation (WOI). Edward J Nejat, Michael J Szmyga, and U Thomas Meier. Bronx, NY, USA.

F-119 a2V Plays a Pivotal Role in Decidualizing Human Endometrium. Kuniaki Ota, Mukesh Jaiswal, Bala Koli, Sahithi Pamarthy, Joaane Kwak-Kim, Alice GilmanSachs, and Kenneth Beaman. North Chicago, IL, USA.

F-120 Preliminary Analysis of Uterine Leptin Receptor (Lepr) Null Mice. Kathleen A Pennington, Kelly E Pollock, John $\mathrm{P}$ Lydon, Francesco J DeMayo, and Laura C Schulz. Columbia, MO, USA and Houston, TX, USA.

F-121 EP2 and FP Receptor Activation Promote Blastocyst Adhesiveness to Endometrial Epithelial Cells.

Leslie Ramirez, Felipe Vilella, Sebastian Martinez, Antonio Pellicer, and Carlos Simon. Valencia, Spain.

F-122 Beta-Oxidation of Fatty Acids Is Critical for Endometrial Stromal Cell Decidualization In Vitro.

Jui-He Tsai, Julie S Rhee, and Kelle H Moley. St Louis, MO, USA. 
F-123 Unbiased Mass Spectrometry Based Identification of Proteins of the Uterine Epithelium and Stroma Discriminates between the Proliferative and Secretory Phases of the Menstrual Cycle.

John I Risinger, Addie Alkas, Brian L Hood, Baoquan Liu, Rusheeswar Challa, Yutaka Shoji, Guisong Wang, Gadisetti VR Chandramouli, Asgerally Fazleabas, Susan Ferguson, Christopher Zahn, G Larry Maxwell, and Thomas P Conrads. Grand Rapids, MI, USA; Washington, DC, USA and Annandale, VA, USA.

F-124 Uterine and Oviductal Abnormalities in Mice Lacking the Follistatin Gene and Expressing a Human Follistatin-315 Transgene.

Sarah J Holdsworth-Carson, Rebecca G Craythorn, Kiranjeet Dhaliwal, Wendy R Winnall, Peter AW Rogers, Mark P Hedger, David M de Kretser, and Jane E Girling. Melbourne, Victoria, Australia.

F-125 Gap Junction Blockade Induces Apoptotic and Chemotactic Responses in Human Endometrial Stromal Cells.

Jie Yu, Wei Zou, Heying Sun, Indrani C Bagchi, Milan K Bagchi, Neil Sidell, and Robert N Taylor. Winston-Salem, NC, USA; Shijiazhuang, China; Atlanta; Urbana, USA.

F-126 Role of COX-2 in Decidualization of Endometrial Stromal Cells.

Joelle Taylor, Terry Jacot, and David Archer. Norfolk, VA, USA.

F-127 Milk Fat Globule EGF Factor 8 (MFG-E8) Secretion by Human Endometrium Is UpRegulated by Tumor Necrosis Factor $\alpha\left(T_{N F} \alpha\right)$ Via p42/44 MAPK and Nuclear Factor- $\kappa B$ Signaling Pathways and Is Involved in TNF $\alpha$-Mediated Apoptosis in Endometrial Epithelial Cells. Liang Yu, Silvina Bocca, Sandra Anderson, and Sergio Oehninger.

F-128 Quantitative Analysis of Morphological Differentiation by Human Endometrial Stromal Cells and Regulation by MAP Kinase. Dimitry Zilberman, Donna Cole, Andrea Wojtczuk, Gerson Weiss, and Laura Goldsmith. Newark, NJ, USA.

\section{ANDROLOGY/TESTIS BIOLOGY}

F-129 Consecutive Daily Intrauterine Inseminations Do Not Alter Motile Sperm Recovery. Stephanie Marshall Thompson, Aimee Seungdamrong, Sara S Morelli, Michael Cho, and Peter G McGovern. Newark, NJ, USA.
GAMETOGENESIS/FERTILIZATION/PGD

F-130 Comparative Genomic Hybridization (CGH) after Day 3 Blastomere Biopsy Results in Lower Multiple Pregnancy and Miscarriage Rates, as Well as Improved Clinical and Ongoing Pregnancy Rates in Fresh IVF. Mario Vega, Martin Keltz, Ido Sirota, and MayTal Sauerbrun-Cutler. New York, NY, USA.

\section{INFERTILITYIART}

F-131 Very Low Anti-Mullerian Hormone (AMH): Is It Worth Attempting In Vitro Fertilization (IVF)? Anate Aelion Brauer, Evelyn Mok-Lin, Alexis P Melnick, Steven D Spandorfer, and Zev Rosenwaks. New York, NY, USA.

F-132 Treatment of Choice for Low AMH: IVF or IUI? Lusine Aghajanova, Elliott G Richards, Erik C Mazur, William E Gibbons, and Ertug Kovanci. Houston, TX, USA.

F-133 Fertility Drug Use Does Not Increase the Risk of Ovarian Tumors in Infertile Women. Albert Asante, Phoebe H Leonard, Weaver L Amy, Jani R Jensen, Stewart A Elizabeth, and Coddington C Charles. Rochester, MN, USA.

F-134 How To Optimize Donor IVF Cycles: Are Response Rates of Donor and Pregnancy Outcomes of Recipient Different Based on Treatment Protocol? Stephanie Baum, Katherine Melzer, and Frederick Licciardi. Detroit, MI, USA and New York, NY, USA.

F-135 How To Optimize Donor IVF Cycles: Are Response Rates of Donor and Pregnancy Outcomes of Recipient Different Based on the Recruitment Location of the Donor? Stephanie Baum, Katherine Melzer, and Frederick Licciardi. Detroit, MI, USA and New York, NY, USA.

F-136 Omega-3 Fatty Acids (O3FA) and In-Vitro Fertilization (IVF): Do Serum Levels Affect Outcomes?

Kelly P Comerford, Margaret H Papadakis, Michelle L Matthews, Paul B Marshburn, Rebecca S Usadi, HJ Norton, and Bradley S Hurst. Charlotte, NC, USA.

F-137 Comparison of Pregnancy Rates in D3 vs D5 Embryo Transfer (ET) Using Selective ET Guidelines. Meaghan Delaney, Ertug Kovanci, Alfred WanSong, and William Gibbons. Houston, TX, USA

F-138 Can Nitric Oxide Explain the Poor Follicle Quality of Women with Diminished Ovarian Reserve? Manuel A Doblado, K Joseph Hurt, and Nanette Santoro. Aurora, CO, USA. 
F-139 Something To Talk About: Racial,

Socioeconomic \& Cultural Influences on Seeking, Initiating \& Continuing Infertility Treatment.

Tanaka J Dune, Elizabeth S Sweet, Hannah S Recht, Catherine A Ahern, Kenzie A Cameron, and Erica E Marsh. Chicago, IL, USA.

F-140 Aneuploidy Rates in Human Metaphase I Oocytes Utilized for Assisted Reproduction Analyzed by Array Comparative Genomic Hybridization (aCGH).

Sanaz Ghazal, Maria R Maduro, and Pasquale Patrizio. New Haven, CT, USA.

F-141 Route of Luteal Phase Support for Frozen Embryo Transfers: A Randomized Control Trial. Alexis N Hokenstad, Phoebe H Leonard, Dean E Morbeck, Zaraq Khan, Albert Asante, and Charles C Coddington. Rochester, MN, USA.

F-142 Is Hydro Contrast Sonography (HyCoSy) Using Femvue Saline-Air Device Equivalent to Hysterosalpingogram (HSG) for Assessment of Tubal Patency? A Preliminary Analysis. Alan M Martinez, Thomas C Winter III, Julie M Sroga, Rose Maxwell, Michael A Thomas, and Steven R Lindheim. Cincinnati, OH, USA; Salt Lake City, UT, USA and Tucson, AZ, USA.

F-143 Identification of Ideal Candidates for Single Embryo Transfer (SET) of a Euploid Blastocyst Based upon Overall Embryo Cohort Euploidy Rate.

Scott Morin, Katherine Melzer, Jamie Grifo, Pere Colls, Xyezhong Zheng, and Santiago Munne. New York, NY, USA and Livingston, NJ, USA.

F-144 Changes in the Endometrial Lining during In Vitro Fertilization (IVF) Cycles Predict Pregnancy Outcomes.

Martha Noel, Anate Aelion, and Steven Spandorfer. New York, NY, USA.

F-145 Endometrial Expression of Urocortin 1 in Infertile Women Preparing for In Vitro Fertilization: A Potential Indicator of Treatment Outcome?

Carolina P Rezende, Helen L Del Puerto, Pasquale Florio, and Fernando M Reis. Belo Horizonte, Brazil and Siena, Italy.

F-146 Assessment and Treatment of Same Sex Couples: A National Survey of Assisted Reproductive Technology (ART) Programs. llana B Ressler, David N McKinney, Julie M Sroga, Alan M Martinez, Krystene B DiPaola, and Steven R Lindheim. Cincinnati, OH, USA and Tucson, AZ, USA.

F-147 What Women Want: A Survey of Overweight and Obese Women Presenting for Fertility Care. Julie S Rhee, Margaret M Hopeman, George A Macones, Kelle H Moley, and Emily S Jungheim. St Louis, MO, USA.
F-148

A Comparison of Treatment and Pregnancy Outcomes of Egg Donation and IVF in a Dutch Single-Center Cohort.

W van Dorp, J Laven, C den Bakker, J Rietveld, C Hukkelhoven, and I Schipper. Netherlands and Utrecht, Netherlands.

\section{MEMBRANES, CERVIX, MMPS}

F-149 Do Biomarkers Aid Cervical Length in the Prediction of Preterm Birth in Asymptomatic, High Risk Women?

Jamie A Bastek, Adi Hirshberg, Suchitra Chandrasekaran, Carter Owen, and Michal A Elovitz. Philadelphia, PA, USA.

F-150 A Differential Pattern of Functions Is Exhibited by Leukocytes Isolated from the Choriodecidua at Term of Human Gestation.

Marisol Castillo-Castrejon, Noemi Meraz-Cruz, Jorge Beltran-Montoya, Martin Viveros-Alcaraz, and Felipe Vasdillo-Ortega. Mexico, DF, Mexico.

F-151 Gene Expression Pattern in Cervix during Spontaneous Preterm Labor.

Aurelija Dubicke, Birgitte Sophie Oxlund, Emma Fransson, Birgitta Bystrom, Lalit Kumar, and Gunvor Ekman-Ordeberg. Stockholm, Sweden and Copenhagen, Denmark.

F-152 Myeloid Differentiation Factor 2 (MD2)

Participates in Matrix Metalloproteinase (MMP)9 and Prostaglandin (PG) E2 Release in InfectionInduced Preterm Birth (PTB).

Antonette T Dulay, Catalin S Buhimschi, Megan E McCarthy, John T Hardy, Ramesha Papanna, Christina M Duzyj, Guomao Zhao, and Irina A Buhimschi. New Haven, CT, USA.

F-153 Direct Electrical Stimulation Softens the Cervix in Pregnant and Nonpregnant Rats.

Dajun Fang, Shao-Qing Shi, Leili Shi, Huishu Liu, and Robert Garfield. Phoenix, AZ, USA and Guangzhou, China.

F-154 Alfa 1 Antitrypsin Activity in Human Amnion Epithelial Cells.

Campolo Federica, Lanzo Gabriele, Ribotta Marisa, and Benedetto Chiara. Turin, Italy.

F-155 Stimulation of PGF2 $\alpha$ Synthesis by Cortisol Via GR-Mediated Increase of CBR1 in Human Amnion Fibroblasts.

CM Guo, K Sun, and L Myatt. TX, USA and Shanghai.

F-156 Fetal Membranes Generate Distinct Cytokine Profiles in Response to Different Bacterial TollLike and Nod-Like Receptor Agonists. Mai Hoang, Julie A Potter, Christina S Han, Seth Guller, Errol R Norwitz, and Vikki M Abrahams. 
F-157 Expression of Calgranulin A in the Fetal Membranes and Placenta in the Presence and Absence of Bacterial DNA. Jenifer A Loudon, Alona Courtney, and Phillip R Bennett. London, United Kingdom.

F-158 Focused Ultrasound Stimulation (FUS) Ripens the Cervix during Pregnancy.

Daishen Luo, Heng Yu, Bruce Towe, Shao-Qing Shi, and Robert Garfield. Tempe, AZ, USA and Phoenix, AZ, USA.

F-159 Magnesium Sulfate and Dexamethasone Inhibit Matrix Metalloproteinase-9 Induced Blood Brain Barrier Degradation. Monica Lutgendorf, Danielle Ippolito, Mary DeHart, Deborah Tinnemore, Brad Dolinsky, and Peter Napolitano. Tacoma, WA, USA.

F-160 LPS-Mediated Preterm Cervical Remodeling Promotes Local Collagen Reorganization Leading to Increased Tissue Compliance. Meredith Akins, Simona Socrate, Kate LubyPhelps, Michael House, and Mala Mahendroo. Dallas, TX, USA; Cambridge, MA, USA and Boston, MA, USA.

F-161 Evaluation of the Mechanism of Pre-Term Delivery Induced by IL-1 $\beta$. Shintaro Makino, Hitomi Okabe, Kiyoko Kato, Tetsunori Inagaki, Akemi Matsumoto, Kikumi Matsuoka, Hiroyuki Seki, and Satoru Takeda. Tokyo, Japan and Saitama, Japan.

F-162 Reactive Oxygen Species (ROS) Induce DNA Damage and Senescence in Human Amniochorionic Membranes and Amnion Cells. Ramkumar Menon, Robert N Taylor, Rheanna Urrabaz-Garza, Talar Kechichian, Tariq A Syed, John Papaconstantinou, George Saade, and Istvan Boldogh.

F-163 Biomechanical and Collagen Crosslinking Relationships in Human Cervical Tissue. K Myers, N Zork, J Vink, K Yoshida, W Yao, M Oyen, M Kim, D Paik, and R Wapner.

F-164 In Vivo Detection of Biochemical Change in the Pregnant Cervix in Humans and Mouse Models. C O'Brien, E Vargis, N Borwn, J Reese, BC Paria, and A Mahadevan-Jansen.

F-165 Strength of the Human Amnion near Term. M Puthiyachirakkal, K Lemerand, B Chung, R Moore, D Kumar, B Mercer, and JJ Moore.

F-166 Caspase-3 Activity Isolated to the Nerves of the Pregnant Cervix Upregulates ECM Remodeling. Caroline Rieser, Michael D House, Karen Florio, Steve Caritis, Hyagriv Simhan, Jeyasuria Panchanratnam, and Jennifer Condon.
$\mathrm{F}-167$

Amnioreduction Does Not Improve Outcome Prior to Rescue Cerclage in Singleton

Pregnancies.

Amanda Roman, Neeraj Desai, Margarita Chudner, Burton Rochelson, Cristina Sison, Adiel Fleischer, and Hima Tam Tam. Manhasset, NY, USA.

F-168 Thrombin-Induced Tissue Factor Expression in Human Decidual Cells Is Not Affected by Enoxaparin.

Michael P Smrtka, Chad A Grotegut, Liping

Feng, and Amy P Murtha. Durham, NC, USA.

F-169 Distribution of Toll-Like Receptor 4 in Preterm Fetal Membranes. Jennifer L Thompson, Brian C Antczak, Liping Feng, Chad A Grotegut, Patrick C Seed, and Amy $P$ Murtha. Durham, NC, USA.

F-170 A microRNA Cluster Downregulates Key Cytostructural Support Elements in the Chorioamnion during Choriodecidual Infection in Macaca nemestrina. Jeroen P Vanderhoeven, Ryan M McAdams, Theo K Bammler, Richard P Beyer, Federico M Farin, Raj P Kapur, Michael G Gravett, Craig E Rubens, and Kristina M Adams Waldorf. and Seattle, WA, USA.

F-171 Inflammatory Signalling in Fetal Membranes:

The Transcriptome of Chorioamnionitis. Gareth J Waring, Stephen C Robson, Judith N Bulmer, and Alison J Tyson-Capper. Newcastle upon Tyne, United Kingdom.

F-172 Collagen V, Important in Assembly of Fibril Collagens, Is Regulated in the Cervix during Pregnancy. Karen Wilson, and Mala Mahendroo. Dallas, TX, USA.

F-173 Correlation between Cervical Tissue Strength and Collagen Crosslink Density in Normal and Disrupted Parturition Mouse Models. K Yoshida, C Reeves, J Kitajewski, N Zork, J Vink, R Wapner, M Kim, D Paik, and K Myers.

\section{NUTRITION, OBESITY, DIABETES I}

F-174 BMI Is Correlated with Low Levels of $25(\mathrm{OH})$

Vitamin D during Pregnancy. Chander P Arora, Brian Yadegari, Payush Chatta, and Calvin J Hobel. Los Angeles, CA, USA.

F-175 First Trimester Maternal Serum C-Reactive Protein as a Predictor of Third Trimester Impaired Glucose Tolerance.

Erica Berggren, Hilary Roeder, Emilia Campbell, Kevin Moss, Stephen Offenbacher, Kim Boggess, and Chad Grotegut. 


\section{Friday, March 22, 2013 - Poster Session II - Bonnett Creek Ballroom}

F-176 Weight Gain in Pregnancy and Neonatal Birth Weight.

Annelee Boyle, Julia Timofeev, Masia Feghali, Sameer Desale, Rita W Driggers, and Menachem Miodovnik. Washington, DC, USA and Hyattsville, MD, USA.

F-177 Association between Air Pollution and Fetal Growth: Effect Modification of Maternal PrePregnancy Body Mass Index.

Marisol Castillo-Castrejon, Melissa M Smarr, Brisa Sanchez, Elizabeth Martinez-Hernandez, Noemi Meraz-Cruz, Marie S O'Neill, Martin Viveros-Alcaraz, and Felipe Vadillo-Ortega. Mexico, DF, Mexico and Ann Arbor, MI, USA.

F-178 Effects of DHA Supplementation during Pregnancy on Fetal Body Composition. Francesca Parisi, Monica Brunetti, Cristiana Berti, llaria V Capriata, Martina I Mazzocco, and Irene Cetin. Milan, Italy.

F-179 Antenatal Dietary and Lifestyle Intervention To Limit Gestational Weight Gain in Women Who Are Overweight or Obese - The LIMIT Randomized Trial.

Jodie M Dodd, Deborah Turnbull, Andrew J McPhee, Andrea R Deussen, Lisa N Yelland, Gary Wittert, and Jeffrey S Robinson. Adelaide, South Australia, Australia and North Adelaide, South Australia, Australia.

F-180 A Healthy Pattern Characterized by High Intake of Vegetables, Fruits, and Vegetable Oils Is Associated with Reduced Risk of Preterm Delivery; Results from a Cohort Study of 60,761 Pregnant Norwegian Women. Linda Englund-Ogge, Bo Jacobsson, Anne-Lise Brantsaeter, and Verena Singpiel. Gothenburg, Sweden and Oslo, Norway.

F-181 Impaired Lipid Transport in Gestational

Diabetes.

Shannon K Flood-Nichols, Monica A Lutgendorf, Peter G Napolitano, and Danielle L Ippolito.

Tacoma, WA, USA.

F-182 Effects of Pre-Pregnancy Maternal Obesityon

Adiponectin Plasma Concentration and

Adipose Tissue Expression.

Lourdes Flores, Angela G Massmann, and Jorge P Figueroa. Winston-Salem, NC, USA.

F-183 Mechanism of Programmed Obesity: Altered Central Insulin Sensitivity in Growth Restricted Juvenile Female Rats. Tatsuya Fukami, Xiaoping Sun, Tie Li, Mina Desai, and Michael G Ross. Torrance, CA, USA and Fukuoka, Japan.

F-184 Can First Trimester PAPP-A, beta-hCG, NT and Maternal Characteristics Improve the Prediction of Gestational Diabetes Mellitus?

Padmalatha Gurram, Kisti Fuller, Peter Benn, Christine Crawford, Garry Turner, and Winston Campbell. Farmington, CT, USA.
F-185

Does the Number of Abnormal Values on the One Step (2 Hour GTT) Correlate with the Severity of Gestational Diabetes? Kimberly Herrera, Lois Brustman, Janelle Foroutan, Katarzyna Suffecool, Sophia Scarpelli, and Barak Rosenn. New York, NY, USA.

F-186 Effects of LMWH Prophylaxis on the Morbidly Obese Pregnant Women. Siti K Ismail, Lucy A Norris, Susan I O'Shea, and John R Higgins. Cork, Ireland and Dublin, Ireland.

F-187 Leptin Levels, Body Mass Index, and Gestational Age at Delivery: A Prospective Case-Control Study. Michelle A Kominiarek, Cecilia T Gambala, Weihua Gao, and Krista Varady.

F-188 Waist to Hip Ratio Versus BMI as Predictor of Obesity Related Pregnancy Outcomes. Mollie A McDonnold. Bethesda, MD, USA.

F-189 Adipose Tissue Architecture and Gestational Weight Gain in Normoglycemic Pregnancies. Tiffany A Moore Simas, Olga Gealekman, NingNing Zhang, Milagros Rosal, Mary Lee, and Silvia Corvera.

F-190 Prenatal Omega-3 Fatty Acid Supplementation Reduces Pro-Inflammatory Cytokine Production in Umbilical Cord Blood: A Secondary Analysis of the Mothers, Omega-3, \& Mental Health Study. Ellen L Mozurkewich, Chelsea M Clinton, Vivian C Romero, Joey Tyner, Steffen Brown, Jennifer Z Williams, Ronald Schrader, and Zora Djuric. Albuquerque, NM, USA; New York, NY, USA; Grand Rapids, MI, USA; Ypsilanti, MI, USA and Ann Arbor, MI, USA.

F-191 Maternal Obesity in the Periconceptional Period Results in Altered Insulin Signalling in Visceral but Not Subcutaneous Fat of the Offspring.

LM Nicholas, L Rattanatray, JL Morrison, SE Ozanne, DO Kleemann, SK Walker, SM McLaughlin, S Zhang, MS Martin-Gronert, and IC McMillen. Australia and United Kingdom.

F-192 Thyroid Dysfunction: A Risk Factor for Gestational Diabetes?

Valentina Sacchi, Maddalena Bozzo, Mona Mansour, Serena Migliaccio, Letizia Laffranchi, and Anna Maria Marconi. Milano, Italy.

F-193 Does Trans-Placental Transfer of Glyburide Affect the Newborn Infant?

Rachelle A Schwartz, Barak M Rosenn, Katarina Aleksa, and Gideon Koren. New York, NY, USA and Toronto, ON, Canada. 


\section{Friday, March 22, 2013 - Poster Session II - Bonnett Creek Ballroom}

F-194 Is Pharmacological Therapy during Induction of Labor in Gestational Diabetes Mellitus Patients Needed?

Ido Sirota, Lois Brustman, Sophia Scarpelli, Mario Vega, and Oded Langer. New York, NY, USA.

F-195 Fetal HDL-Associated ApoM-S1P Complex Mediates Vasoprotective Action on the FetoPlacental Endothelium. In Gestational Diabetes Mellitus (GDM) Endothelial Barrier Integrity Is Impaired.

Ivana Sreckovic, Nicole Sommer, Eva Bernhart, Uwe Lang, Gernot Desoye, and Christian Wadsack. Graz, Austria.

F-196 Does Insulin Detemir Increase the Risk of Excessive Fetal Growth in Pregnant Women with Diabetes?

Katarzyna Suffecool, Barak Rosenn, Janelle Forutan, and Kimberly Herrera. New York, NY, USA.

F-197 Pregnancy Weight Gain and Risk of Hypertensive Disorders in Obese Mothers. Julia Timofeev, Maisa Feghali, Annelee Boyle, Eshetu Tefera, and Rita W Driggers. Washington, DC, USA and Hyattsville, MD, USA.

F-198 Physical Activity in Pregnancy and Maternal Glucose and Insulin in Overweight and Obese Women.

Mireille NM van Poppel, Marelise WM Eekhoff, Maurice JAG Wouters, and Patrick M Catalano. Amsterdam, Netherlands and Cleveland, Oh, USA.

\section{OVARIAN BIOLOGY}

F-199 Peroxynitrite Affects the Metaphase-Il Mouse Oocyte Spindle Structure In Vitro in Presence and Absence of Cumulus Cells. Jashoman Banerjee, Faten Shaeib, Dhiman Maitra, Michael P Diamond, and Husam M AbuSoud. Detroit, MI, USA.

F-200 Hydroxyl Radical and Mouse Oocyte Quality. Jashoman Banerjee, Faten Shaeib, Dhiman Maitra, Michael P Diamond, and Husam M AbuSoud. Detroit, MI, USA.

F-201 Follicular Function in Poor Ovarian Response

- Analysis of Gene Expression in Human Granulosa Cells.

Eran Barzilay, Tomer Drori, Nirit Rubinshtein, Jigal Haas, Gil M Yerushalmi, Ettie Maman, Yuval Yung, and Ariel Hourvitz. Ramat Gan, Israel.
F-202

Dehydroepiandrosterone Alters Lipid Metabolism in the Oocyte Via the Pentose Phosphate Pathway. Natalia M Grindler, Patricia T Jimenez, Alexandra R Willcockson, Maggie M Chi, and Kelle H Moley. St Louis, MO, USA and Dallas, TX, USA.

F-203 microRNAs in the Serum Might Serve as a Biomarker for the Ovulation Process. Iris Eisenberg-Loebl, Nibal Bashir, Caryn Greenfield, Debar Goldman-Wohl, Ronit Haimov-Kochman, Arye Hurwitz, Simcha Yagel, and Tal Imbar. Jerusalem, Israel.

F-204 Differential Expression of microRNAs in the Granulosa Lutein Cells of Anovulatory and Ovulatory Women.

Nibal Bashir, Iris Eisenberg, Caryn Greenfield, Debra Goldman-Wohl, Ronit Haimov-Kochman, Arye Hurwitz, Simcha Yagel, and Tal Imbar. Jerusalem, Israel.

F-205 Weight Fluctuations Induce Opposing Changes in Luteal Molecular Signals in Vervet Monkeys. Satu Kuokkanen, Alex J Polotsky, Justin Chosich, Andrew Bradford, Anna Jasinska, Tzu Phang, Nanette Santoro, and Susan Appt.

F-206 Down Regulation of Anti Mullerian Hormone Receptor Type II Expression in Human Granulosa Cells Correlates with Oocytes Fertilization Capacity. Ettie Maman, Nirit Rubenstein, Yuval Yung, Libby Shalev, and Ariel Hourvitz. Ramat Gan, Israel and Tel Aviv, Israel.

F-207 Oxygen Consumption of Human Granulosa Cells and Impact on Follicular Oxygen Levels. Gabe P Redding, and John E Bronlund. Palmerston North, New Zealand.

F-208 Endothelial Growth Factor (VEGF) Gene Expression in Human Luteinizing Granulosa Cells.

Li Hou, Antonio CM Francisco, Robert N Taylor, and Tamer M Yalcinkaya. Winston-Salem, NC, USA.

F-209 Vascular Endothelial Growth Factor (VEGF) Is Regulated by Gonadotropins in Luteinizing Granulosa Cells (GC) through Protein Kinase A (PKA) Independent Pathways.

Li Hou, Antonio CM Francisco, Robert N Taylor, and Tamer M Yalcinkaya. Winston-Salem, NC, USA. 


\section{Friday, March 22, 2013 - Poster Session II - Bonnett Creek Ballroom}

\section{PLACENTA}

F-210 Is There an Association between Abnormal Cord Insertion and Serum Analytes in Singletons?

Tharwat Stewart F Boulis, Burton Rochelson, Morris Edelman, David Krantz, Lisa Rosen, and Nidhi Vohra. Manhasset, NY, USA and Melville, NY, USA.

F-211 Is There an Association between Serum Markers and Concordant or Discordant Velamentous/Marginal Cord Insertion in Twins? Tharwat Stewart F Boulis, David Krantz, Lisa Rosen, and Morris Edelman. Manhasset, NY, USA and Melville, NY, USA.

F-212 Characterization of the Protein C Pathway in Trophoblasts from First Trimester Pregnancies. Evita Calvi, Gessica Fontana, Elena M Faioni, Laura Avagliano, Gaetano Bulfamante, and Anna Maria Marconi. Milano, Italy.

F-213 Decidua-Placental Interface Show Abnormal Epigenetic Profiles in Common Aneuploidies. Sahar Houshdaran, Hannah Tilden, and Katherine Bianco. San Francisco, CA, USA.

F-214 Effects of Low Molecular Weight Heparin on the Uteroplacental Compartment. Siti K Ismail, Lucy A Norris, Lynne Kellly, and John R Higgins. Cork, Ireland and Dublin, Ireland.

F-215 Smoking-Related Changes to Placental DNA Methylation Are Associated with Gestational Age.

Jennifer Z Joukhadar, Devin C Koestler, Karl T Kelsey, and Carmen J Marsit. Providence, RI, USA and Hanover, NH, USA.

F-216 Vascular Network Features, Excluding Anastomotic Communications, Account for Birthweight Discordance in Monochorionic TTTS Placentas.

Moni Kaneti, Carolyn M Salafia, Enrico Lopriore, Theresa Girardi, and Nadav Schwartz. Staten Island, NY, USA; Leiden, Netherlands; Larchmont, NY, USA and Pennsylvania, PA, USA.

F-217 Diet-Induced Obesity in Mice Reduces Placental Efficiency and mTOR Signaling.

Susanne Lager, Anne-Maj Samuelsson, Paul D Taylor, Lucilla Poston, Theresa L Powell, and Thomas Jansson. San Antonio, TX, USA and London, United Kingdom.

F-218 Vascular Growth and Endothelial Junction Protein Expression in Human Placentas from the First Trimester, Normal Term and Preeclamptic Pregnancies. Yan Li, Ying-jie Zhao, Qingyun Zou, Kevin Zhang, Kai Wang, and Jing Zheng. Madison, WI, USA; Chicago, IL, USA and Shanghai, China.
F-219

Effect of Fetal Gender and Maternal Obesity on Mitochondrial Biogenesis Genes in Human Placenta.

J Mele, A Maloyan, and L Myatt. San Antonio, TX, USA.

F-220 Autophagy Plays a Pivotal Role in Regulating Susceptibility of Human Trophoblasts to Infection.

Bin Cao, and Indira U Mysorekar. St. Louis, MO, USA.

F-221 Placental Metabolic Reprogramming: Is Hypoxic Up-Regulation of Pyruvate Dehydrogenase Kinase-1 a Part of the Mechanism? Joseph Panza, Stacy Zamudio, and Nicholas P Illsley. Grenada and Hackensack, NJ, USA.

F-222 Abnormal Uterine Artery Doppler Velocimetry Is Associated with Pathologic Markers of Placental Insufficiency in Patients with Abnormal Analytes.

Hilary A Roeder, Sandra M Leon-Garcia, Lynlee $M$ Wolfe, D Yvette Lacoursiere, Douglas A Woelkers, Louise C Laurent, and Mana M Parast. San Diego, CA, USA.

F-223 Regulation of Voltage-Gated Channel $\left(\mathrm{K}_{\mathrm{v}}\right)$ Expression in Ovine Reproductive and Nonreproductive Arteries during Pregnancy. Charles R Rosenfeld, and Xiao-tie Liu. Dallas, TX, USA.

F-224 Evidence for Population Differences in Placental Morphology: A Preliminary Report from Cebu, Philippines. Julienne N Rutherford, Victoria A DeMartelly, Nanette R Lee, Derek E Wildman, and Christopher W Kuzawa. Chicago, IL, USA; Cebu City, Cebu, Philippines; Detroit, MI, USA and Evanston, IL, USA.

F-225 A microRNA Expression Profile of Normal Placental Development. Mark K Santillan, Eric J Devor, Kimberly K Leslie, Stephen K Hunter, and Donna A Santillan. lowa City, IA, USA.

F-226 Mathematical Modelling of Amino Acid Transport across the Microvillous Plasma Membrane of the Placental Syncytiotrophoblast. K Widdows, N Panitchob, I Crocker, S Brooks, E Johnstone, C Please, C Sibley, B Sengers, J Glazier, and R Lewis. United Kingdom.

\section{PREECLAMPSIA AND RELATED DISORDERS}

F-227 Liver Problems during Pregnancy. Sagi Amzallag, Mati Shnell, Nitsan Maharshak, Eliyahu Rimon, Nadav Michaan, Ido Laskov, Shira Zelber-Sagi, Michael Kupfermintz, Joseph Lessing, and Ran Oren. Tel Aviv, Israel and Jerusalem, Israel. 
F-228 Sildenafil Therapy Alters the Aberrant Metabolomic Profile in a Mouse Model of Preeclampsia/Fetal Growth Restriction. Philip N Baker, Wen Hong, Joanna L Stanley, Irene J Andersson, Colin Sibley, Sandra Davidge, Louise C Kenny, Rupasri Mandal, David Wishart, and David Broadhurst. ; Canada; China; United Kingdom; Ireland and New Zealand.

F-229 SUMO and SENP3 Regulation of HIF-1a Stability and Activity in Placental Development and Preeclampsia.

Jayonta Bhattacharjee, and Isabella Caniggia. ON, Canada.

F-230 Effects of Prior Pre-Eclampsia on First Trimester Maternal Blood Pressure and Placental Development. Dana Block-Abraham, Ozhan Turan, Robert Atlas, Jerome Kopelman, Chuka Jenkins, Lauren Doyle, Christopher Harman, and Ahmet Baschat.

F-231 Identification, Origin and Molecular Modeling of the Preeclampsia Amylome.

Irina A Buhimschi, Lydia Shook, Unzila A Nayeri, Christina Duzyj, Guomao Zhao, and Catalin S Buhimschi. New Haven, CT, USA.

F-232 Developing Novel Therapeutics for Preeclampsia.

Bertha Campo, Emiel D Post Uiterweer, and Kirk P Conrad. Gainesville, FL, USA and Utrecht, Netherlands.

F-233 Lab Abnormalities in Pregnancy-Associated Hypertension: Frequency and Impact on Pregnancy Outcomes. Jessica Cantu. Bethesda, MD, USA.

F-234 Subsequent Outcomes after Preeclampsia (SOAP). Suchitra Chandrasekaran, Sindhu K Srinivas, and Michal A Elovitz. Philadelphia, PA, USA.

F-235 Differential Urinary Protein Expression between Women with Pre-Eclampsia at Time-of-Disease and Healthy Controls.

Kate Bramham, Hiten D Mistry, Andrew J Weston, Steve Lynham, Malcolm A Ward, Lucilla Poston, and Lucy C Chappell. London, United Kingdom.

F-236 Preeclampsia Is Associated with Decreased Expression of Intermedin: Potential Angiogenic Role of Intermedin.

Madhu Chauhan, Rexanna Chan, Meena Balakrishnan, and Chandra Yallampalli. Galveston, TX, USA.
F-237

Downregulation of Cystathionine y-Lyase (CSE) in Pre-Eclampsia in Placentas with Abnormal Umbilical Artery Doppler Waveforms and Its Potential Regulation by microRNA-21. T Cindrova-Davies, EA Herrera, J Kingdom, DA Giussani, and GJ Burton. United Kingdom; Chile and Canada.

F-238 Pregnancy Complicated by Chronic Hypertension: A State of Vitamin D Deficiency and Immune Activation. Marie Darby, Kedra Wallace, Janae Moseley, James N Martin, Michelle Owens, and Babbette LaMarca. Jackson, MS, USA.

F-239 Renin-Angiotensin System (RAS)

Overexpression Increases Placental Injury and Maternal Mortality Rate.

Jeffrey M Denney, Cynthia E Shaw, Annette Gendron-Fitzpatrick, and Dinesh M Shaw. Madison, WI, USA.

F-240 Meta-Analysis of Pre-Eclampsia Microarray Data.

Justyna A Dopierala, Gordon C Smith, and Stephen D Charnock-Jones. Cambridge, United Kingdom.

F-241 Elevated Systemic Vascular Resistance Correlates with Circulating sFlt-1 and Precedes the Development of Severe Early-Onset Preeclampsia.

Sascha Drewlo, Anne Doherty, Afif El-Khuffash, Kristie Downie, Madelaine Dodds, Jose Carvalho, and John Kingdom. Toronto, ON, Canada.

F-242 Placental STOX1 Y153H Mutation Is Associated with Severe Early Onset Preeclampsia.

Caroline Dunk, Marie Van-Djik, and Stephen $\mathrm{J}$ Lye. Toronto, ON, Canada and Amsterdam, Netherlands.

F-243 Stromal Cell-Derived Factor-1 (SDF-1) Is Significantly Elevated in Obesity and Associated with Hypoxic and Fibrotic Adipose Tissue. Julia V Gefter, Robin E Gandley, Stacy McGonigal, and Robert W Powers. Pittsburgh, PA, USA.

F-244 Obesity Increases Circulating Endothelial Progenitor Cells in Human and Mouse Pregnancy. Julia V Gefter, Marlise Franke-Snyder, Robert W Powers, and Carl A Hubel. Pittsburgh, PA, USA.

F-245 Aromatase Pathway Is Altered in Patients That Develop Preeclampsia (PE).

Pedro P Espana-Perrot, Alejandra PerezSepulveda, Ximena B Fernandez, Alejandra Guzman, Francisca Mena, Isabel Gonzalez, Javier Caradeux, and Sebastian E Illanes. Santiago, Chile. 


\section{Friday, March 22, 2013 - Poster Session II - Bonnett Creek Ballroom}

F-246 The Development of New Onset Preeclampsia in the Postpartum Period: Are We Missing Something?

Mary K Johnson, Danielle Tate, Luis Gomez, Brian Brocato, and Giancarlo Mari. Memphis, TN, USA.

F-247 Preeclampsia-Related Toll Receptor-4 Expression in Decidual Cells across Pregnancy. UA Kayisli, M Basar, N Ocak, E Vatandaslar, S Faramarzi, F Schatz, and CJ Lockwood. Columbus, OH, USA.

F-248 NMR Profiling in Early Pregnancy Reveals a Metabolomic Signature the Predicts the Subsequent Development Preeclampsia. Louise C Kenny, David I Broadhurst, Wen Hong, Joanna Stanley, Irene Andersson, Christian Rueda-Clausen, Ruparsi Mandal, David Wishart, and Philip N Baker. Cork, Ireland.

F-249 The Impact of Vitamin D Status in Early Pregnancy on Later Uteroplacental Dysfunction.

Ali S Khashan, Mairead Kiely, Joy Y Zhang, Michael Kinsella, and Louise C Kenny. Ireland.

F-250 Rosiglitazone-Mediated Activation of PPAR- $\gamma$ Promotes HO-1 Induction in BeWo Cells: Implications for the Pathogenesis and Treatment of Severe Pre-Eclampsia. Khrystyna Levytska, Sascha Drewlo, Dora Baczyk, and John CP Kingdom. and ON, Canada.

F-251 The Influence of Vaccinium angustifolium Var. laevifolium House (Ericaceae) Extracts on Trophoblast Biology.

Christina Ly, Julien Yockell-Lelievre, Jonathan Ferrier, Lana Saciragic, Ammar Saleem, John T Arnason, and Andree Gruslin.

F-252 Pregnancy-Induced Hypertension Model Mouse Using CD40L Gene Delivery.

Yuko Matsubara, Keiichi Matsubara, Miki Mori, and Yuka Uchikura. Toon, Ehime, Japan.

F-253 Peroxisome Proliferator Activated Receptor Gamma and Cardiac Remodelling in an Animal Model of Preeclampsia.

Aoife C Delany, Sarah K Walsh, Louise C Kenny, and Fergus P McCarthy. Ireland and United Kingdom.

F-254 Differences in Brain Water Diffusion as Quantified by MRI in Women with a History of Preterm Preeclampsia as Compared to Nulliparous Patients.

Erin Morris, Richard Watts, Christopher Fillippi, Carole McBride, Sara Hale, Marilyn Cipolla, and Ira Bernstein. and Burlington, VT, USA.

F-255 Identification of Different Phenotypes of Preeclampsia by Clustering Analysis of Biomarker Profiles.

Leslie Myatt. Bethesda, MD, USA.
F-256 Relationship of Inflammatory Biomarkers in Preeclampsia to BMI. Leslie Myatt. Bethesda, MD, USA.

F-257 Epigenetic Regulation of Interleukin-17 Cytokines and Their Role in Neutrophil Infiltration in Preeclampsia.

William H Nugent, Sonya L Washington, Jerome F Strauss III, and Scott W Walsh. Richmond, VA, USA.

F-258 JunB/Cyclin-D1 Unbalance Inhibits Cell Proliferation in Preeclamptic Placental Mesenchymal Stromal Cells. Anna Maria Nuzzo, Domenica Giuffrida, Tullia Todros, and Alessandro Rolfo. Turin, Italy.

F-259 Eclampsia Characteristics and Maternal Outcomes Based on Onset of the Disease. Mauro H Schenone, Dorothy Miller, Jacques E Samson, and Giancarlo Mari. Memphis, TN, USA.

F-260 Role of Matrix Metalloproteinase-14 (MMP-14) in Trophoblast Invasion and Preeclampsia. Serkalem Tadesse, Tianmeng Luo, Vikki Abrahams, Seth Guller, Paolo Toti, Felice Arcuri, Errol Norwitz, and Anika Agarwal. Boston, MA, USA; New Haven, CT, USA and Siena, Italy.

F-261 Is Delivery of the Placenta Really the End? A Look into Postpartum Persistence of Hypertensive Disorders.

Danielle Tate, Mary K Johnson, Luis Gomez, Brian Brocato, and Giancarlo Mari. Memphis, TN, USA.

F-262 The LincRNA Associated with the HELLP. Syndrome Functions in the Trophoblast Cell Cycle.

Marie Van Dijk, Hari K Thulluru, Sandra Windhorst, Gunilla Kleiverda, Daoud Sie, and Cees BM Oudejans. Amsterdam, Netherlands and Almere, Netherlands.

F-263 Haptoglobin Phenotype, Preeclampsia Risk and Response to Vitamin C and E Supplementation in Pregnant Women with Type 1 Diabetes. Tracey L Weissgerber, Robin E Gandley, James M Roberts, Christopher C Patterson, Valerie A Holmes, lan S Young, and David R McCance. ; USA; Belfast and Belfast, United Kingdom.

F-264 Involvement of Specific Receptor Activity Modifying Protein (RAMP) in Mesenteric Artery Smooth Muscle Cells in cAMP Generation in Response to the CGRP-Family Peptides. Chandra Yallampalli, Uma Yallampalli, and Madhu Chauhan. Galveston, TX, USA.

F-265 Circulating and Endothelial Cell-Derived Factors Deregulate Podocyte Functional Protein Expression in Preeclampsia. Shuang Zhao, Yang Gu, Lynn J Groome, and Yuping Wang. Shreveport, LA, USA. 
F-266 Urinary Nephrin and Podocalyxin Concentrations before and after Delivery in Normal and Preeclamptic Pregnant Women: Evidence of Kidney Podocyte Function Recovery Postpartum in Women with Preeclampsia.

Shuang Zhao, Yang Gu, Susan Loyd, Lynn J Groome, and Yuping Wang. Shreveport, LA, USA.

\section{REPRODUCTIVE ENDOCRINOLOGY}

F-267 Impact of Subclinical Hypothyroidism in Women with Recurrent Pregnancy Loss.

Lia A Bernardi, Ronald N Cohen, and Mary D Stephenson. Chicago, IL, USA.

F-268 Modulation of Cx43 by Retinoic Acid in Human Granulosa Cells.

Monica W Best, and Neil Sidell. Atlanta, GA, USA.

F-269 Testosterone Upregulates PKCס in Mesenteric Arterial Smooth Muscle Cells through Novel Androgen Response Elements.

Chellakkan S Blesson, Chandra Yallampalli, and Kunju Sathishkumar. Galveston, TX, USA.

F-270 Effect of Biologic pH Buffers on the Rate of Embryo Development and Blastocyst Size. Natalie A Clark, Matthew Will, and Jason E Swain.

F-271 Downregulation of LH Receptor mRNA in Response to hCG Treatment To Mimic Preovulatory LH Surge Is Coupled to Suppression of VEGF-A mRNA Expression in Rat Ovaries.

Sonia Hovelson, Bindu Menon, Helle Peegel, and KMJ Menon. Ann Arbor, MI, USA.

F-272 Effect of the Anti-Androgenic Endocrine Disruptor Vinclozolin on Human CYP3A4 Expression In Vitro.

Oumar Kuzbari, John G Lamb, Ahmad Hammoud, Erica B Johnstone, Michael R Franklin, and C Matthew Peterson. Salt Lake City, UT, USA.

F-273 Chronic Endometritis in Patients with Recurrent Pregnancy Loss or Fetal Miscarriage.

Dana B McQueen, Lia A Bernardi, and Mary D Stephenson. Chicago, IL, USA. 


\section{CANCER BIOLOGY, RESPONSE, MODULATORS}

S-001 Ulipristal Acetate Does Not Predispose the Fallopian Tube Epithelium to Neoplastic Changes. Jeris Cox, Mary Egbuniwe, Gary Levy, Alicia Armstrong, Jennifer Drieling, and Lynnette Neiman. Bethesda, MD, USA and New York, NY, USA.

S-002 The Histone Demethylase JMJD2B Regulates Genes That Contribute to General Tumorigenesis and to Progression of Ovarian Serous Adenocarcinoma.

Lei Qiu, Yan Hong, Jacob New, Ying Mu, Judith Chapman, Amato J Giaccia, and Adam J Krieg. Kansas City, KS, USA; Manhattan, KS, USA and Stanford, CA, USA.

S-003 MiR-200c Can Mediate Either Poor or Good Outcome in Ovarian Cancer Depending on HuR Pattern of Staining.

Marisa Mariani, Steven Seiber, Robert

Samuelson, Cristiano Ferlini, and Shoreh

Shahabi. Danbury, CT, USA.

S-004 Fourteen Day Exposure to Palliative

Medicine Consultation Results in Decreased Aggressiveness in End-of-Life Care for Women with Gynecologic Malignancies.

Nicole S Nevadunsky, Gordon Sharon, Lori Spoozak, Anne Van Arsdale, and Goldberg G Gary. Bronx, NY, USA.

S-005 Chronic Maternal Protein Deprivation Affects Body Composition and Energy Expenditure of Adult Male Offspring.

A Balasa, M Fiorotto, and I Van den Veyver. and Houston, TX, USA.

S-006 Chronic Maternal Protein Deprivation Causes Anxiety-Like Traits in Adult Male Offspring Mice.

A Balasa, and I Van den Veyver. and Houston, TX, USA.

\section{CERVIX}

S-007 Untreated High-Grade Cervical Intra-Epithelial Lesions: Is There a Role for the Use of HPVRelated Biomarkers? Maria Kyrgiou, Katerina Papakonstantinou, George Valasoulis, Miranda Cowen, Sofia Melina Stasinou, Petros Karakitsos, Sadaf Ghaem-Maghami, Deidre Lyons, and Evangelos Paraskevaidis. London, United Kingdom; Ioannina, Greece and Athens, Greece.
S-008 Proportion of Excision, Cervical Healing and Pregnancy Outcomes after Large Loop Excision of the Transformation Zone for Cervical Intraepithelial Neoplasia.

Maria Kyrgiou, Christina Founta, George Valasoulis, Sofia Melina Stasinou, Pierre MartinHirsch, Marc Arbyn, Sadaf Ghaem-Maghami, Phillip Bennett, and Evangelos Paraskevaidis. London, United Kingdom; loannina, Greece; Preston, United Kingdom and Brussels, Belgium.

\section{DEVELOPMENTAL ORIGINS OF HEALTH III}

S-009 Transcriptome Analysis of the Hypothalamus of 21-Day and 1-Year Old Male Mice Exposed to Chronic Maternal Protein Deprivation during Early Development.

A Balasa, C Dove, AAnders, G Allen, and I Van den Veyver. and Houston, TX, USA.

S-010 Differences in Vulnerable Periods for Programming of Hypothalamic Pituitary Adrenal Axis (HPAA) Acitivity, Neuropsychiatric and Cerebrovascular Disorders in Rats. C Bergmeier, M Schulze, S Rupprecht, OW Witte, and M Schwab. Germany.

S-011 Prenatal Resveratrol Treatment Fails To Prevent the Development of Hypertension in the Spontaneously Hypertensive Rat.

Stephane L Bourque, Miranda Sung, Jason RB Dyck, and Sandra T Davidge. Edmonton, AB, Canada.

S-012 Negative Effects of Antenatal Betamethasone Treatment in Twin Pregnancies. Thorsten Braun, Hanna Gil, Boris Tutschek, Deborah Sloboda, Thomas Harder, Andreas Plagemann, and Wolfgang Henrich. Berlin; Hamilton and Düsseldorf.

S-013 Gender Differences in Effects of Prenatal Betamethasone Exposure on Sheep Renal ACE and ACE2 Activity: A Possible Mechanism in Fetal Programmed Hypertension in Males. Kai Chen, Jianli Bi, Jorge Figueroa, Mark Chappell, and James Rose.

S-014 Maternal Malnutrition Impacts Fetoplacental Growth and Placental Fatty Acid Transport in Late Gestation.

KL Connor, M Lee, R Maganga, E Bloise, and SJ Lye.

S-015 Renal Markers of Senescence Are Differentially Increased in Male and Female IUGR Rats Exposed to Postnatal Nutritional Mismatch. Christy-Lynn Cooke, Lin Zhao, Edith Arany, Dean Betts, and Timothy Regnault. and London, Canada. 
S-016 Vascular Endothelial Growth Factor $\left(\right.$ VEGF $\left._{165}\right)$ Isoform Expression in Amnion of Human Subjects with Normal and Complicated Pregnancies.

Amy E Doss, Michael K Beardall, Robert A Brace, and Cecilia Y Cheung. Portland, OR, USA.

S-017 Effects of an Early Maternal Dietary Intervention during Maternal Overnutrition/Obesity (MO) on Maternal and Fetal Hypothalamic-PituitaryAdrenal Axis (HPAA) Activity. Stephen P Ford, Tursunjan Nurmamat, John F Odhiambo, and Peter W Nathanielsz. Laramie, WY, USA and San Antonio, TX, USA.

S-018 Maternal Pre-Pregnancy BMI Predicts Neonatal Hepatic Fat in Obese GDM Women. David E Brumbaugh, Phillip Tease, Melane Cree-Green, Ann Scherzinger, Regina Reynolds, Camille Hoffman, Linda A Barbour, and Jacob E Friedman. Aurora, CO, USA.

S-019 Gestational Protein Restriction Increases Angiotensin II Production in Rat Lung. Haijun Gao, Uma Yallampalli, and Chandra Yallampalli. Galveston, TX, USA.

S-020 Low Protein Diet Biphasically Regulates Appetite during Pregnancy with Gut Hormones Being Involved in Late Pregnant Rat. Haijun Gao, Uma Yallampalli, Meena Balakrishnan, and Chandra Yallampalli. Galveston, TX, USA.

S-021 Elevated Hepatic miR-29 Expression in Male Growth Restricted Rats Is Inversely Correlated with Its Target Insulin-Like Growth Factor 1 (IGF-1) Long-Term.

Andrew Revesz, Gurjeev Sohi, Thin Vo, Noelle L $\mathrm{Ma}$, and Daniel B Hardy. London, ON, Canada.

S-022 High Fat Diet and IUGR Alter mRNA Levels of PPAR $\gamma$ and Setd8 in a Sex-Dependent Matter in Newborn Rat Lung. S Ashmore, S Shupe, C Wilson, Y Wang, C Jiang, A Sainz, E Zinkhan, R Lane, and L JossMoore.

S-023 IUGR Affects Elastin Alternative Splicing and DNA Exon Methylation in Newborn Rat Lung. L Joss-Moore, Y Wang, C Jiang, A Saniz, J Stiers, K Albertine, and R Lane.

S-024 Effects of Maternal Nutrient Restriction on Key Gluconeogenic Enzyme Phosphoenolpyruvate Carboxykinase (PEPCK)-1 and -2 Expression in Fetal Baboon Hepatocytes.

Cun Li, Zhen-Ju Shu, Laura A Cox, Peter W Nathanielsz, and Amrita Kamat. San Antonio, TX, USA.
Maternal Undernutrition Alters VEGF Receptor Coupling to Cytosolic Signaling Pathways in Offspring Microvascular Endothelial Cells. Omid A Khorram, Guang Han, and William J Pearce.

S-026 Intrauterine Growth Restriction (IUGR) in Baboon Pregnancy Alters Key Regulatory Factors in Fetal Pancreatic Proliferation and Differentiation.

Cun Li, Dongbin Xie, Mark J Nijland, Thomas J McDonald, and Peter W Nathanielsz. San Antonio, TX, USA.

S-027 Maternal Nicotine Exposure Leads to Elevated Triglycerides in Adult Rat Offspring: The Role of the Liver X Receptor (LXR $\alpha$ ). Noelle L Ma, Michael Wong, Catherine J Nicholson, Alison C Holloway, and Daniel B Hardy. London, ON, Canada and Hamilton, ON, Canada.

S-028 Dietary Intervention in Early Pregnancy Reduces the Negative Impacts of Obesity/ Overnutrition on Fetal Growth and Organ Development, and Improves Glucose-Insulin Dynamics in Late Gestation.

Tursunjan Nurmamat, John F Odhiambo, Peter W Nathanielsz, and Stephen P Ford. Laramie, WY, USA and San Antonio, TX, USA.

S-029 Perinatal Polychlorinated Biphenyl Exposure Impairs Offspring Glucose Homeostasis in a Sex-Specific Manner. Cetewayo S Rashid, Kisten M Platt, Lindsay G Carter, and Kevin J Pearson. Lexington, KY, USA.

S-030 Exercise as a Therapeutic Approach for FetalProgrammed Cardiovascular Dysfunction. Laura M Reyes, Jude S Morton, Raven Kirschenman, and Sandra T Davidge. Edmonton, $A B$, Canada.

S-031 Beta $(\beta)$ and Alpha ( $\alpha)$ Cells in Islets of Female Rat Offspring (OFF) Exposed to a Maternal (M) Restricted (R) Low Protein (LP) Diet in Pregnancy. Lizbeth Calzada, Angelica Morales, Mara A Cadenas-Rodriguez, Tonantzin C Sosa, Luis A Reyes-Castro, Guadalupe L RodriguezGonzalez, Peter W Nathanielsz, Elena Zambrano, and Sumiko Morimoto. Mexico, DF, Mexico and San Antonio, TX, USA.

\section{FERTILITY PRESERVATION}

S-032 Goserelin for the Prevention of Cyclophosphamide-Induced Ovarian Damage in Pre-Pubertal Mice. Laura Detti, Jie Zhang, Meifen Lu, Lucy J Williams, Shelby E Osborne, and Rebecca A Uhlmann. Memphis, TN, USA. 
S-033 Acute Cyclophosphamide-Induced Effects on Pre-Pubertal Mice Ovaries. Laura Detti, Rebecca A Uhlmann, Lucy J Williams, Meifen Lu, and Jie Zhang. Memphis, TN, USA.

S-034 New Molecular Markers To Detect Occult Metastases in Ovarian Cortex from Breast Cancer Patients.

Sonia Herraiz, Beatriz Rodriguez, Cesar Diaz, Ana Santaballa, Francisco Vera, Ester Rosello, Maria Sanchez-Serrano, and Antonio Pellicer. Valencia, Spain and Spain.

S-035 Fertility Preservation Decision Making in an Urban Patient Population: Do Disparities Exist? Jennifer E Hirshfeld-Cytron, Nichola Winston, and Bert Scoccia. Chicago, IL, USA.

S-036 Fertility Preservation Outcomes May Differ by Cancer Diagnosis. Mary Ellen Pavone, Jennifer Hirshfeld-Cytron, Angela Lawson, Kristen Smith, and Susan Klock. Chicago, IL, USA.

S-037 The Practice of Fertility Preservation: A National Provider Survey. Kasey Reynolds, Natalia Grindler, Amber Cooper, Valerie Ratts, and Emily Jungheim. St. Louis, MO, USA.

S-038 Characterization of the Gonadotropin Releasing Hormone Response in the Ovary. Saioa Torrealday, Ozlem Guzeloglu-Kayisli, Maria Lalioti, and Emre Seli. New Haven, CT, USA and Columbus, $\mathrm{OH}, \mathrm{USA}$.

S-039 Investigating the Role of Apoptosis in the Chemoprotection Effect of GnRH Antagonist. Bo Yu, Snezana Haymes, Yaling Zhou, Gary Levy, James Segars, and Alicia Armstrong. Bethesda, MD, USA.

\section{FETUS}

S-040 How Does the TEI Indice Correlate with Bile Acid Levels in Women with Intrahepatic Cholestasis of Pregnancy? Kelly Cummings, Ryan Stone, and David Chaffin. Huntington, WV, USA.

S-041 Perinatal Intra-Cranial Gene Transfer for Permanent Astrocyte Specific Expression in Mice.

Rajvinder Karda, Simon N Waddington, and Mark R Johnson. United Kingdom.

S-042 Beneficial Effects of Resveratrol in Transgenic Murine Models of Preeclampsia and Fetal Growth Restriction. Rajan Poudel, Joanna L Stanley, Christian F Reuda-Clausen, Irene J Andersson, Colin P Sibley, Sandra T Davidge, and Philip N Baker. Canada and United Kingdom.
S-043 Cortisol Independent Transfer of Maternal Stress Effects to the Fetus.

F Rakers, SJ Bischoff, R Schiffner, S Rupprecht, M Haase, H Schubert, PW Nathanielsz, and M Schwab. Germany and USA.

\section{GENETICS, TERATOLOGY, PRENATAL DIAGNOSIS}

S-044 Diagnosis of Congenital Heart Disease: Evolution of Cardiac Defects Identified in the First Trimester. Maria Chiara Autuori, Maria Bellotti, Giulia C Rognoni, Arianna Prada, Cinzia L Paolini, and Anna Maria Marconi. Milano, Italy.

S-045 New Frontiers in Fetal Imaging: Magnetic Resonance - Ultrasonography Collaboration Team.

Itai Gat, Chen Hoffmann, Lisa Zilka, Elli Konen, Reuven Achiron, and Eldad Katorza. Ramat Gan, Israel.

S-046 Dilation and Evacuation Compared to Induction of Labor for Midtrimester Termination: A Cohort Study of Postmortem Analysis. Ann Lal, Weihua Gao, and Nicole Sprawka.

S-047 Ultrasound Screening for Cardiac and Extracardiac Malformations at the Time of Nuchal Translucency [NT] To Identify Fetuses at Risk for Chromosomal Anomalies. Maria Bellotti, Serena Migliaccio, Elisa Matarazzo, Jennifer Grazia Lara Riparini, Piero Bruzzese, and Anna Maria Marconi. Milano, Italy.

S-048 7-Dehydrocholesterol Reductase Gene Mutations and Stillbirth.

Robert Silver, and For the Stillbirth Collaborative Research Network. Salt Lake City, UT, USA and Rockville, MD, USA.

S-049 Effects of Chronic Binge Alcohol during Pregnancy on Maternal Uterine Endothelial Adaptations. K Subramanian, K Sathishkumar, VD Naik, C Yallampalli, and J Ramadoss.

S-050 Increased Amount of Chorionic Villi Obtained by Chorionic Villus Sampling within a Single Center Compared to Previously Published Reports.

Atena Asiaii, Margaret Myers, Adam Wolfberg, and Neeta L Vora. Cambridge, MA, USA; Boston, MA, USA and Chapel Hill, NC, USA.

S-051 SOD1 Overexpression Blocks Maternal Diabetes-Induced Endoplasmic Reticulum Stress in Diabetic Embryopathy. Fang Wang, Xuezheng Li, and Peixin Yang. Baltimore, MD, USA. 
S-052 Comparison of Simplex and Duplex Real-Time PCR Strategies in Fetal RhD Genotyping with Maternal Dry Blood Spot.

Yali Xiong, Indhu M Prabhakaran, Eliezer J Holtzman, Dan A Liebermann, Barbara Hoffman, Stacey Jeronis, and Ossie Geifman-Holtzman. Philadelphia, PA, USA; Tel Hashomer, Israel and Phialdelphia, PA, USA.

S-053 RNASeq and Microarray Analyses Highlight Different Aspects of the Fetal Transcriptome. Lillian M Zwemer, Lisa Hui, Heather C Wick, and Diana W Bianchi. Boston, MA, USA; Australia and Medford, MA, USA.

\section{GROWTH, METABOLISM AND TRANSPORT}

S-054 Placental Glucose Transporter Expression and Activity in Relation to Maternal BMI and Fetal Growth.

Ometeotl Acosta, Susanne Lager, Donald Dudley, Theresa L Powell, and Thomas Jansson. San Antonio, TX, USA.

S-055 Placental Transient Receptor Potential Vanilloid 6 (TRPV6) in Pre-Eclampsia.

Camilla A Marini, Benjamin P Luescher, Ruth Sager, Christiane Albrecht, Matthias A Hediger, Daniel V Surbek, and Marc U Baumann. Bern, Switzerland.

S-056 Regional Distribution and Differential Expression of Aquaporins in Human Amnion. Amy $\mathrm{E}$ Doss, Michael K Beardall, Cecilia Y Cheung, and Robert A Brace. Portland, OR, USA.

S-057 Maternal Obesity during Pregnancy Induces Nitrosative Stress in Mitochondria in the Human Placenta.

LaShauna Evans, and Leslie Myatt.

S-058 Maternal Obesity Activates Placental mTOR Signaling and Increases Fetal Growth in Rats. F Gaccioli, V White, A Jawerbaum, TL Powell, and T Jansson. San Antonio, TX, USA and Argentina.

S-059 Transcription Profiling of Autophagy

Associated Genes in the Placenta of Preeclampsia.

Ronit Haimov-Kochman, Tamar Cesla, Caryn Greenfield, Yoav Smith, Simcha Yagel, and Debra Goldman-Wohl. Jerusalem.

S-060 Altered Lipid Accumulation in Mouse Placentas Following Generalized Disruption of Genomic Imprints.

Katherine P Himes, Megan Campbell, Erik Koppes, and Richard Chaillet. Pittsburgh, PA, USA and North Field, MN, USA.
S-061 Regulation of Multidrug Resistance in Term Human Placental Explants in Culture. Mohsen Javam, Melanie C Audette, William Gibb, and Stephen G Matthews. Toronto, ON, Canada and Ottawa, ON, Canada.

S-062 Effect of Oxygen on Drug Transporters in the First Trimester Human Placenta. Phetcharawan Lye, Enrrico Bloise, Caroline Dunk, Sascha Drewlo, Stephen Lye, William Gibb, and Stephen G Matthews. and Canada.

S-063 Apoptotic Gene Expression Profiles Are Altered in Human Placentas from Gestational Diabetes Pregnancies.

Thomas R Magee, Michael G Ross, Mina Desai, Siri Kjos, and Louiza Belkacemi. Torrance, CA, USA and Los Angeles, CA, USA.

S-064 Uterine Space Restriction-Induced Placental Inefficiency Leads to Alterations in the Biosynthesis and Metabolism of Estrogens and Estrogen Metabolites. SO Jobe, JL Austin, GE Lopez, and RR Magness.

S-065 Increased Trophoblast Oxygen Consumption in IUGR.

C Mando, C De Palma, GM Anelli, M Figus, MI Mazzocco, F Calascibetta, D Trabattoni, T Stampalija, E Ferrazzi, El Clementi, and I Cetin. Italy and Milan, Italy.

S-066 Prostaglandin E2 Alters Placental Drug Transfer Via Modulation of Efflux Transporter Proteins in Placental Cells. Clifford W Mason, Yafeng Dong, Lily He, and Carl P Weiner. Kansas City, KS, USA.

S-067 Use of Innovative Digital Image Analysis for Three-Dimensional Reconstruction of Stem Villous Architecture in the Normal and Growth Restricted Placenta.

Olivia Moran, Lara C Morley, Maartje Vernooij, Shires Mike, Stalhschmidt Jens, Magee Derek, D Treanor, J Walker, and NAB Simpson. Leeds, United Kingdom and United Kingdom.

S-068 Quantitative Analysis of the Placental Vascular Network Using an Innovative Digital Imaging Tool.

Lara C Morley, Rini Viyas, Olivia Moran, Treanor Darren, Jens Stahlschmidt, Mike Shires, and Nigel Simpson. Leeds, United Kingdom.

S-069 Ly6E Is Essential for Normal Placental Labyrinth Formation in the Mouse. David RC Natale, Michael B Langford, Martha Hughes, Bryony V Natale, and David G Simmons. Calgary, AB, Canada and Brisbane, Queensland, Australia. 
S-070 A Retrospective Case-Controlled Blinded Review of Placentas from Patients with Cholestasis of Pregnancy. Shivani R Patel, Meaghan O'Keefe, Juan Felix, Neisha Opper, Joseph G Ouzounian, and Richard H Lee. Los Angeles, CA, USA.

S-071 Maternal-Fetal Relationship at Term between Levels of Vitamin D3, Its C3 Epimer and Total D3 (D3+Epi-D3).

Maria Prosszer, Samuel H Pepkowitz, Niree A Hindoyan, Chander P Arora, Brett Holmquist, and Calvin J Hobel. Los Angeles, CA, USA and Calabasas Hills, CA, USA.

S-072 A Novel Approach towards Three-Dimensional Reconstruction and Visualisation of Placental Terminal Villi.

Maartje Vernooij, Lara Morley, Darren Treanor, Jens Stahlschmidt, Mike Shires, Derek Magee, James Walker, and Simpson Nigel. Leeds, United Kingdom.

S-073 Targeted Disruption of Caveolin-1 Gene Leads to IUGR in Association with Markedly Decreased Angiogenesis and Increased Nitrosative Stress in the Placenta.

Yong Zheng, Justin Song, Zhenmin Lei, and Dong-bao Chen. Irvine, CA, USA and Louisville, KY, USA.

\section{INFLAMMATION, INFECTION}

S-074 Surfactant Protein (SP)-A Suppresses Inflammation in Gestational Tissues and Amniotic Fluid Macrophages.

Varkha Agrawal, and Emmet Hirsch. Evanston, IL, USA and Chicago, IL, USA.

S-075 Fetal Membranes Generate Different Inflammatory Profiles towards Viral ssRNA and Viral dsRNA through Distinct Mechanisms. Stephanie L Bakaysa, Julie A Potter, Christina S Han, Seth Guller, Errol R Norwitz, and Vikki M Abrahams.

S-076 Discordant Transcriptional Expression of Histamine Receptors 1 and 2 in Pregnant Mouse Uterus.

Julie Nicole, Joyce K Thompson, Karen Oppenheimer, and Elizabeth A Bonney. Burlington, VT, USA.

S-077 Role of miR-21 in the Inflammatory Response Elicited by Human Decidual Cells after Streptococcal Infection. Violeta Castro-Leyva, Silvia Giono-Cerezo, Francisco Arenas-Huertero, Iyari MoralesMendez, Aurora Espejel-Nunez, and Guadalupe Estrada-Gutierrez. Mexico.
S-078 Degree of Blood Contamination after an Amniocentesis and the Effect on Markers of Amniotic Fluid Inflammation. Marcos Cordoba, Eduardo Aguin, Samet Albayrak, Benjamin Kuritzkes, Laura Meints, and Ray O Bahado-Singh. New York, NY, USA; Ann Arbor, MI, USA and Detroit, MI, USA.

S-079 The Effects of LPS on Intermediate Filaments in the Developing Fetal Ovine Lung.

Thomas W Cox, John P Newnham, Jeffrey A Keelan, and Matthew W Kemp. Perth, Western Australia, Australia.

S-080 The Role of Endothelin-1 in EndotoxinTriggered Release of Placental ProInflammatory Cytokines.

Roopali V Donepudi, Prathamesh Mahajan, Francine Einstein, and Sandra E Reznik. Bronx, NY, USA and Queens, NY, USA.

S-081 The Effect of Neutrophil Depletion on Preterm Delivery in a Mouse Model of E. coli-Induced Labor.

Yana Filipovich, Varkha Agrawal, and Emmet Hirsch. Evanston, IL, USA and Chicago, IL, USA.

S-082 Prenatal Treatment of Cytomegalovirus Infection with Maternal Hyperimmune Globulin. Dahiana M Gallo, Arturo Cardona, Dario A Santacruz, Jorge H Gutierrez, Brian L Shaffer, Catalina Valencia, and Jorge E Tolosa. Cali, Colombia; Medellin, Colombia; Portland, OR, USA and Bogotá, Colombia.

S-083 Reactive Oxygen Species (ROS) Play a Key Role in the Induction of Labor-Related Features.

T Hadi, M Bardou, M Barrichon, P Mourtialon, $M$ Wendremaire, M Dumas, $P$ Sagot, and $F$ Lirussi. and Dijon.

S-084 LPS Enhances Myometrial Myocyte Contractility In Vitro through TLR4 Stimulation and RhoA/ROCK Pathway Activation. James L Hutchinson, Shalini P Rajagopal, and Jane E Norman. Edinburgh, United Kingdom.

S-085 microRNA Profiling of Cultured Third-Trimester Decidual Cells Following Inflammatory Challenge. SA Ibrahim, TL Summerfield, R Li, SJ Huang, F Schatz, CJ Lockwood, WE Ackerman IV, and DA Kniss. Columbus, OH, USA.

S-086 Variation in Beta Defensin 1 Genotype Is Associated with Preterm Birth. Catherine P James, Mona Bajaj-Elliott, Argyro Syngelaki, Nigel Klein, Kypros Nicolaides, and Donald Peebles. 
S-087 Characterisation of Cultured Human Myocytes to Passage Four as a Model To Investigate the Role of Progesterone in Myometrial Function. Gayle Bishop, Mark Johnson, Phil Bennett, and Yun Lee. London, United Kingdom.

S-088 Effects of Caspase 1 Inhibition on Inflammatory Responses and Steroid-Regulated Gene Expression in Mouse Macrophages. Jing Lu, Joshua Reese, and Emmet Hirsch. Evanston, IL, USA.

S-089 TLR4-Mediated Activation of AP1 Via JNK Induces Preterm Labour in the Mouse.

David A Maclntyre, Roberta Migale, Yun S Lee, Bronwen Herbert, Lynne Sykes, Vasso Terzidou, Mark R Johnson, and Phillip R Bennett. London, United Kingdom.

S-090 mi-RNA-155 Is Differentially Expressed in Early Fetal Lung Injury Following a Limited Choriodecidual Infection in Macaca nemestrina. Ryan M McAdams, Jeroen P Vanderhoeven, James W MacDonald, Theo K Bammler, Federico M Farin, H Denny Liggitt, Michael G Gravett, Craig E Rubens, and Kristina M Adams Waldorf. and Seattle, WA, USA.

S-091 The Inflammatory Response of Preterm Lambs to Injurious Ventilation Is Altered by Human Amnion Epithelial Cell Administration. Jacqueline M Melville, Courtney A McDonald, Robert J Bischof, Graham Jenkin, and Timothy JM Moss. Clayton, Victoria, Australia.

S-092 Omega-3 Fatty Acid-Derived Pro-Resolving Lipid Mediators in the Human Fetus: An Exploratory Secondary Analysis of the Mothers, Omega-3, \& Mental Health Study. Ellen L Mozurkewich, Chelsea M Clinton, Vivian C Romero, Deborah R Berman, John Barks, Zora Djuric, Jesmond Dalli, and Charles $\mathrm{N}$ Serhan. Albuquerque, NM, USA; New York, NY, USA; Grand Rapids, MI, USA; Ann Arbor, MI, USA and Boston, MA, USA.

S-093 Mucosal Immunity in Cervicovaginal Infection. Christopher J Nold, Monique Maubert, Lauren Anton, and Michal Elovitz. Philadelphia, PA, USA.

S-094 Progestational Agents and Their Effect on the Extracellular Matrix.

Christopher Nold, Monique Maubert, Lauren Anton, and Michal Elovitz. Philadelphia, PA, USA.

S-095 Do Increased Peripheral Markers of Inflammation Predate the Occurrence of a Short Cervical Length?

Courtney Olson-Chen, Loralei L Thornburg, and David N Hackney. Rochester, NY, USA and Cleveland, $\mathrm{OH}$, USA.
S-096 Intra-Amniotic Candida albicans Infection Elicits a Major Inflammatory Response in the Ovine Fetal Skin. Matthew Payne, Thomas Cox, Sarah Stock, John Newnham, Alan Jobe, Suhas Kallapur, Andreas Noe, Sean Carter, Rory Watts, and Matthew Kemp. Subiaco, Western Australia, Australia and Cincinnati, $\mathrm{OH}$, USA.

S-097 Progesterone Modulates LPS-Induced Synergistic Pro-Inflammatory Cytokine Production in a Coculture Model of Myometrial Smooth Muscle and Primary Monocytes from Term Pregnant Women. Shalini P Rajagopal, James L Hutchinson, Adriano Rossi, and Jane E Norman. and Edinburgh, United Kingdom.

S-098 Investigating the Anti-Inflammatory Agents Epi-Lipoxin and IL-10 in a Mouse Model of Infection-Induced Preterm Labour. Sara F Rinaldi, Rob D Catalano, Jean Wade, Adriano G Rossi, and Jane E Norman.

S-099 Investigating the Role of Neutrophils in a Mouse Model of Infection-Induced Preterm Labour.

Sara F Rinaldi, Rob D Catalano, Jean Wade, Adriano G Rossi, and Jane E Norman. United Kingdom.

S-100 Co-Stimulation of TLR and NOD2 Results in Synergistic NF-KB Response in Macrophages. Ankit A Shah, and Emmet Hirsch. Evanston, IL, USA and Chicago, IL, USA.

S-101 Molecular Markers of Early and Established Labour in Human Myometrium. Natasha Singh, Kaiyu Lei, Suren R Sooranna, and Mark R Johnson. London, United Kingdom.

S-102 Development of a Clinically Relevant Model of Perinatal Hypoxic Ischaemic Encephalopathy in Mice.

Xia Zheng, Hailin Zhao, Suren R Sooranna, Daqing Ma, and Mark R Johnson. London, United Kingdom.

\section{INVASION, ANGIOGENESIS, TROPHOBLAST}

S-103 Hydroxychloroquine Prevents Antiphospholipid Antibody-Induced Inhibition of Trophoblast Migration.

Caroline R Albert, Melissa J Mulla, Christina S Han, Jan J Brosens, Larry W Chamley, and Vikki M Abrahams.

S-104 Trophoblast Cells Obtained by Noninvasive Transcervical Sampling during Early Pregnancy Have an Extravillous Phenotype. Jay M Bolnick, Brian A Kilburn, Michael P Diamond, Roohi Jeelani, and D Randall Armant. Detroit, MI, USA and Bethesda, MD, USA. 
S-105 Apoptosis of Alcohol-Exposed Human Placental Cytotrophoblast Cells Occurs

Downstream of Intracellular Calcium Signaling. Jay M Bolnick, Rita Namo, Po Jen Chiang, Brian A Kilburn, Michael P Diamond, Susan M Smith, and Randall D Armant. Detroit, MI, USA; Madison, WI, USA and Bethesda, MD, USA.

S-106 Thyroid Hormone Action in the Decidua during Human Pregnancy.

Elisavet Vasilopoulou, Laurence S Loubiere, Gendie E Lash, Omi Ohizua, Jayne A Franklyn, Mark D Kilby, and Shiao Y Chan. Birmingham, United Kingdom; Newcastle upon Tyne, United Kingdom and Walsall, United Kingdom.

S-107 Cytotrophoblast-Derived Hydrogen Sulfide Regulates Placental Artery Endothelial Cell Migration.

Lin Feng, Wen Wang, Jing Zheng, and Dongbao Chen. Irvine, CA, USA and Madison, WI, USA.

S-108 Metformin Reverses Hyperglycemia-Induced Upregulation of IL- 6 Secretion by Human First Trimester Trophoblast.

Mary C Pitruzzello, Jordan Hastie, Melissa A Herrin, Clare Flannery, Erika F Werner, Vikki M Abrahams, and Christina S Han. New Haven, CT, USA and Baltimore, MD, USA.

S-109 Metformin Partially Reverses HyperglycemiaInduced Angiogenic Factor Imbalance in Human First Trimester Trophoblast. Melissa A Herrin, Mary C Pitruzzello, Clare A Flannery, Christian M Pettker, Erika F Werner, Vikki M Abrahams, and Christina S Han. New Haven, CT, USA and Baltimore, MD, USA.

S-110 The Migration Induced by Scratching Regulates the Secretion of sFIt1 in TCL-1 Cells. Chihiro Hirai, Motoi Sugimura, Naoko Suga, Takashi Yorihuji, Shintaro Makino, and Satoru Takeda. Tokyo, Japan and Shizuoka, Japan.

S-111 Marked Alterations in Microtuble Nucleation in Fused BeWo Cells. Gen Ishikawa, Toshiyuki Takeshita, William Ackerman, Dale Vandre, and John M Robinson. Bunkyo-ku, Tokyo, Japan; Columbus, OH, USA and Kalamazoo, MI, USA.

S-112 Nanoparticle-Mediated Trophoblast-Specific Gene Transfer in an In Vitro Model of Human Trophoblast.

Helen Jones, Chuck Klanke, Neil Ayres, Mounira Habli, Aimen Shaaban, Sundeep Keswani, and Timothy Crombleholme. Cincinnati, OH, USA.

S-113 Developmental Expression of High-Temperature Requirement A1 (HtrA1) Protein Correlates with Trophoblast Stem Cell Up-Regulation of Differentiation-Dependent Genes.

TS Summerfield, VS Auyeung, CA Ahn, R Li, WE Ackerman, and DA Kniss. and Columbus, $\mathrm{OH}$, USA.
S-114 Kisspeptin Alters Spiral Artery Remodeling by Inhibiting Trophoblast Invasion/Migration.

Renju S Raj, Natalia I Gokina, and George Osol. Burlington, VT, USA.

S-115 Hypoxia Increases Exosome Releases from Placental Mesenchymal Stem Cell (pMSC) and Promotes the Migration and Angiogenesis in Human Placental Microvascular Endothelial Cell (hPMEC).

Carlos Salomon, Murray Mitchell, Luis Sobrevia, Jenny Ryan, Keith Ashman, Sebastian Illanes, and Greg Rice. Chile and Australia.

S-116 Hypoxia Induces Exosome Deportation from Trophoblast Cells during the First Trimester of Pregnancy and Promotes Placental Mesenchymal Stem Cell Migration (pMSC). Carlos Salomon, Murray Mitchell, Luis Sobrevia, Jennifer Ryan, Keith Ashman, Kanchan Waswani, and Illanes Sebastian.

S-117 Trophoblast Invasion in Endotoxin Infused Pregnant Rats.

Floor Spaans, Gea Kiewiet, Theo Borghuis, Pieter A Klok, Winston W Bakker, and Marijke M Faas. Groningen, Netherlands.

S-118 Estrogen Receptor-beta Mediates Impaired Fetoplacental Angiogenesis in Fetal Growth Restriction.

Emily J Su, Hong Xin, Diana Monsivais, and Serdar E Bulun. Chicago, IL, USA.

\section{NUTRITION, OBESITY, DIABETES II}

S-119 Effects of Severe Obesity on the Levels of Inflammatory Markers in Maternal and Fetal Compartments at Term.

Ugochi N Akoma, Valenzuela J Guillermo, Kristin L Searing, Angela G Massmann, and Jorge P Figueroa. Winston-Salem, NC, USA and Colton, CA, USA.

S-120 Increased Placental Thickness but Not Surface Area in Obese Women without Diabetes. S Calabrese, C Mando, M Mazzocco, and I Cetin. Italy.

S-121 Serum Hemopexin Concentrations across Gestation Are Associated with Maternal and Neonatal Iron Status in Pregnant Adolescents. Chang Cao, Elizabeth Cooper, Eva Pressman, Ronnie Guillet, and Kimberly O'Brien. Ithaca, NY, USA and Rochester, NY, USA.

S-122 Can Pre-Gestational Diabetes Mellitus Be Treated with Oral Hypoglycemic Agents? Valeria Di Stefano, Revital Faro, and Marlene Schwebel. New Brunswick, NJ, USA.

S-123 Borderline Macrosomia in Obese Women at Term: An Indication for Cesarean Delivery? Andrea G Edlow, Sarah E Little, and Nicole A Smith. Boston, MA, USA. 
S-124 Association of BMI, Leptin and Markers of Inflammation in the First Trimester.

Rebecca Epstein, Samantha Mast, Kristin Ashford, and John O'Brien. Lexington, KY, USA.

S-125 The Importance of the Fasting Blood Glucose in Screening for Gestational Diabetes: Are We Missing Anything by Using the 2 Step Method? Kimberly Herrera, Lois Brustman, Janelle Foroutan, Katarzyna Suffecool, Sophia Scarpelli, and Barak Rosenn. New York, NY, USA.

S-126 Characteristics of Recurrent LGA in Obese Women. Arun P Jain, Sarah A Hopkins, Jeffrey A Gavard, Jim J Rice, Rosemary B Catanzaro, and Raul Artal. Saint Louis, MO, USA.

S-127 Changes in Flow Mediated Vasodilation Predicts Development of Gestational Diabetes. Joesph Kowalski, Robyn Netz, Chris Sinkey, Donna Santillan, Diedre Fleener, Wendy Hamilton, Brenda Boese, Stephen K Hunter, Kimberly Leslie, William Haynes, and Mark K Santillan.

S-128 Iron Insufficiency Is Prevalent in Pregnant Adolescents and Is Linked to Low Iron Status in Neonates at Birth. Sunmin Lee, Ronnie Guillet, Elizabeth Cooper, Eva Pressman, Mark Orlando, and Kimberly O'Brien. Ithaca, NY, USA and Rochester, NY, USA.

S-129 Activity and Expression of Placental Glutathione Peroxidase in Pregnancies Affected by IUGR and Macrosomia. Margarida Y Lei, Suvajit Sen, Gautam Chaudhuri, and Carla Janzen. Los Angeles, CA, USA.

S-130 Risk of Cesarean Delivery in Obese Nulliparous Women with Unfavorable Cervix, Undergoing Elective Induction of Labor vs. Expectant Management at Term. Heather Mahaffey, Julia Timofeev, Eshetu Tefera, Sameer Desale, and Rita W Driggers. Washington, DC, USA and Hyattsville, MD, USA.

S-131 Prediction of Gestational Diabetes in Obese Pregnant Women.

Rahat A Maitland, Naveed A Sattar, Paul T Seed, Annette L Briley, Stephen M Thomas, Dharmintra Pasupathy, and Lucilla Poston. London, United Kingdom and Glasgow, United Kingdom.
S-132

Influence of Fetal Sex, Maternal Obesity, and Gestational Weight Gain on Perinatal Outcomes.

Nicole E Marshall, Jonathan M Snowden, Perrie F O'Tierney-Ginn, Kathryn Melsap, Judith Chung, Elliot Main, William Gilbert, and Aaron B Caughey. Portland, OR, USA and Stanford, CA, USA.

S-133 Pregnancy Alters Urinary Excretion of MyoInositol and D-Chiro-Inositol.

Aisling Murphy, Lina Ma, Amir Shamshirsaz, Richard E Ostlund, and Brian Koos. Los Angeles, CA, USA and St Louis, MO, USA.

S-134 Hemoglobin A1C Levels Early in Pregnancy as Predictors of Gestational Diabetes in a County Hospital Population.

Kristina Roloff, Sara Garcia, and Guillermo J Valenzuela. Colton, CA, USA.

S-135 The Effect of Obesity on C-Reactive Protein Levels and Poor Pregnancy Outcomes. Katelyn Talcott, Ashley Christensen, Eric Tyler, Wendy Hamilton, Brenda Boese, Donna Santillan, Stephen K Hunter, Kimberly Leslie, and Mark Santillan.

S-136 Maternal Obesity Influences Utero-Placental Development.

Daniel Tessier, Emily Hayes, Julien YockellLelievre, Alison Holloway, Andree Gruslin, and Sandepp Raha. Ottawa, ON, Canada and Hamilton, ON, Canada.

S-137 Metformin Versus Insulin in Gestational Diabetes: A Meta-Analysis.

Aneesha Varrey, Joanne E Brady, Heather Hume, and Shari E Gelber. New York, NY, USA.

S-138 Maternal Obesity (MO) in Pregnancy and Lactation Accelerates Age-Related Male Offspring (OFF) Lipid Metabolism Dysfunction. Elena Zambrano, Carlos Ibanez, Luis A ReyesCastro, Claudia Vega-Garcia, and Peter W Nathanielsz. Mexico City, DF, Mexico and San Antonio, TX, USA.

\section{OVARY}

S-139 Risk of Recurrence and Management of Borderline Ovarian Tumors. Jonathan D Black, Thomas J Rutherford, Elena Ratner, Naomi Yoo, Masoud Azodi, Natalia Buza, Fattaneh Tavassoli, and Peter E Schwartz. New Haven, CT, USA.

S-140 Potential Targets for Immunotherapy in Epithelial Ovarian Cancer.

Sayeema Daudi, Tony Miliotto, Adrienne Groman, Shashikant Lele, and Kunle Odunsi. Buffalo, NY, USA. 
S-141 Primary Carcinoid Tumor of the Ovary: A Case Series.

Karissa A Johnson, Robert N Samuelson, Pei Hui, Peter Schwartz, and Shoreh Shahabi. Danbury, CT, USA and New Haven, CT, USA.

S-142 Fetal Microchimerism and Epithelial Ovarian Cancer. Kai Ling Liang, Uzma Mahmood, Fong Chui Yee, Diana Lim, Mahesh Choolani, and Keelin O'Donoghue. Cork, Ireland and Singapore, Singapore.

S-143 Down-Regulation of microRNA-31 Induces Taxane Resistance in Ovarian Cancer Cells through Increase of Receptor Tyrosine Kinase MET.

Hidemichi Watari, Takashi Mitamura, Shinya Tanaka, and Noriaki Sakuragi. Sapporo, Japan.

S-144 miR-205 Triggers Epithelial-Mesenchymal Transition (EMT) Mediated by TCF21/E-

Cadherin in Ovarian Cancer. Helen H Zhou, Yafeng Dong, Julia Chapman, Minghui Tai, and Carl P Weiner.

\section{OXIDATIVE STRESS, APOPTOSIS}

S-145 Expression of Apoptosis-Inducing Factor (AIF) during Hypoxia in Neuronal Nuclei and Mitochondrial Fraction in the Cortical Neuronal Cells of Guinea Pig Fetus at Term. Qazi M Ashraf, and Maria DelivoriaPapadopoulos. Philadelphia, PA, USA.

S-146 Infusion of IL-17 Blocking Protein Blunts Hypertension and Oxidative Stress in Response to Placental Ischemia. James P Hogg, Denise Cornelius, Kedra Wallace, Janae Moseley, and Babbette LaMarca. Jackson, MS, USA.

S-147 Glucose Metabolic Pathway and ROS Production in Endothelial Dysfunction Induced by TNF-alpha: Clinical Implications. Rashmi Rao, Suvajit Sen, and Gautam Chaudhuri. Los Angeles, CA, USA.

\section{RENAL, ADRENAL, BRAIN}

S-148 Comparative Aspects in Cerebral Myelination between Sheep and Humans. Iwa Antonow-Schlorke, Michael Brodhun, Alexandra Helgert, Peter W Nathanielsz, and Matthias Schwab. Jena, Germany; Erfurt, Germany and San Antonio, TX, USA.

S-149 Middle Cerebral Artery Doppler Ultrasonography in Fetuses with Congenital CNS Abnormalities and Prediction of Perinatal Death and VP Shunt Placement.

Brian Brocato, Mauro Schenone, and Giancarlo Mari. Memphis, TN, USA.
S-150 Fetal Inflammation-Induced IL-1 $\beta$ Is Not Essential for Fetal Brain Injury. Wance Firdaus, Talaibek Borbiev, Shorouq AIRebh, Tahani Dada, Michael Johnston, Roger Reeves, and Irina Burd.

S-151 Monocarboxylate Transporter 8 (MCT8) Expression in the Human Fetal Cerebral Cortex Is Reduced in Severe Intrauterine Growth Restriction (IUGR). Shiao Y Chan, Laura A Hancox, Azucena Martin-Santos, Laurence S Loubiere, Merlin Walter, Ana-Maria Gonzalez, Phillip Cox, Ann Logan, Christopher J McCabe, Jayne A Franklyn, and Mark D Kilby. Birmingham, United Kingdom.

S-152 Synthesis of Estrogen by the Ovine Fetal Adrenal.

Teresa Collins, Ashley Grapes, and Charles Wood.

S-153 Neurogical Maturational Trend in Low-Risk, High-Risk and IUGR Fetuses.

Hari Eswaran, Rathinaswamy B Govindan, Srinivasan Vairavan, Bhargavi Sriram, Eric R Siegel, Naim I Haddad, and Curtis L Lowery.

S-154 The Ovine Fetal Adrenal as an Estrogen Target Tissue.

Ashley Grapes, Teresa Collins, and Charles E Wood.

S-155 IUGR in Fetal Baboons at 0.9 Gestation

(G) Results in Increased Fetal Kidney

11-Betahydroxysteroid Dehydrogenase ( $\beta \mathrm{HSD}) 1$ and Decreased 11- $\beta$ HSD2: Potential Implications for Dysfunctional Fetal Renal Mineralocorticoid Receptor (MR) Activity and Development in IUGR. Mark J Nijand, Dongbin Xie, Thomas J McDonald, Peter W Nathanielsz, and Cun Li. San Antonio, TX, USA.

S-156 Effects of IUGR on Fetal Baboon Kidney MultiDrug Resistance Protein 1 (MDRP 1) at 0.9 Gestation (G); Potential Implications for Fetal Renal Mineralocorticoid Development and Function.

Cun Li, Dongbin Xie, Thomas J McDonald, Peter W Nathanielsz, and Mark J Nijland. San Antonio, TX, USA.

S-157 Down-Regulated Leptin Receptor (ObRb) Peptide Expression in the Fetal Hypothalamic Paraventricular Nucleus (PVN) and Adrenal Cortex Explains the Observed HypothalamoPituitary-Adrenal Axis (HPAA) Up-Regulation in Fetal Baboon Intrauterine Growth Restriction (IUGR).

Thomas J McDonald, Cun Li, Dean A Myers, Dongbin Xie, Mark J Nijland, and Peter W Nathanielsz. San Antonio, TX, USA and Oklahoma City, OK, USA. 
S-158 AAV9-Mediated Expression in Fetal Kidneys Following In-Utero Maternal Systemic Delivery. Jason L Picconi, Melissa Muff-Luett, Erik Bunchman, Di Wu, and Patrick D Brophy. lowa City, IA, USA.

S-159 Late Onsetting Growth Restriction with Chronic Hypoxia in Fetal Sheep Does Not Alter Neuronal Connections or Induce Brain Apoptosis.

Karolina Piorkowska, Arpon Shahed, Margaret Kazanczuk, Alex Xu, Robert R Hammond, and Bryan J Richardson.

S-160 Agonist Genomic Effects of 17B-Estradiol and ICI 182780 in the Late Gestation Ovine Fetal Hypothalamus.

Maria B Rabaglino, Elaine Richards, Eileen I Chang, and Charles E Wood.

S-161 The Impact of Maternal Dietary Restriction during the Periconceptional Period on the Insulin-Like Growth Factor Type I Receptor (IGF1R) and Signal Transducer and Activator of Transcription (STAT) Signalling Pathways in the Adrenals of Offspring.

Song Zhang, Janna Morrison, Leewen Rattanatray, Severence MacLaughlin, David Kleemann, Simon Walker, and Caroline McMillen. Australia.

\section{REPRODUCTIVE BIOLOGY}

S-163 Microchimerism from an Older Sibling? Hilary S Gammill, Christine Luu, Kimberly K Ma, Vijayakrishna Gadi, Anne M Stevens, and J Lee Nelson.

S-164 Notch Pathway Promotes and Controls Uterine Decidual Angiogenesis during Early Pregnancy in Mouse.

Carmen M Garcia-Pascual, Ralph C

Zimmermann, Hortensia Ferrero, Carrie J

Shawber, Carlos Simon, Antonio Pellicer, and

Raul Gomez. Paterna, Valencia, Spain and New York, NY, USA.

S-165 GnRH Agonist vs. hCG for Triggering of Ovulation - Differential Effects on Gene Expression in Human Granulosa Cells. Jigal Haas, Libby Ophir, Eran Barzilay, Gil M Yerushalmi, Yuval Yung, Ettie Maman, and Ariel Hourvitz. Ramat Gan, Israel.

S-166 Gamma-Hexachlorocyclohexane and Other Hexachlorocyclohexane Isomers Activate the Pregnane X Receptor and Induce Human CYP3A4 Expression In Vitro; Implications for Steroid Metabolism.

Oumar Kuzbari, John G Lamb, Michael R Franklin, Ahmad Hammoud, Erica B Johnstone, and $C$ Matthew Peterson. Salt Lake City, UT, USA.
S-167

Estrogen Stimulation of Hydrogen Sulfide Biosynthesis Via Estrogen Receptor $(E R \alpha / \beta)$ Dependent Transcription of CBS and CSE in Uterine Artery Endothelial Cells. Thomas J Lechuga, Jason Jia, Ronald R Magness, and Dong-bao Chen. CA, USA and WI, USA.

S-168 A Whole Genome Microarray Study To Determine Differences in Menstrual Phase Endometrium from Women with Normal and Heavy Menstrual Bleeding. Jacqueline A Maybin, Elaine Marshall, Philippa TK Saunders, and Hilary OD Critchley. United Kingdom.

\section{REPRODUCTIVE IMMUNOLOGY}

S-169 Excess Nitric Oxide Enhances Complement Mediated Killing of Trophoblast Cells by DownRegulating Complement Regulatory Proteins. Manu Banadakoppa, Daniel Liebenthal, Dara Havemann, Madhu Chauhan, and Chandra Yallampalli. Galveston, TX, USA.

S-170 Prelmplantation Factor $\left(\mathrm{PIF}^{*}\right)$ ImmuneRegulatory Effects on Human PBMC: Balance Embryo Tolerance/Acceptance with Vigorous Response to Challenge. Eytan R Barnea, David Kirk, Kathryn Corelli, and Michael J Paidas.

S-171 Roles of Uterine Natural Killer Cells in the Pregnant Uterus before Placental Formation. Barbara A Croy, Alexander P Hofmann, Edith M Lord, and Scott A Gerber. Kingston, ON, Canada and Rochester, NY, USA.

S-172 Cross-Talk between JAK/STAT and NF-KB Signaling Pathways Mediates CytokineEnhanced IP-10 Expression in Human First Trimester Decidual Cells.

Saeed Faramarzi, Frederick Schatz, John Shapiro, Sammi Tabbah, Umit A Kayisli, Murat Basar, and Charles J Lockwood. Columbus, $\mathrm{OH}$, USA.

S-173 Neonatal Death in Interleukin-1 Deficient Mice:

A Role for the Placenta?

Sylvie Girard, Sarah Isherwood, Mark R Dilworth, Colin P Sibley, Rebecca L Jones, and Stuart M Allan. Manchester, United Kingdom.

S-174 IL6 Regulates Decidual T Cell Phenotypes To Restore Parturition in IL6 KO Mice. Nardhy Gomez-Lopez, David M Olson, and Sarah A Robertson. Adelaide, SA, Australia; Detroit, MI, USA and Edmonton, AB, Canada.

S-175 Maternal Monocyte-Derived Cell Depletion Promotes Preterm Delivery in Mice. Nardhy Gomez-Lopez, MT Bijland, David M Olson, and Sarah A Robertson. Adelaide, SA, Australia; Edmonton, AB, Canada and Detroit, MI, USA. 
S-176 CD4-Lymphocytes and Anti-Müllerian Hormone Levels in a Cohort of HIV-Infected and -Uninfected Women.

R Scherzer, P Bacchetti, G Messerlian, D Seifer, and RM Greenblatt. San Francisco, CA, USA; Providence, RI, USA and Brooklyn, NY, USA.

S-177 Regulation of Placental Hofbauer Cell Function by TLR-3 Agonist: Poly (I:C).

Seth Guller, Mustafa Demirturk, Zhonghua Tang, Graciela Krikun, Vikki M Abrahams, and Gil Mor. New Haven, CT, USA.

S-178 Role of Caspase-1 in Fetal Membrane IL-1 $\beta$ Production in Response to Bacterial Toll-Like Receptor and Nod Protein Agonists.

Mai Hoang, Julie A Potter, Christina S Han, Seth Guller, Errol R Norwitz, and Vikki M Abrahams.

S-179 First Trimester Decidual Cells Mediate ProInflammatory-Induced M1 Macrophage Polarization-Implication in Preeclampsia. Min Li, Chie-Pein Chen, Chang-Ching Yeh, Salley Pels, and S Joseph Huang. New Haven, CT, USA; Taipei, Taiwan and Columbus, $\mathrm{OH}$, USA.

S-180 An Emerging Role for Vacuolar-ATPase Isoform A2 in Preterm Labor: Regulation of Apoptosis and Polarization of M1/M2 Macrophage. Mukesh K Jaiswal, Varkha Agrawal, Alice Gilman Sachs, Emmet Hirsch, and Kenneth Beaman. North Chicago, IL, USA; Evanston, IL, USA and Chicago, IL, USA.

S-181 Repeated Coital Exposure to Male Seminal Fluid Progressively Builds Tolerogenic Regulatory T Cell Populations in Mice. Sarah A Robertson, Hanan H Wahid, Norsyifa Harun, Bihong Zhang, and Lachlan M Moldenhauer. Adelaide, SA, Australia.

S-182 Pregnancy Is Associated with Greater PIBF Expression on Peripheral Blood CD8+ T-Cells In-Vitro.

Nishel Shah, Nesrina Imami, and Mark Johnson. London, United Kingdom.

S-183 A Program of Myeloid Cell Infiltration into Decidua Promotes the Initiation of Labour and Post-Partum Uterine Remodelling in Mouse. Oksana Shynlova, Tamara Nedd-Roderique, Tina Nguyen, and Stephen Lye. Toronto, ON, Canada and Canada.

S-184 Characterization of Ovarian Antibody Reactivity with Cellular and Exosomal Antigens in Patients with Endometriosis. Divya C Sridharan, Douglas D Taylor, Bruce A Lessey, and Cicek Gercel-Taylor.
S-185 Coordinated Modification of Decidual NK Cell Phenotype and Function during Human Pregnancy. Jianhong Zhang, Caroline E Dunk, and Stephen J Lye. Canada.

\section{RISK FACTORS, OUTCOMES, MORTALITY}

S-186 Recurrent Intrahepatic Cholestasis of Pregnancy among a Hispanic Inner City Population: An Eight Year Retrospective Cohort Analysis.

Adanna L Anyikam, Jonathan K Mays, Sari J Kaminsky, Gladys Lee-Hwang, and My-Linh Nguyen. New York, NY, USA.

S-188 Risk Factors for Unscheduled Delivery in Patients with Placenta Accreta. Zachary S Bowman, Tracy A Manuck, Alexandra G Eller, Marilee Simons, and Robert M Silver. Salt Lake City, UT, USA.

S-189 Risk Factors for the Development of Placenta Accreta.

Zachary S Bowman, Alexandra G Eller, Tyler Bardsley, Tom Green, Michael W Varner, and Robert M Silver. Salt Lake City, UT, USA.

S-190 CARPREG and ZAHARA Scores for Stratifying Risks of Congenital Heart Disease in Pregnancy. Annelee Boyle, and Melissa H Fries. Washington, DC, USA.

S-191 Pregnancy in Women with Breast Cancer: How Do Outcomes Differ in Pregnancy Associated Breast Cancer and Breast Cancer Diagnosed Prior to Pregnancy? Emily E Bunce, Anjali J Kaimal, and Nicole A Smith. Boston, MA, USA.

S-192 Maternal Cardiac Output as a Marker for Subclinical Aortocaval Compression in the Second and Third Trimesters. Kristen Buono, Jerasimos Ballas, Kristin Mantell, and Thomas Archer. San Diego, CA, USA.

S-193 Umbilical Cord Blood Gases: Predicting Fetal Acidemia Using Venous Cord Gas Parameters. Jessica Cantu, Jeff Szychowski, Xuelin Li, Adi Abramovici, Joseph Biggio, Rodney Edwards, William Andrews, and Alan Tita.

S-194 Development and Validation of a Model To Determine Contribution of Modifiable Factors to Uncomplicated Pregnancy.

Lucy C Chappell, Paul T Seed, Lesley M McCowan, Robyn A North, Lucilla Poston, and SCOPE Consortium. United Kingdom and New Zealand. 
S-195 Development of a Dosing Regimen for Recombinant Human Antithrombin (rhAT) in Pregnant Patients.

Joost DeJongh, Johan Frieling, Elizabeth Clark, Simon Lowry, and Henk-Jan Drenth. Leiden, Netherlands and Framingham, MA, USA.

S-196 Mapping Adverse Pregnancy Outcomes: The Obesity Belt as a Predictor of Perinatal Indicators in the United States. Kacey $Y$ Eichelberger, Robert A Strauss, and Veronica Escamlla. Chapel Hill, NC, USA.

S-197 Multi-Gene Model To Predict Spina Bifida Risk. Dennis Gilbert, Kit Lau, Jill Hardin, Katherine Lazaruk, and John Witte. Foster City, CA, USA and San Francisco, CA, USA.

S-198 Prenatal Diagnosis and Neonatal Outcomes in Non Immune Hydrops: A Comparison of Two Decades at an Academic Center. Padmalatha Gurram, Kisti Fuller, AnnMarie Prabulos, Naveed Hussain, Christine Crawford, and Winston Campbell. Farmington, CT, USA.

S-199 A Comparative Study of Early Multifetal Pregnancy Reduction from Triplets to Twins Versus Triplets to Singeltons Performed at 7-8 Weeks of Gestation. Jigal Haas, Jehoshua Dor, Ariel Hourvitz, Yoav Yinon, and Adrian Shulman. Ramat Gan, Israel and Kfar Saba, Israel.

S-200 A Retrospective Study on the Timing of Delivery and Outcome in Women with Placenta Previa.

Hirotaka Hamada, Masatoshi Saitoh, Hidekazu Nishigori, Junichi Sugawara, and Nobuo Yaegashi. Sendai, Miyagi, Japan.

S-201 Placental Pathology Analysis in Severe IUGR Pregnancies Fails To Reveal a Distinct Phenotype When Uterine Artery Doppler Studies Are Normal: Implications for Clinical Practice. Mary Higgins, Melissa Walker, Catherine Windrim, Sarah Keating, and John Kingdom. Toronto, ON, Canada.

S-202 Allostatic Load in Women Reporting Low Birth Weight in the National Health and Nutrition Examination Survey (NHANES). Vanessa J Hux, Janet M Catov, and James M Roberts. Nashville, TN, USA; Pittsburgh, PA, USA.

S-203 Systematic Follow-Up of Pregnancies after Bariatric Surgery: A Prospective Controlled Study.

Goele Jans, Annelies Mattheus, Sander Galjaard, Annick Bogaerts, Greet Vansant, and Roland Devlieger. Belgium.
S-204

Effect of Vitamin K1 Supplementation on Vitamin K1 Status and Maternal Coagulation

Factors in Pregnant Women after Bariatric

Surgery.

Goele Jans, Isabelle Guelinckx, Sara Pauwels, Greet Vansant, and Roland Devlieger. Belgium.

S-205 Cesarean in the Second Stage of Labor:

Pushing the Head or Pulling the Feet through a Low Segment Incision.

Clark T Johnson, and Andrew J Satin. Baltimore, MD, USA.

S-206 Assessing Methods of Blood Loss

Quantification at Time of Cesarean Section. Jasmine Lai, Emily S Lukacz, Stephen A Hebert, and Douglas A Woelkers. San Diego, CA, USA.

S-207 Association of Maternal Biomarkers with Obstetric Outcomes. Leslie Myatt. Bethesda, MD, USA.

S-208 The New Management of Pregnancy of Women with Congenital Afibrinogenemia The Fibrinogen Replacement Therapy with Evaluating Fibrinogen Clearance. Kotomi Nagahashi, Keiko Muramatsu, Kaori Yamazaki, Toshiyuki Uchida, Kazunao Suzuki, Kazuhiro Sugihara, Hiroaki Ito, and Naohiro Kanayama. Hamamatsu City, Shizuoka-ken, Japan.

S-209 Is There a Role for Multidisciplinary Obstetrical Rapid Response Teams? Donna Neale, Ellen Thompson, and Digna Wheatley.

S-210 Does an Intense Prenatal Care Management Program Improve Perinatal Outcomes in a High Risk Population? Lin Wang, Regina Richardson, Kathy Evans, Yan Lu, Melissa Sherry, Michelle Hawkins, and Donna M Neale. and Baltimore, MD, USA.

S-211 Antenatal Prediction of Large for Gestational Age by Customized Centiles - A Measure Associated with Adverse Birth Outcomes. Dharmintra Pasupathy, Lesley ME McCowan, Alexandra Gillett, Robyn North, Louise C Kenny, Gus Dekker, Lucilla Poston, and SCOPE Consortium. United Kingdom; New Zealand; Ireland and Australia.

S-212 Womb to Womb: Developmental Origins of Fetal Loss in Adult Female Common Marmoset Monkeys (Callithrix jacchus). Julienne N Rutherford, Victoria A DeMartelly, Donna G Layne Colon, Corinna N Ross, and Suzette D Tardif. Chicago, IL, USA and San Antonio, TX, USA.

S-213 Perinatal Outcome by Birthweight in IUGR Fetuses Delivered at $>25$ Weeks. Jacques E Samson, Mauro Schenone, Brian Brocato, Danielle Tate, and Giancarlo Mari. 
S-214 Perinatal Outcome of Stage 0 IUGR Fetuses. Jacques E Samson, Mauro Schenone, Brian Brocato, Danielle Tate, and Giancarlo Mari.

S-215 Shoulder Dystocia Risk Factor Analysis in NonDiabetic Versus Diabetic Pregnant Patients: Is Induction of Labor the Right Choice? Ido Sirota, Graham G Ashmead, Michelle Chevalier, Sandra Sarpong, and Erin Moshier. New York, NY, USA.

S-216 Labor Induction in Women with an Unfavorable Cervix: Randomized Controlled Trial of Double Balloon Catheter Versus Dinoprostone. Katarzyna Suffecool, Barak Rosenn, Janelle Forutan, and Kimberly Herrera. New York, NY, USA.

S-217 Postnatal Glucocorticoid Therapy Affects Growth Patterns in Early Childhood. D Tijsseling, M ter Wolbeek, JB Derks, WB de Vries, CJ Heijnen, F van Bel, and EJH Mulder. Netherlands.

S-218 Neonatal Mortality after Early Elective Repeat Cesarean Delivery. Gustavo Vilchez, Anushka Chelliah, Pedro Argoti, and Ray Bahado-Singh. Detroit, MI, USA and Houston, TX, USA.

S-219 Fetal Growth Restriction and Maternal Smoking in the Macedonian Roma Population: A Causality Dilemma.

Asnat Walfisch, Sotir Nikolovski, Biljana Talevska, and Mordechai Hallak. Hadera, Israel; Skopje, Macedonia, The Former Yugoslav Republic of and Bitola, Macedonia, The Former Yugoslav Republic of.

S-220 Maternal Vitamin D Status and Adverse Pregnancy Outcomes: A Systematic Review and Meta-Analysis.

Shu-Qin Wei, Hui-Ping Qi, Zhong-Cheng Luo, and William D Fraser. Montreal, QC, Canada.

S-221 Misoprostol for Labor Induction in Pregnancies with Oligohydramnios: What's the Risk? Dalia Wenckus, Weihua Gao, and Michelle Kominiarek. Chicago, IL, USA.

\section{UROGYNECOLOGYI PELVIC FLOOR}

S-222 A Potential Urothelial Model for Studying Cannabinoid and Excitatory Receptor Interactions.

E Bakali, D Lambert, T Taylor, R Elliott, J Willets, and D Tincello.

S-223 The Recovery of Pelvic Organ Support during the First Year Postpartum.

Yi Chen, Xiaohua Lin, Jingjing Chen, Cong Chen, and Marsha Guess. Wenzhou, Zhejiang, China and New Haven, CT, USA.
S-224 Gender Affects Responses of Renal ACE and ACE2 Activity to Unilateral Nephrectomy.

Kai Chen, Jianli Bi, Yixin Su, Jorge Figueroa, Mark Chappell, and James Rose. WinstonSalem, NC, USA.

S-225 Physical Activity during Pregnancy and Postpartum Urinary Incontinence in Primiparous Women. Jamie Lo, Erin Clark, Tyler Bardsley, Marlene Egger, Janet Shaw, and Ingrid Nygaard.

S-226 Hormonal Regulation of Oxytocin Receptor in Murine Uterosacral Ligaments.

Ritsuko Iwanago, Jameson Arnett, Kelsey E Breen, Brian Wakefield, Marsha K Guess, K Joseph Hurt, and Kathleen A Connell. Aurora, CO, USA and New Haven, CT, USA.

S-227 Prepregnancy Pelvic Floor Dysfunction and Postnatal Pathology.

Constantin Durnea, Ali S Khashan, Sabina Tabirca, Louise C Kenny, and Barry A O'Reilly. Cork, Ireland.

S-228 Pelvic Organ Prolapse (POP) in Primiparous Women One Year Post-Partum. Constantin Durnea, Ali S Khashan, Louise C Kenny, and Barry A O'Reilly. Cork, Ireland.

S-229 The Problem of Pyuria 1-9 wbc ul-1; Are We Missing Significant Disease? Kiren Gill, Anthony Kupelian, Sheela Swamy, and James Malone-Lee. London, United Kingdom.

S-230 Synthetic Mesh Implantation Results in Increased Active MMP-2 and -9 in a Mouse Model.

Marcia E Klein-Patel, Wenjun Zong, Stacy Palcsey, Deepa Mani, and Pamella Moalli. Pittsburgh, PA, USA.

S-231 Effect of Static Mechanical Stretch and Extracellular Matrix Proteins on Vaginal Fibroblasts Derived from Women with and without Pelvic Organ Prolapse.

Hala Kufaishi, May Alarab, Harold Drutz, Stephen Lye, and Oksana Shynlova. Toronto, ON, Canada and Canada.

S-232 Retraction Technique for Urinary Catheterization of Women with Female Genital Mutilation. Abdulrahim Rouzi, Nora Sahly, Nedaa Bahkali, and Hassan Abduljabbar.

S-233 Ertapenem in the Treatment of Overactive Bladder.

Sheela Swamy, Kiren Gill, Anthony Kupelian, and James Malone-Lee. London, United Kingdom. 


\section{Saturday, March 23, 2013 - Poster Session III - Bonnett Creek Ballroom}

\section{UTERUS}

S-234 Development and Validation of an Endometrial Ablation Model in New Zealand White Rabbits: A Pilot Study. Mariam M AlHilli, Brost C Brian, Marler Robert, Hopkins Matthew, Andrea Mariani, and Famuyide Abimbola. Rochester, MN, USA and Scottsdale, AZ, USA.

S-235 Identification and Management of Cutaneous Metastasis of Uterine Papillary Serous Carcinoma Complicated by Tumor Lysis Syndrome.

Fausto Andrade, Dene C Wrenn, Samer Schuman, Joseph A Lucci III, and Sabrina Gerkowicz. Miami, FL, USA.

S-236 Mini-Invasive Approach to Preneoplastic and Neoplastic Endometrial Lesions. Comparative Study among Histological, Cytological and Immunohistochemical Diagnosis.

Enrico Betto, Stefania Ronzoni, Stefania Rossi, Delfina Tosi, Gaetano Bulfamante, and Anna Maria Marconi. Milano, Italy.

S-237 T-DM1, a Novel Antibody-Drug Conjugate, Is Highly Effective Against Primary Uterine Serous Carcinoma Cell Lines Overexpressing HER2. Diana P English, Stefania Bellone, Joyce Varughese, Elena Ratner, Dan-Arin Silasi, Masoud Azodi, Peter E Schwartz, Thomas J Rutherford, Sergio Pecorelli, and Alessandro D Santin. New Haven, CT, USA and Brescia, Italy.

S-238 Laparoscopic Versus Open Hysterectomy for Endometrial Cancer: The ASTEC Trial. Maria Kyrgiou, Jane Warwick, AM Swart, W Qian, Sadaf Ghaem-Maghami, and Henry Kitchener. London, United Kingdom and Manchester, United Kingdom.

S-239 Low-Temperature, Heat Induced Epitope Retrieval on Free-Floating/Whole-Mount Archival Human Gynaecological Pathology Paraffin Sections.

Frank Manconi, Eleanor PW Kable, Robert Markham, and lan S Fraser. Sydney, New South Wales, Australia.

S-240 Hyperlipidemia and Statin Use Is Associated with Improved Endometrial Cancer Survival. Nicole S Nevadunsky, Anne Van Arsdale, Lori Spoozak, Eugenia Girda, and Gary L Goldberg. Bronx, NY, USA.

S-241 Fenretinide: A Novel Treatment for Endometrial Cancer.

Mary Ellen Pavone, Navdha Mittal, Saurabh Malpani, Julian Shink, J Julie Kim, and Serdar E Bulun. Chicago, IL, USA.
Aldehyde Dehydrogenase Activity Earmarks Cancer Stem Cells in Endometrial Cancer. Marten van der Zee, Andrea Sacchetti, Medine Cansoy, Leen Blok, and Riccardo Fodde.

S-243 Malignant Transformation of a Foci of Endometriosis of the Colonic Wall: The First Reported Case.

Charis A Venditti, Robert Kelley, Shohreh Shahabi, Robert Samuelson, Mary Chacho, and Robert Kloss. Danbury, CT, USA. 